\title{
Discovery of deshydroxy bicalutamide derivatives as androgen receptor antagonists
}

\author{
Sahar Kandil ${ }^{1 *}$, Kok Yung Lee ${ }^{1}$, Laurie Davies ${ }^{2}$, Sebastiano A. Rizzo ${ }^{1}$, D. Alwyn Dart ${ }^{2}$ and Andrew D. Westwell ${ }^{1}$ \\ ${ }^{1}$ School of Pharmacy \& Pharmaceutical Sciences, Cardiff University, King Edward VII Avenue, Cardiff, CF10 3NB, Wales, UK. ${ }^{2}$ Cardiff \\ China Medical Research Collaborative, Cardiff University School of Medicine, Cardiff, CF14 4XN, Wales, UK.
}

Keywords: Androgen receptor (AR), prostate cancer (PC), castration-resistant prostate cancer (CRPC), bicalutamide, deshydroxy, double branched propioanilide.

Graphical abstract

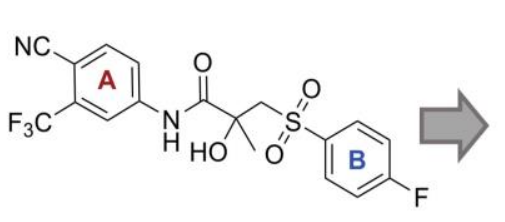

Bicalutamide

$\mathrm{IC}_{50}=20.44 \mu \mathrm{M}$

LNCaP

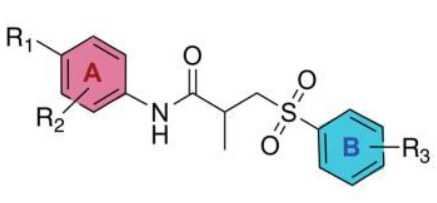

Deshydroxy single branched Compound $33, \mathrm{IC}_{50}=2.67 \mu \mathrm{M}$ LNCaP

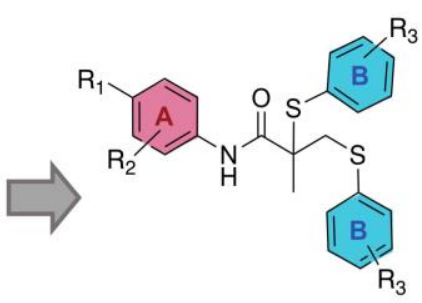

Deshydroxy double branched Compound 28, $\mathrm{IC}_{50}=0.43 \mu \mathrm{M}$

\section{Highlights}

- Synthesis of 23 novel deshydroxy bicalutamide derivatives.

- Identification of novel and potent double branched AR antagonists.

- Enhanced anticancer activity against PC compared to bicalutamide and enzalutamide.

- Strong downregulation of PSA expression in qPCR analysis of LnCaP cell line.

- Molecular modelling provides a rational explanation of the SAR observed.

\section{Abstract}

Deshydroxy propioanilides were synthesised by Michael addition reaction between substituted thiophenols onto four different phenylacrylamide derivatives to give twenty-four novel deshydroxy bicalutamide derivatives lacking the central hydroxyl group. The antiproliferative activities of these compounds were evaluated against human prostate cancer cell lines and eleven compounds showed better inhibitory activities $\left(I C_{50}=2.67-13.19 \mathrm{uM}\right)$ compared to bicalutamide $\left(I C_{50}=20.44 \mathrm{uM}\right)$ in $\mathrm{LNCaP}$. Remarkably, novel double branched bicalutamide analogues (27 and $\mathbf{2 8}$ ) were isolated as major byproducts and found to have the best activity across three human prostate cancer cell lines (LNCaP, VCaP and PC3). The most active compound 28 shows sub-micromolar activity ( $\mathrm{C}_{50}=0.43 \mathrm{uM}$ in LNCaP), which represents more than 40 -fold improvement over the clinical anti-androgen bicalutamide $\left(I_{50}=\right.$ $20.44 \mathrm{uM}$ ) and a more than 3 fold improvement over enzalutamide $\left(\mathrm{IC}_{50}=1.36 \mathrm{uM}\right)$. Moreover, strong reduction of PSA expression in LNCaP cells upon treatment with compounds 27, 28 and 33 was

\footnotetext{
* Corresponding author

E-mail address: kandils1@ cardiff.ac.uk (S. Kandil)
} 
observed during qPCR analysis, confirming their AR antagonist activity. Molecular modelling studies revealed a novel binding mode of these structurally distinct double branched analogues within the ligand binding domain (LBD) of the androgen receptor.

\section{Introduction}

The androgen receptor (AR) is expressed in many cell types and plays critical anabolic and reproductive roles in men and women. Androgen receptor (AR) signalling has been found to play crucial functions in modulating tumourigenesis and metastasis in several types of cancers including prostate, bladder, kidney, lung, breast and liver. ${ }^{1}$ The initiation and progression throughout the different stages of prostate cancer $(P C)$ is uniquely dependent on the androgen receptor (AR) signalling pathway. ${ }^{2,3}$ Androgen receptor $(A R)$, like other members of the nuclear receptor family, is comprised of three main functional domains: a variable $\mathrm{N}$-terminal domain, a highly conserved DNA-binding domain (DBD) and a conserved ligand binding domain (LBD). ${ }^{4}$ Binding of endogenous hormones; testosterone and dihydrotestosterone (DHT) to the LBD induces conformational changes in the AR that results in its translocation into the nucleus, interaction with DNA, and modulation of specific gene transcription (e.g. prostate specific antigen, PSA). ${ }^{5}$ Androgen receptor antagonists, so-called anti-androgens, are designed to inhibit these processes and are clinically used for the treatment of advanced prostate cancer (PC). ${ }^{6,7}$ Several non-steroidal anti-androgens (NSAA) have been approved for the treatment of PC. The first generation NSAAs include flutamide, hydroxyflutamide, nilutamide and bicalutamide (Figure 1). They decrease androgenic effects by competitively inhibiting the binding of androgens (testosterone and DHT) to the AR and induce conformational change of H12 via steric clashes. However, these antiandrogens eventually fail to inhibit the $A R$ with the development of castration resistant prostate cancer (CRPC). The development of AR-LBD point mutants (e.g. AR-T877A and AR-W741L) upon long term treatment with NSAAs ultimately result in switching these AR antagonists to AR agonists leading to the relapse of CRPC, which is a more aggressive form of the disease associated with poor prognosis. Similar to the first-generation androgen receptor (AR) antagonists, resistance to the new second generation anti-androgens (enzalutamide, apalutamide) are developing in PC patients, despite the fact that these drugs have better affinity for the AR. ${ }^{8}$ Anti-androgen resistance can also be triggered by the upregulation of the androgen receptor expression, which promotes signalling from low levels of residual hormone. ${ }^{8}$ More recently, darolutamide (ODM-201, Figure 1) is under evaluation in phase 3 clinical trials in patients with non-metastatic CRPC. ${ }^{9}$ The discovery of new AR antagonists is urgently needed to improve anti-androgen efficacy and to avoid cross-resistance with the clinically used compounds. 


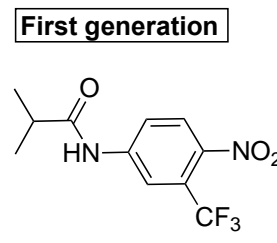

Flutamide

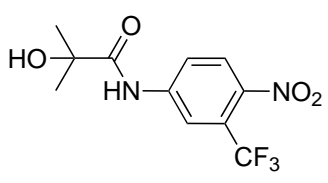

Hydroxyflutamide

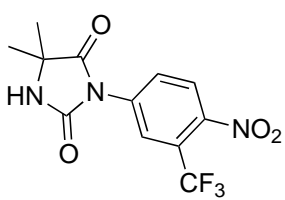

Nilutamide<smiles>CC(O)(CS(=O)(=O)c1ccc(F)cc1)C(=O)Nc1ccc(C#N)c(C(F)(F)F)c1</smiles>

Bicalutamide

Second generation
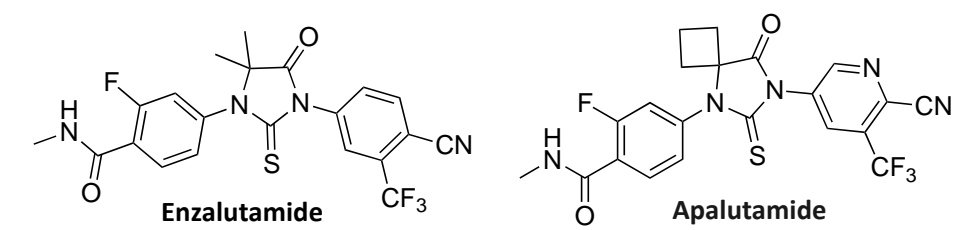

Phase III

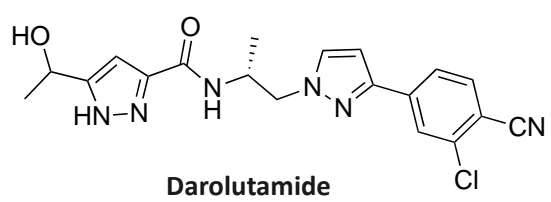

Figure 1. Chemical structures of the non-steroidal anti-androgens (NSAA); flutamide, hydroxyflutamide, nilutamide, and bicalutamide (first generation), enzalutamide and apalutamide (second generation) and darolutamide (phase III clinical trials).

\section{Results and discussion}

Unfortunately, resistance to clinical anti-androgens has plagued the development of effective therapeutics for advanced prostate cancer (PC). Flutamide and bicalutamide (Figure 1) were first generation non-steroidal AR antagonists. However, these antiandrogens lose their activity with time upon the development of AR-LBD point mutants (AR-T877A and AR-W741L) triggered by flutamide and bicalutamide, respectively. On the other hand, AR-F876L mutation causes enzalutamide and apalutamide (ARN-509) to function as AR agonists and confers drug resistance across multiple AR models both in vitro and in vivo. ${ }^{10}$ The X-ray structure of bicalutamide inside the LBD site of the AR W741L mutant, (PDB 1295), provides a significant insight into the protein-drug interactions and explains the structural basis for the conversion of bicalutamide from AR antagonist into AR agonist. ${ }^{10,}$ ${ }^{11}$ The binding mode of bicalutamide as an antagonist of the AR-wild type compared to its binding mode as an agonist of the AR-W741L mutant is shown in Figure 2. It is observed that helix $12(\mathrm{H} 12)$ has changed its position from an open antagonist conformation (AR- wild type, blue) to a closed agonist conformation (AR- W741L mutant, green). In the case of the antagonist mode, ring B of bicalutamide 
is pointing outwards away from $\operatorname{Trp}^{741}$ and towards helix 12, thus preventing AR from adapting the closed AR agonist conformation. The loss of the steric bulk of the indolyl side chain of tryptophan ${ }^{741}$ to the smaller size side chain of Leucine ${ }^{741}$ lead to the elimination of the steric clash and hence the incorporation of bicalutamide molecule into the closed activated conformation of AR. ${ }^{10-12}$

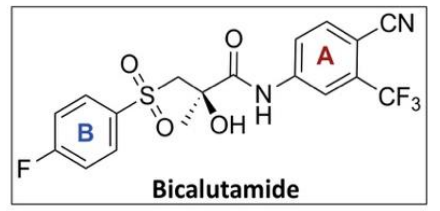

Bicalutamide

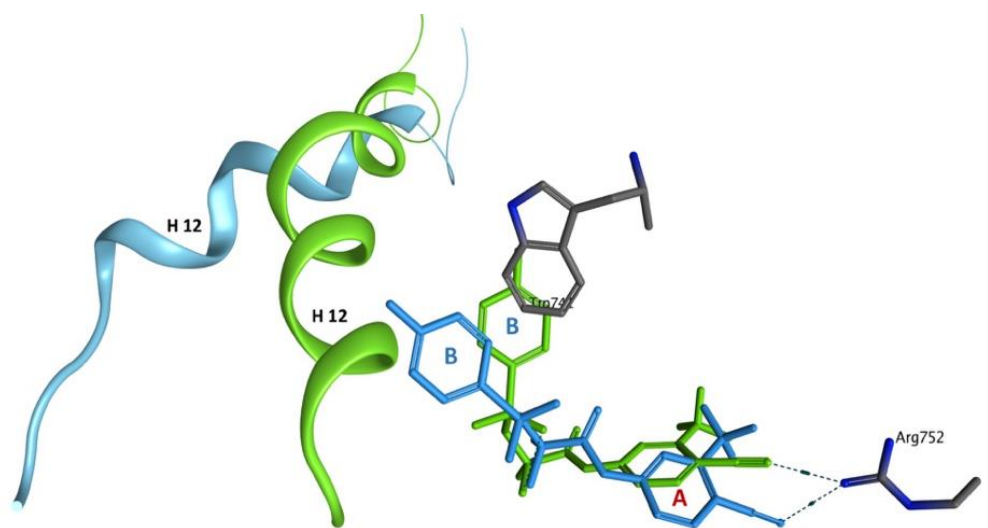

Figure 2. Proposed structural basis for the conversion of bicalutamide from AR antagonist into AR agonist by the gain-offunction mutation (W741L); the X-ray structure of bicalutamide (green) inside the closed agonist conformation of AR LBDW741L, (green, PDB 1Z95) compared to its binding mode (blue) inside the open antagonist conformation of AR LBD-wt, showing ring $B$ orientation to hinder helix 12 from closing to an agonist conformation.

From previous studies, we have learnt that the size and structure of ring B determine the activity of the anti-androgen and if possesses the correct volume and orientation, it will prevent the antiandrogen molecule from being completely confined in the AR-LBD pocket cavity, leaving its bulky substituents protruding against helix $12(\mathrm{H} 12)$ and stopping the latter from adopting a position essential for coactivator interaction (agonist closed conformation). ${ }^{10-12}$

Previously, we have found that the introduction of 3,5-bis-trifluoromethyl (3,5-bis- $\left.\mathrm{CF}_{3}\right)$ substituents into ring B of bicalutamide, enobosarm and umbelliferone derivatives, has profoundly modified their anti-proliferative activity, pharmacokinetic and tissue distribution profiles by providing the geometric bulk needed to keep ring $B$ towards Helix 12 while keeping the crucial interactions of the nitrile/nitro group of ring A with Arg 752. ${ }^{13-15}$ Noting that both flutamide and darolutamide (ODM-201) are lacking the linker $\mathrm{OH}$ group, Figure 1, in this work we studied whether the central hydroxyl group of bicalutamide is necessary for maintaining the anti-androgen activity and if the successive increase in the bulk size of ring B substituents (from 4-F $\rightarrow 4-\mathrm{CF}_{3} \rightarrow 3,5-$ bis- $-\mathrm{CF}_{3}$ ) would compensate for the smaller size of the deshydroxy linker (lacking the central $\mathrm{OH}$ group). We used four different variations of aromatic ring A (Figure 3); all containing the necessary 4-CN or 4- $\mathrm{NO}_{2}$ for the interaction with $\mathrm{Arg} 752$ in addition to either $2-\mathrm{CF}_{3}$ or $3-\mathrm{CF}_{3}$ substituent to understand better the structure activity relationship. 

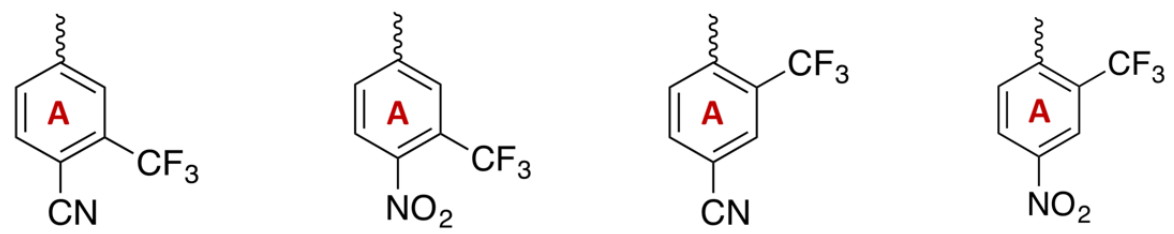

Figure 3. Four different variations of ring $A$ containing $4-\mathrm{CN}$ or $4-\mathrm{NO}_{2}$ group in addition to either $2-\mathrm{CF}_{3}$ or $3-\mathrm{CF}_{3}$

\subsection{Chemistry}

The novel series of deshydroxy propioanilide analogues (29-41) were synthesised in three steps. An acylation reaction between the corresponding substituted trifluoromethyl anilines (1-4) with methacryloyl chloride (5) in dimethylacetamide (DMA) to obtain phenylmethacrylamide derivatives (69) 16,17 was followed by Michael addition of the corresponding substituted thiophenols (10-13) to obtain the thioether intermediates (14-26, 19-56\% yield), which were subsequently oxidised to the corresponding sulfone derivatives (29-41, 19-95\% yield) using 3-chloroperbenzoic acid (mCPBA) (Scheme 1). It is worth noting that the thioethers (14-20 and 24-26) were prepared using sodium hydride $(\mathrm{NaH})$ in tetrahydrofuran (THF) at room temperature (method $\mathrm{A}$ ), whereas the thioethers (2123) corresponding to the $\mathrm{N}$-(4-cyano-2-(trifluoromethyl)phenyl) methacrylamide (8) were prepared using aqueous sodium hydroxide solution and tetrabutylammonium chloride in 1,4-dioxane and reflux for 3 hours instead (method B), as the first method did not yield any products. ${ }^{18}$ The intermediate sulphides $(\mathbf{1 5}, \mathbf{1 6}, \mathbf{2 0 - 2 2})$ were used directly into the next oxidation step since further purification was not feasible. Interestingly, alongside the thioether compounds (15 and 26) we obtained two unusual disubstituted (double branched) acrylamide derivatives (27 and $\mathbf{2 8}$, respectively) as major by-products in an approximate ratio of 2 (double branched 27 and 28) : 1 (single branched 15, 26), scheme 1. 


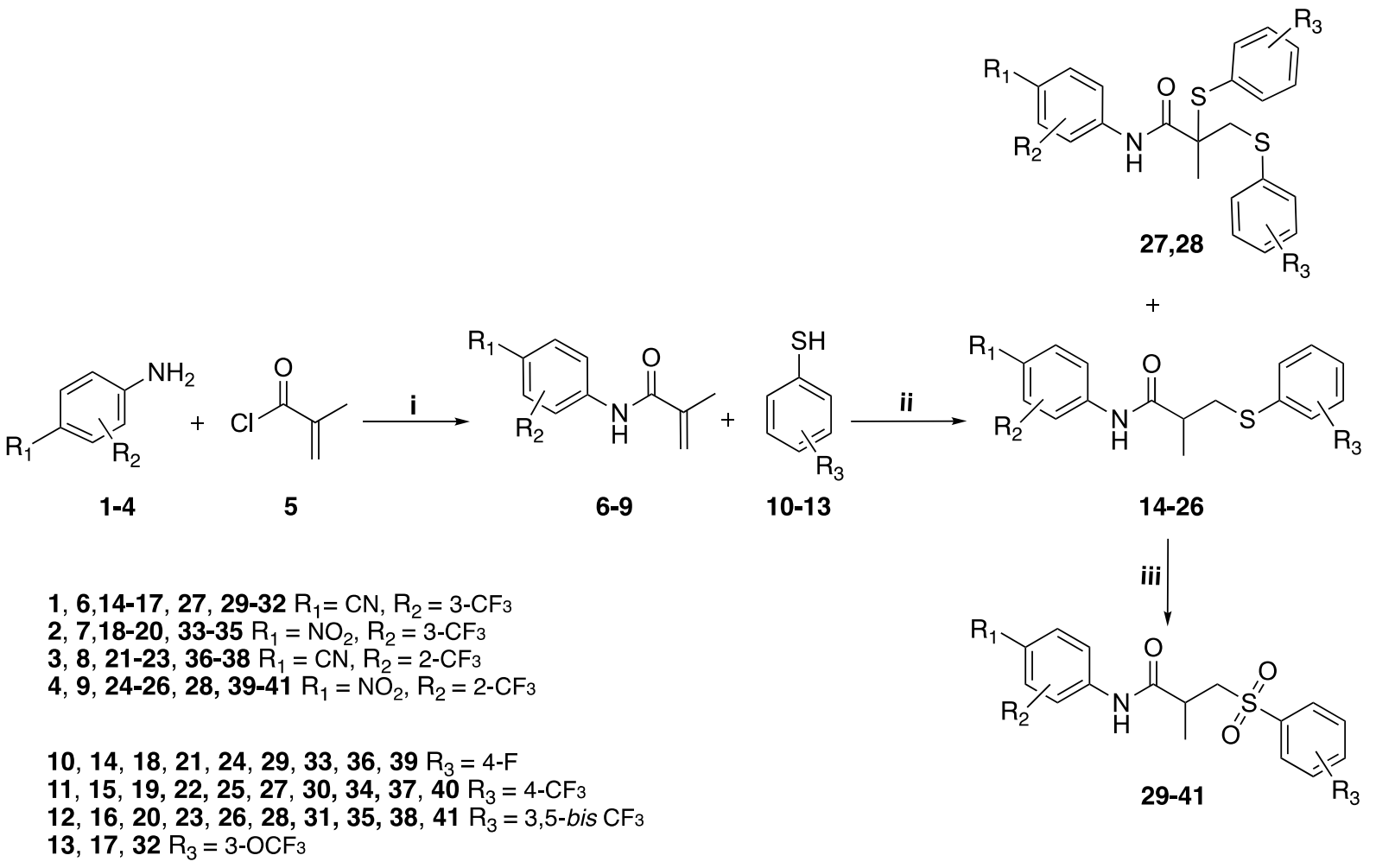

Scheme 1. Synthesis of racemic deshydroxy propioanilide derivatives. Reagents and conditions: (i) methacryloyl chloride 5 (8 equiv), DMA, rt, 3 h; (ii) thiophenol derivatives (10-13, 1.2 equiv), method A: NaH (1.2 equiv), THF, rt, 24 h (6,7,9) or method B: $\mathrm{NaOH}, 1$,4-dioxane, tetrabutylammonium chloride reflux $3 \mathrm{hr}$ (8); (iii) mCPBA (1.4 equiv), DCM, rt, 4-6 h.

The mechanism of the formation of the double branched products remains to be fully clarified. All compounds were purified by column chromatography and/or recrystallised. The structures of all the synthesised compounds were confirmed using analytical and spectroscopic data $\left({ }^{1} \mathrm{H} N M R,{ }^{13} \mathrm{C} N M R\right.$, ${ }^{19} \mathrm{~F}$ NMR and mass spectrometry), which were in full accordance with their depicted structures.<smiles>[R]c1ccc(NC(=O)C(C)CC[X]c2ccccc2)cc1</smiles><smiles>[R]c1ccc(NC(=O)C(C)(CSc2ccccc2)Sc2ccccc2)cc1[R]</smiles>

14-26, 29-41

27,28

\begin{tabular}{|c|c|c|c|c|c|}
\hline ID & $\mathbf{R}_{\mathbf{1}}$ & $\mathbf{R}_{\mathbf{2}}$ & $\mathbf{R}_{\mathbf{3}}$ & $\mathbf{X}$ & $\mathbf{I C}_{\mathbf{5 0}}$ (uM) \\
\hline $\mathbf{1 4}$ & $\mathrm{CN}$ & $3-\mathrm{CF}_{3}$ & $4-\mathrm{F}$ & $\mathrm{S}$ & 8.69 \\
\hline $\mathbf{1 5}$ & $\mathrm{CN}$ & $3-\mathrm{CF}_{3}$ & $4-\mathrm{CF}_{3}$ & $\mathrm{~S}$ & - \\
\hline $\mathbf{1 6}$ & $\mathrm{CN}$ & $3-\mathrm{CF}_{3}$ & $3,5-\mathrm{BisCF}_{3}$ & $\mathrm{~S}$ & - \\
\hline $\mathbf{1 7}$ & $\mathrm{CN}$ & $3-\mathrm{CF}_{3}$ & $3-\mathrm{OCF}_{3}$ & $\mathrm{~S}$ & 114.97 \\
\hline $\mathbf{1 8}$ & $\mathrm{NO}_{2}$ & $3-\mathrm{CF}_{3}$ & $4-\mathrm{F}$ & $\mathrm{S}$ & 27.16 \\
\hline $\mathbf{1 9}$ & $\mathrm{NO}_{2}$ & $3-\mathrm{CF}_{3}$ & $4-\mathrm{CF}_{3}$ & $\mathrm{~S}$ & 4.41 \\
\hline $\mathbf{2 0}$ & $\mathrm{NO}_{2}$ & $3-\mathrm{CF}_{3}$ & $3,5-\mathrm{BisCF}_{3}$ & $\mathrm{~S}$ & - \\
\hline $\mathbf{2 1}$ & $\mathrm{CN}$ & $2-\mathrm{CF}_{3}$ & $4-\mathrm{F}$ & $\mathrm{S}$ & - \\
\hline $\mathbf{2 2}$ & $\mathrm{CN}$ & $2-\mathrm{CF}_{3}$ & $4-\mathrm{CF}_{3}$ & $\mathrm{~S}$ & - \\
\hline $\mathbf{2 3}$ & $\mathrm{CN}$ & $2-\mathrm{CF}_{3}$ & $3,5-\mathrm{BisCF}_{3}$ & $\mathrm{~S}$ & 4.57 \\
\hline $\mathbf{2 4}$ & $\mathrm{NO}_{2}$ & $2-\mathrm{CF}_{3}$ & $4-\mathrm{F}_{3}$ & $\mathrm{~S}$ & 43.19 \\
\hline
\end{tabular}




\begin{tabular}{|c|c|c|c|c|c|}
\hline $\mathbf{2 5}$ & $\mathrm{NO}_{2}$ & $2-\mathrm{CF}_{3}$ & $4-\mathrm{CF}_{3}$ & $\mathrm{~S}$ & 54.33 \\
\hline $\mathbf{2 6}$ & $\mathrm{NO}_{2}$ & $2-\mathrm{CF}_{3}$ & $3,5-\mathrm{BisC}_{3}$ & $\mathrm{~S}$ & 43.68 \\
\hline $\mathbf{2 7}$ & $\mathrm{CN}$ & $3-\mathrm{CF}_{3}$ & $4-\mathrm{CF}_{3}$ & - & 1.68 \\
\hline $\mathbf{2 8}$ & $\mathrm{NO}_{2}$ & $2-\mathrm{CF}_{3}$ & $3,5-\mathrm{BisCF}_{3}$ & - & 0.43 \\
\hline $\mathbf{2 9}$ & $\mathrm{CN}$ & $3-\mathrm{CF}_{3}$ & $4-\mathrm{F}$ & $\mathrm{SO}_{2}$ & 114.74 \\
\hline $\mathbf{3 0}$ & $\mathrm{CN}$ & $3-\mathrm{CF}_{3}$ & $4-\mathrm{CF}_{3}$ & $\mathrm{SO}_{2}$ & 57.98 \\
\hline $\mathbf{3 1}$ & $\mathrm{CN}$ & $3-\mathrm{CF}_{3}$ & $3,5-\mathrm{BisCF}_{3}$ & $\mathrm{SO}_{2}$ & 6.16 \\
\hline $\mathbf{3 2}$ & $\mathrm{CN}$ & $3-\mathrm{CF}_{3}$ & $3-\mathrm{OCF}_{3}$ & $\mathrm{SO}_{2}$ & 13.19 \\
\hline $\mathbf{3 3}$ & $\mathrm{NO}_{2}$ & $3-\mathrm{CF}_{3}$ & $4-\mathrm{F}$ & $\mathrm{SO}_{2}$ & 2.67 \\
\hline $\mathbf{3 4}$ & $\mathrm{NO}_{2}$ & $3-\mathrm{CF}_{3}$ & $4-\mathrm{CF}_{3}$ & $\mathrm{SO}_{2}$ & 3.31 \\
\hline $\mathbf{3 5}$ & $\mathrm{NO}_{2}$ & $3-\mathrm{CF}_{3}$ & $3,5-\mathrm{BisCF}_{3}$ & $\mathrm{SO}_{2}$ & 12.23 \\
\hline $\mathbf{3 6}$ & $\mathrm{CN}_{37}$ & $2-\mathrm{CF}_{3}$ & $4-\mathrm{F}$ & $\mathrm{SO}_{2}$ & 137.7 \\
\hline $\mathbf{C N}$ & $2-\mathrm{CF}_{3}$ & $4-\mathrm{CF}_{3}$ & $\mathrm{SO}_{2}$ & 28.79 \\
\hline $\mathbf{3 8}$ & $\mathrm{CN}_{39}$ & $2-\mathrm{CF}_{3}$ & $3,5-\mathrm{BisCF}_{3}$ & $\mathrm{SO}_{2}$ & 9.56 \\
\hline $\mathbf{N 0}$ & $\mathrm{NO}_{2}$ & $2-\mathrm{CF}_{3}$ & $4-\mathrm{F}$ & $\mathrm{SO}_{2}$ & 4.05 \\
\hline $\mathbf{4 1}$ & $\mathrm{NO}_{2}$ & $2-\mathrm{CF}_{3}$ & $4-\mathrm{CF}_{3}$ & $\mathrm{SO}_{2}$ & 26.34 \\
\hline Bical & - & $-\mathrm{CF}_{3}$ & $3,5-\mathrm{BisCF}_{3}$ & $\mathrm{SO}_{2}$ & 3.08 \\
\hline Enzal & - & - & - & - & 20.44 \\
\hline
\end{tabular}

Table 1. Chemical structure and in vitro anti-proliferative activity $\left(I_{50}\right.$ in $\left.\mu \mathrm{M}\right)$ of single $(\mathbf{1 4 - 2 6 , 2 9 - 4 1 )}$ and double $(\mathbf{2 7}, \mathbf{2 8})$ branched deshydroxy propioanilide analogues compared to bicalutamide and enzalutamide in the LNCaP cell line. IC50 values presented are the mean of three independent experiments.

\subsection{Cell growth inhibition activity}

The twenty-four novel deshydroxy antiandrogen compounds 14, 17-19, 23-41, were tested for their anti-cancer activity as racemic mixtures against human androgen-sensitive prostate cancer cell line LNCaP at 9 concentrations in half-log increments up to $100 \mu \mathrm{M}$ for 96 hours in triplicate. Bicalutamide and enzalutamide were used as positive controls. Potency is expressed as absolute $I_{50}$ values, calculated by non-linear regression analysis. The results summarised in Table 1 indicated that thirteen compounds $(14,19,23,27,28,31-35,38,39$ and 41$)$ showed better anti-proliferative activity than bicalutamide with $\mathrm{IC}_{50}$ values in the range of 0.43-13.19 $\mu \mathrm{M}$, while the positive controls, bicalutamide and enzalutamide exhibited $I C_{50}$ values of 20.44 and $1.31 \mu \mathrm{M}$, respectively. Interestingly, the double branched compounds $\mathbf{2 7}$ and $\mathbf{2 8}$ exhibited significantly potent activity compared to bicalutamide and enzalutamide in LNCaP cell line (Table 2). The most active compounds $\mathbf{2 7 ,} \mathbf{2 8}$ and $\mathbf{3 3}$ (Figure 4) were selected to be further tested against VCaP and PC3 human prostate cancer cell lines, which represent metastatic and more aggressive forms of prostate cancer (CRPC). ${ }^{19}$

\begin{tabular}{|c|c|c|c|}
\hline Compound ID & LNCaP IC $_{\mathbf{5 0}}(\mathbf{u M})$ & VCaP IC $_{\mathbf{5 0}}(\mathbf{u M})$ & PC3 $_{\text {IC }}$ 50 \\
\hline $\mathbf{2 7}$ & 1.68 & 0.13 & 5.45 \\
\hline $\mathbf{2 8}$ & 0.43 & 0.18 & 0.91 \\
\hline $\mathbf{3 3}$ & 2.67 & 8.21 & 112.30 \\
\hline Bicalutamide & 20.44 & 5.96 & 92.63 \\
\hline Enzalutamide & 1.31 & 3.66 & 15.07 \\
\hline
\end{tabular}

Table 2. In vitro anti-proliferative activity $\left(\mathrm{IC}_{50}\right.$ in $\left.\mu \mathrm{M}\right)$ of compounds $(\mathbf{3 3}, \mathbf{2 7}$ and 28$)$ compared to bicalutamide and enzalutamide in human prostate cancer cell lines; LNCaP, VCaP and PC3 
A

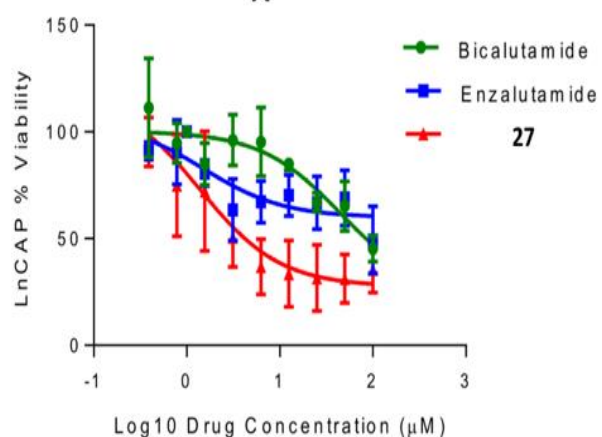

B

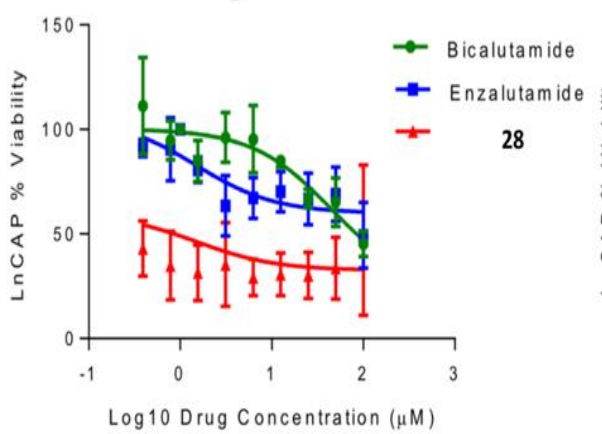

C

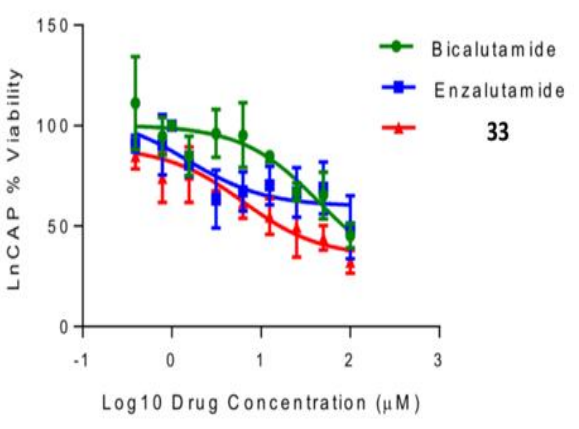

Figure 4. Dose-response relationship of LNCAP cells treated with 0-100 $\mu \mathrm{M}$ of compounds; $(\mathbf{2 7}, \mathbf{A}),(\mathbf{2 9}, \mathbf{B})$ or $(\mathbf{3 3}, \mathbf{C})(\mathrm{red})$, bicalutamide (green) and enzalutamide (blue) for $96 \mathrm{~h}$. Data is presented as the mean \pm SD of three replicates at each concentration.

\subsection{Downregulation of PSA Expression in LNCaP Cells}

Prostate specific antigen (PSA) is a serine protease that is synthesised by both normal and malignant epithelial cells of the human prostate. The expression of PSA is mainly induced by androgens and regulated primarily by the androgen receptor $(A R)$ at the transcriptional level 20,21 . The effect of compounds 27, 28 and $\mathbf{3 3}$ on prostate specific antigen (PSA, an AR-regulated gene) expression was analysed using qPCR after incubation of LNCaP cells with 5, 10, 50 and $100 \mu \mathrm{M}$ of bicalutamide, compounds $\mathbf{2 7}, \mathbf{2 8}$ and $\mathbf{3 3}$, for 24-hours. The analysis shows that the three compounds $\mathbf{2 7}, \mathbf{2 8}$ and $\mathbf{3 3}$ exhibited dose dependent inhibition of PSA expression with compound $\mathbf{2 8}$ showing the best activity significantly exceeding that of bicalutamide (Figure 5). The significant reduction of the AR-regulated PSA expression in the qPCR analysis, suggests that these compounds have strong AR-antagonist activity. 

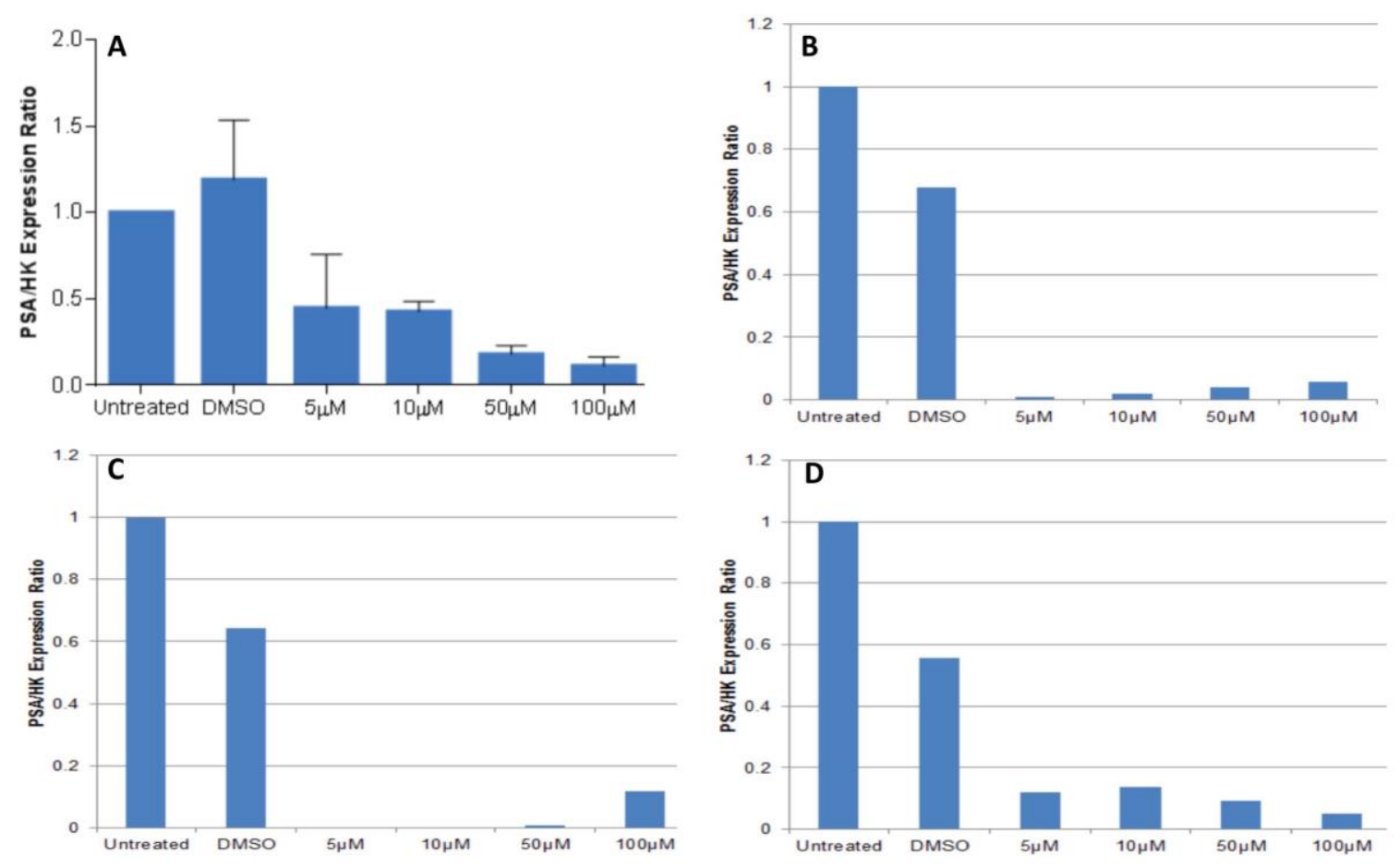

Figure 5. The relative change in PSA expression (PSA/HK) in LNCaP cells upon treatment with increasing doses of bicalutamide (A), compounds; 27 (B), 28 (C) and $\mathbf{3 3}$ (D). HK: housekeeping genes (Bactin and GAPDH)

\subsection{Docking studies reveal a structural basis for anti-androgen activity}

Previous X-ray crystallographic studies of androgen receptor have elucidated the structures of the AR ligand binding domain (LBD) bound to agonists, and of mutant AR bound to antagonists in an agonist like conformation. However, there are no crystal structures of the AR-LBD in an antagonist conformation reported so far. ${ }^{22,23}$ The human progesterone receptor (hPR residues 683-931) has 56\% primary sequence homology to the hAR (residues 669-918) and $32 \%$ of these residues are conservative mutations, giving an overall sequence homology of $87 \% .{ }^{24}$ Building on this information, the hPR crystal structure [PDB 2OVH] $]^{25}$ was used as a template to build an hAR homology model (HM) using the sequence of the hAR in the agonist conformation [PDB 2AMA] ${ }^{26}$ Applying the default parameters of MOE (Molecular Operating Environment - Chemical Computing Group, Montreal, Canada) homology modelling module and using the AMBER99 force field, a total of 10 homology models were generated. The quality of each model was assessed within MOE, and the best model was chosen for the docking studies.

Computational docking studies were performed to explore the binding modes of the deshydroxy propioanilide analogues (14-41) within the AR-LBD binding site. The chemical structures of our compounds (14-41) were constructed, rendered and minimized with the MMFF94x force field in MOE. Docking simulations were performed using Glide SP in Maestro (Glide, version 9.5, Schrödinger, LLC, 
New York, NY. http://www.schrodinger.com). The putative docking modes of the most active single branched deshydroxy propioanilide compounds 41,34 and $33\left(\mathrm{IC}_{50}=3.08,3.31\right.$ and $2.67 \mu \mathrm{M}$, respectively) are shown in Figure $\mathbf{6}$ (A-C, respectively). All three compounds show the crucial H-bond interaction between their nitro group (4- $\mathrm{NO}_{2}$, ring A) and the guanidine group of the Arg-752 residue. Other key interactions of compound $\mathbf{4 1}$ include an $\mathrm{H}$-bond between the aromatic ring $\mathrm{B}(\mathrm{Ar} H)$ and carbonyl group of Asn 705 and the carbonyl group and Met 742 (Figure 5A). Compound 34 shows an additional $\mathrm{H}$-bond between the nitro group $\left(4-\mathrm{NO}_{2}\right.$, ring $\left.\mathrm{A}\right)$ and the amino group of $\mathrm{Gln} 711$, and another $\mathrm{H}$-bond between the amide $\mathrm{NH}$ group and the carbonyl group of Leu 704. Also, a H-bond between the sulphone group and the side chain of Met 745 residue was observed (Figure 5B). Compound 33 shows a hydrogen bond between the aromatic ring $\mathrm{A}$ and the side chain of Met 742 residue, and another $\mathrm{H}$ bond between the sulphone group and the side chain of Met 745 residue.

A

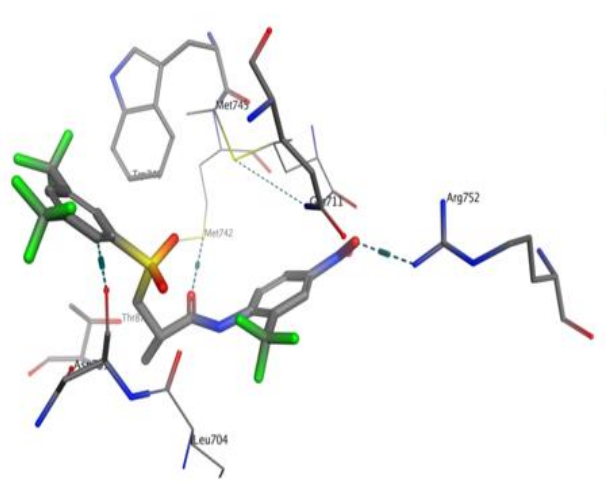

B

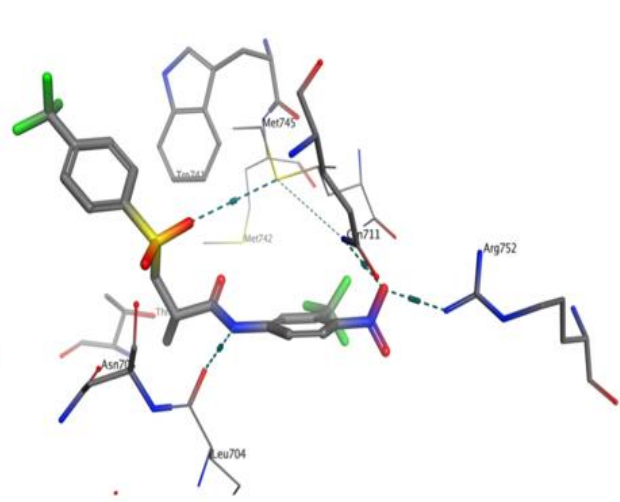

C

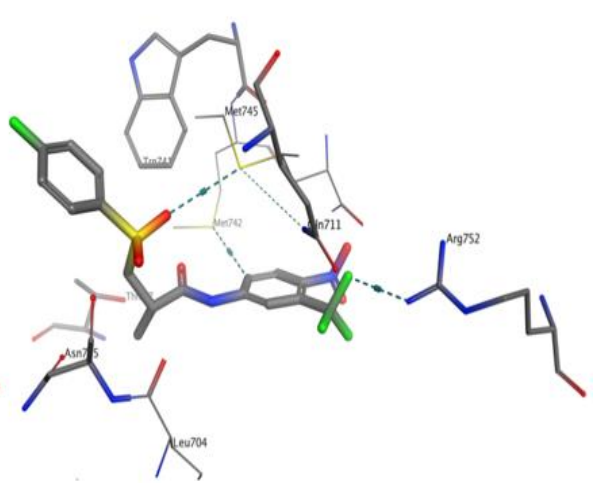

Figure 6. The predicted binding modes of compounds $(41, \mathbf{A}),(34, \mathbf{B})$ and $(33, \mathrm{C})$ inside the hAR-LBD showing H-bond interactions with key amino acids; Arg752, Gln711, Met 742, Met 745, Leu704, Thr877 and Asn705.

On the other hand, the docking of the double branched deshydroxy compounds ( 27 and 28 ) revealed an interesting binding mode where the ring A aryl nitrile $(4-\mathrm{CN}, 27)$ and aryl nitro $\left(4-\mathrm{NO}_{2}, 28\right)$ groups form a hydrogen bond with the guanidine group of Arg752 in the AR ligand binding pocket, mimicking the interaction between the 3-keto functionality of the hormone dihydrotestesterone (DHT) and the androgen receptor. The two branches of ring B occupy simultaneously the two sub-pockets that are known to be involved in the binding of bicalutamide and enzalutamide ${ }^{27}$ which may explain well the high potency observed with this type of distinctive scaffold (Figure 7). 


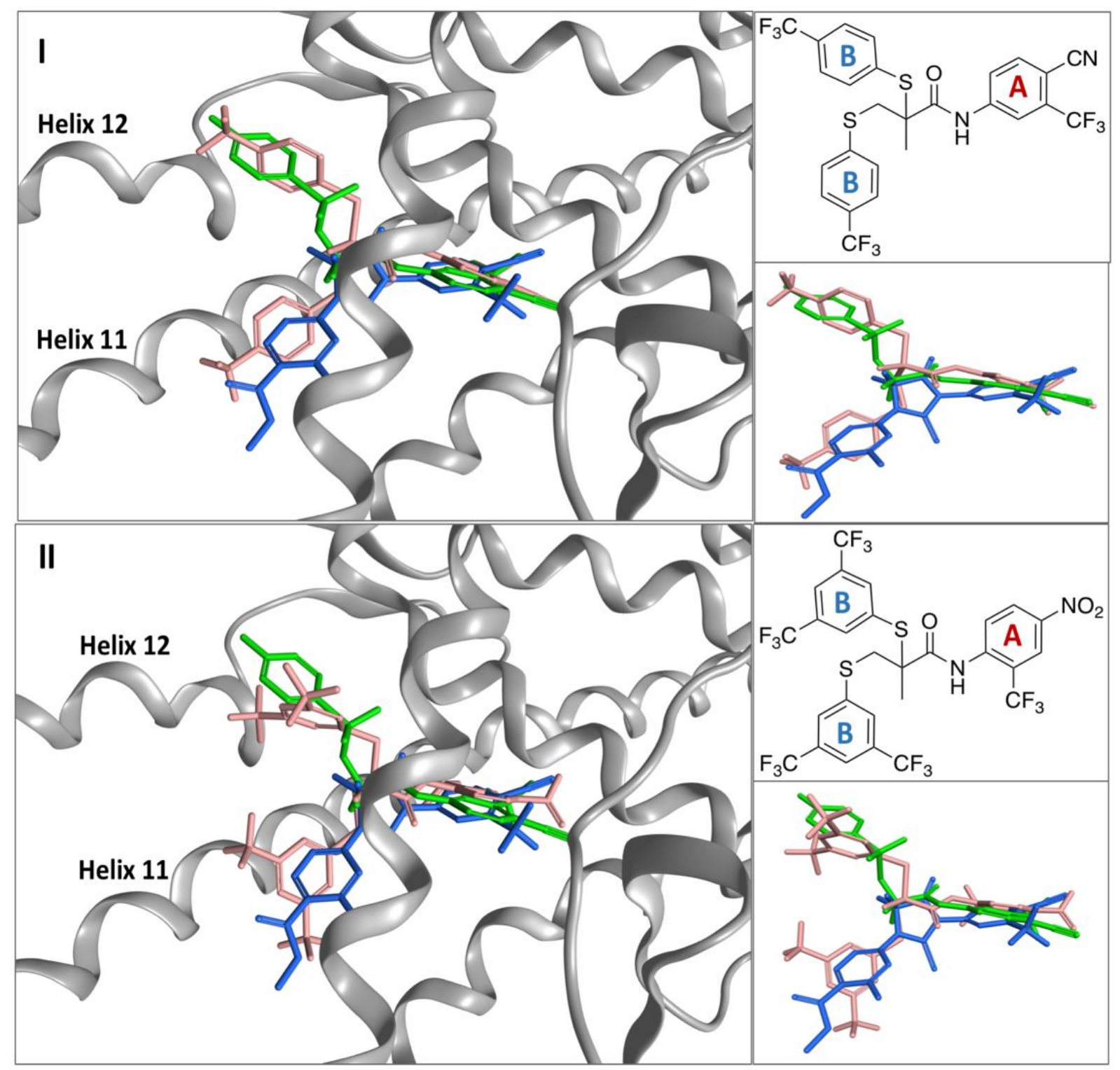

Figure 7. The predicted binding modes of bicalutamide (green), enzalutamide (blue) compared to the double-branched compounds (pink); $\mathbf{2 7}$ (I) and $\mathbf{2 8}$ (II) within the hAR-LBD (grey ribbon). Left panel (top) is showing the 2D representation of compound 27 (I) and compound 28 (II).

Generally, our SAR analysis of this family of compounds indicates that the lack of the linker hydroxy group of the propioanilide scaffold seems to be tolerated in terms of the anti-proliferative activity in PC cell lines and in some cases showed enhanced activity compared to bicalutamide; compounds (14, $19,23,27,28,31-35,38,39$ and 41 ). Compounds 27 and 28 were significantly more potent than both bicalutamide and enzalutamide in our models. Docking studies suggest that this enhanced activity can be attributed to the steric bulk added by the two branches of the aromatic ring B which occupy both the proposed binding pockets of bicalutamide and enzalutamide simultaneously and would provide the geometric bulk needed to keep ring B pointing outwards away from $\operatorname{Trp}^{741}$ and towards helix 12, thus preventing AR from adapting the AR agonist (closed) conformation (Figure 7). These double 
branched compounds (27 and $\mathbf{2 8}$ ) are distinct from the structures of other nonsteroidal antiandrogens, which is likely to result in differences in biology and resistance mechanisms.

\section{Conclusion}

A series of twenty-four novel deshydroxy bicalutamide analogues (29-41) were synthesised using a Michael addition reaction between four different acrylamide derivatives (6-9) and various fluorinated thiophenols (10-13) as a key step. Eleven compounds showed anti-proliferative activity $\left(\mathrm{IC}_{50}=0.43\right.$ $13.19 \mu \mathrm{M})$ better than bicalutamide $\left(\mathrm{IC}_{50}=20.44 \mu \mathrm{M}\right)$. Interestingly, compounds $\mathbf{2 7}$ and $\mathbf{2 8}$ exhibited very potent activity with $\mathrm{IC}_{50}$ values of 1.68 and $0.43 \mu \mathrm{M}$, respectively, which is comparable or better than enzalutamide $\left(\mathrm{IC}_{50}=1.31 \mu \mathrm{M}\right)$ in the $\mathrm{LNCaP}$ cell line. Further testing for the in vitro antiproliferative activity in VCaP and PC3 cell lines showed sub-micromolar activity. Furthermore, compounds 27, 28 and $\mathbf{3 3}$ showed remarkable reduction of PSA expression in LNCaP cells confirming their anti-androgenic activity. Molecular modelling studies indicated that the enhanced anti-androgen activity of compounds $\mathbf{2 7}$ and $\mathbf{2 8}$ appears to be a result of the extra bulk conferred by the two aromatic rings $B$, which ensure the occupation of the two sub-pockets of the AR-LBD involved in the binding interaction of bicalutamde and enzalutamide simultaneously. This may forestall the drug resistance seen with current clinical anti-androgens. Compounds $\mathbf{2 7}$ and $\mathbf{2 8}$ have distinctive chemical structure and represents promising lead for further development of AR antagonists. Overall, this study provides, for the first time, the double-branched configuration into the non-steroidal anti-androgen library and lays a foundation for the development of alternative AR antagonist therapies capable of combating prostate cancer.

\section{Acknowledgment}

The authors would like to thank the Welsh Government (A4B-Academic Expertise for Business), the Life Sciences Research Network of Wales (LSRNW), and the Cardiff China Medical Research Collaborative. We also thank the EPSRC National Mass Spectrometry centre (Swansea, U.K.) for provision of accurate mass spectrometry.

\section{Supplementary data}

${ }^{1} \mathrm{H},{ }^{19} \mathrm{~F}$ and ${ }^{13} \mathrm{C}$ NMR spectra, and mass spectrometry data, for representative compounds $\mathbf{2 5}, \mathbf{2 8}$, and 35

\section{Experimental section}

\subsection{Chemistry}

All chemicals were purchased from Sigma-Aldrich or Alfa Aesar and were used without further 
purification. Thin Layer Chromatography (TLC): pre-coated aluminium backed plates ( $60 \mathrm{~F}_{254}, 0.2 \mathrm{~mm}$ thickness, Merck) were visualized under both short and long wave UV light (254 and $366 \mathrm{~nm}$ ). Flash column chromatography was carried out using silica gel supplied by Fisher (60A, 35-70 $\mu \mathrm{m}) .{ }^{1} \mathrm{H}$ NMR (500 MHz), ${ }^{13} \mathrm{C}$ NMR (125 MHz) and ${ }^{19} \mathrm{~F}$ NMR (470 MHz) spectra were recorded on a Bruker Avance 500 $\mathrm{MHz}$ spectrometer at $25^{\circ} \mathrm{C}$. Chemical shifts $(\delta)$ are expressed in parts per million $(\mathrm{ppm})$ and coupling constants $(\mathrm{J})$ are given in hertz $(\mathrm{Hz})$. The following abbreviations are used in the assignment of NMR signals: s (singlet), bs (broad singlet); $d$ (doublet), t (triplet), q (quartet), qn (quintet), m (multiplet), dd (doublet of doublet), dt (doublet of triplet), td (triple doublet); dq (double quartet), m (multiplet), dm (double multiplet). Mass spectrometry was performed as a service through the EPSRC National Mass Spectrometry centre (Swansea, UK).

\subsubsection{General method for the preparation of intermediates 6-9}

Methacryloyl chloride $5(8.4 \mathrm{~mL}, 85.96 \mathrm{mmol})$ was added over the course of 10 minutes to a stirring solution of the appropriate trifluoromethyl-substituted aniline 1-4 $(10.75 \mathrm{mmol})$ in $\mathrm{N}, \mathrm{N}$ dimethylacetamide $(10 \mathrm{~mL})$ at room temperature for $24 \mathrm{~h}$. After the reaction was complete, the mixture was diluted with ethyl acetate $(100 \mathrm{~mL})$, extracted with saturated $\mathrm{NaHCO}_{3}$ solution $(2 \times 50 \mathrm{~mL})$ then cold brine $(2 \times 50 \mathrm{~mL})$. The combined organic layer was dried over anhydrous $\mathrm{Na}_{2} \mathrm{SO}_{4}$ and the solvent was removed under reduced pressure. The crude oil residue was purified by flash column chromatography eluting with chloroform-ethyl acetate $95: 5 \mathrm{v} / \mathrm{v}$ to obtain the titled compounds.

$N$-(4-cyano-3-(trifluoromethyl)phenyl)methacrylamide $(6)^{16}$. Yield; 92\%

${ }^{1} \mathrm{H} \mathrm{NMR}\left(\mathrm{CDCl}_{3}\right) \delta 8.10(\mathrm{~d}, J=2 \mathrm{~Hz}, 1 \mathrm{H}, \mathrm{ArH}), 8.06(\mathrm{bs}, 1 \mathrm{H}, \mathrm{NH}), 8.01(\mathrm{dd}, \mathrm{J}=2,8.5 \mathrm{~Hz}, 1 \mathrm{H}, \operatorname{ArH}), 7.81(\mathrm{~d}$, $J=8.5 \mathrm{~Hz}, 1 \mathrm{H}, \mathrm{ArH}), 5.89\left(\mathrm{~d}, J=1 \mathrm{~Hz}, 1 \mathrm{H}, \mathrm{CH}_{2}\right), 5.62\left(\mathrm{q}, J=1.5 \mathrm{~Hz}, 1 \mathrm{H}, \mathrm{CH}_{2}\right), 2.10(\mathrm{dd}, J=0.5,1.5 \mathrm{~Hz}, 3 \mathrm{H}$, $\left.\mathrm{CH}_{3}\right) \cdot{ }^{19} \mathrm{~F}-\mathrm{NMR}:\left(\mathrm{CDCl}_{3}\right) \delta-62.23$.

$\mathbf{N - ( 4 - n i t r o - 3 - ( t r i f l u o r o m e t h y l ) p h e n y l ) m e t h a c r y l a m i d e ~ ( 7 ) ~}{ }^{16}$. Yield; $80 \%$

${ }^{1} \mathrm{H}-\mathrm{NMR}\left(\mathrm{CDCl}_{3}\right): \delta$ 7.99-7.95 (m, 2H, ArH), $7.93(\mathrm{~d}, J=9 \mathrm{~Hz}, 1 \mathrm{H}, \mathrm{ArH}), 7.8(\mathrm{bs}, 1 \mathrm{H}, \mathrm{NH}), 5.81(\mathrm{q}, J=1 \mathrm{~Hz}$ $\left.1 \mathrm{H}, \mathrm{CH}_{2}\right), 5.55\left(\mathrm{q}, J=1.5 \mathrm{~Hz}, 1 \mathrm{H}, \mathrm{CH}_{2}\right), 2.02$ (dd, $\left.J=1,1.5 \mathrm{~Hz}, 3 \mathrm{H}, \mathrm{CH}_{3}\right) .{ }^{19} \mathrm{~F}-\mathrm{NMR}\left(\mathrm{CDCl}_{3}\right): \delta-60.09$.

N-(4-cyano-2-(trifluoromethyl)phenyl)methacrylamide $(8)^{17}$. Yield; $88 \%$

${ }^{1} \mathrm{H}-\mathrm{NMR}\left(\mathrm{CDCl}_{3}\right): \delta 8.69(\mathrm{~d}, \mathrm{~J}=9 \mathrm{~Hz}, 1 \mathrm{H}, \mathrm{ArH}), 8.07$ (bs, 1H, NH), $7.84(\mathrm{~d}, \mathrm{~J}=1.5 \mathrm{~Hz}, 1 \mathrm{H}, \mathrm{ArH}), 7.78(\mathrm{dd}, \mathrm{J}=$ 2, $9 \mathrm{~Hz}, 2 \mathrm{~Hz}, 1 \mathrm{H}, \mathrm{ArH}), 5.83$ (q, J = $1 \mathrm{~Hz}, 1 \mathrm{H}, \mathrm{CH}_{2}$ ), 5.56 (q, J=1.5 Hz, 1H, CH2), 2.02 (dd, J= 1, 1.5 Hz, 3H, $\left.\mathrm{CH}_{3}\right) \cdot{ }^{19} \mathrm{~F}-\mathrm{NMR}\left(\mathrm{CDCl}_{3}\right): \delta-61.35$.

N-(4-nitro-2-(trifluoromethyl)phenyl)methacrylamide (9) ${ }^{17}$ Yield; $94 \%$ 
${ }^{1} \mathrm{H} \mathrm{NMR}\left(\mathrm{CDCl}_{3}\right) \delta 8.73(\mathrm{~d}, \mathrm{~J}=9 \mathrm{~Hz}, 1 \mathrm{H}, \mathrm{ArH}), 8.46(\mathrm{~d}, \mathrm{~J}=3 \mathrm{~Hz}, 1 \mathrm{H}, \mathrm{ArH}), 8.37(\mathrm{dd}, \mathrm{J}=9 \mathrm{~Hz}, 2.5 \mathrm{~Hz}, 1 \mathrm{H}, \operatorname{Ar} H)$, 8.17 (bs, $1 \mathrm{H}, \mathrm{NH}$ ), 5.85 (q, J= $0.5 \mathrm{~Hz}, 1 \mathrm{H}, \mathrm{CH}_{2}$ ), 5.58 (q, J=1.5 Hz, 1H, CH $), 2.15-2.13$ (dd, J=1, $1.5 \mathrm{~Hz}$, $\left.1 \mathrm{H}, \mathrm{CH}_{3}\right) .{ }^{19} \mathrm{~F}-\mathrm{NMR}:\left(\mathrm{CDCl}_{3}\right) \delta-61.31$.

\subsubsection{General method for the preparation of sulphide intermediates;}

\subsubsection{Method A: (14-20 and 24-28)}

To a mixture of $60 \%$ sodium hydride in mineral oil $(94.43 \mathrm{mg}, 2.36 \mathrm{mmol})$ in anhydrous tetrahydrofuran $(5 \mathrm{~mL})$ at $0^{\circ} \mathrm{C}$ under anhydrous THF under nitrogen atmosphere, was added dropwise the corresponding thiophenol 10-13 $(2.05 \mathrm{mmol})$. This mixture was stirred at room temperature for 20 minutes. A solution of the appropriate intermediate 6-9 $(1.57 \mathrm{mmol}$ in $5 \mathrm{~mL}$ anhydrous tetrahydrofuran) was added slowly to the thiophenol mixture and stirred at room temperature for $24 \mathrm{~h}$. The mixture was concentrated under vacuum then diluted with ethyl acetate $(30 \mathrm{~mL})$, washed with brine $(20 \mathrm{~mL})$ and water $(30 \mathrm{~mL})$, dried over anhydrous sodium sulfate and concentrated under vacuum. The crude residue was purified by column chromatography eluting with chloroform-ethyl acetate gradually increasing from 95:5 to $90: 10 \mathrm{v} / \mathrm{v}$.

\subsubsection{Method B: (21-23)}

The corresponding thiophenol $\mathbf{1 0 - 1 3}(2.05 \mathrm{mmol})$ was added dropwise to an aqueous sodium hydroxide solution (79 $\mathrm{mg}$ in $1 \mathrm{ml}$ water) for $15 \mathrm{~min}$ at room temperature. Then a solution of compound $8(2.05 \mathrm{mmol})$ in 1,4- dioxan $(5 \mathrm{~mL})$ was added at room temperature followed by a catalytic amount of tetrabutylammonium bromide. The reaction mixture was refluxed for $3 \mathrm{~h}$ and cooled to room temperature, followed by addition of $26 \%$ aqueous acetic acid. This mixture was extracted with ethyl acetate $(2 \times 200 \mathrm{~mL})$. The ethyl acetate layer was separated, washed with water, and concentrated under reduced pressure. The crude residue was purified by column chromatography eluting with chloroform-ethyl acetate gradually increasing from 95:5 to 90:10 v/v.

N-(4-cyano-3-(trifluoromethyl)phenyl)-3-((4-fluorophenyl)thio)-2-methylpropanamide (14). Yield; $50 \%$

${ }^{1} \mathrm{H}-\mathrm{NMR}:\left(\mathrm{CDCl}_{3}\right) \delta 8.01(\mathrm{~s}, 1 \mathrm{H}, \mathrm{ArH}), 7.90(\mathrm{~d}, \mathrm{~J}=8.5 \mathrm{~Hz}, 1 \mathrm{H}, \mathrm{ArH}), 7.85(\mathrm{~s}, 1 \mathrm{H}, \mathrm{NH}), 7.79(\mathrm{~d}, \mathrm{~J}=9 \mathrm{~Hz}, 1 \mathrm{H}$, $\operatorname{ArH}), 7.38(\mathrm{dd}, \mathrm{J}=5.5,8 \mathrm{~Hz}, 2 \mathrm{H} \mathrm{ArH}), 7.00(\mathrm{t}, \mathrm{J}=8.5 \mathrm{~Hz}, 2 \mathrm{H}, \operatorname{ArH}), 3.28\left(\mathrm{dd}, \mathrm{J}=8,14 \mathrm{~Hz}, 1 \mathrm{H}, \mathrm{CH}_{2}\right), 3.04$ $\left(\mathrm{dd}, \mathrm{J}=5,13.5 \mathrm{~Hz}, 1 \mathrm{H}, \mathrm{CH}_{2}\right), 2.64(\mathrm{sext}, \mathrm{J}=7 \mathrm{~Hz}, 1 \mathrm{H}, \mathrm{CH}), 1.37$ (d, J = 7Hz, 3H, $\left.\mathrm{CH}_{3}\right) .{ }^{19} \mathrm{~F}-\mathrm{NMR}:\left(\mathrm{CDCl}_{3}\right) \delta-$ 62.23, -114.26, ${ }^{13} \mathrm{C}-\mathrm{NMR}:\left(\mathrm{CDCl}_{3}\right) \delta 173.59(\mathrm{C}=\mathrm{O}), 162.04$ (d, $\left.{ }^{1} \mathrm{~J}_{\mathrm{C}-\mathrm{F}}=246.4 \mathrm{~Hz}, \operatorname{ArC}\right), 142.10(\operatorname{ArC}), 135.79$ $(\operatorname{ArCH}), 133.99\left(q,{ }^{2} \mathrm{~J}_{\mathrm{C}-\mathrm{F}}=32.9 \mathrm{~Hz}, \operatorname{ArC}\right), 132.64\left(\mathrm{~d},{ }^{3} \mathrm{~J}_{\mathrm{C}-\mathrm{F}}=8 \mathrm{~Hz}, \operatorname{ArCH}\right), 130.04\left(\mathrm{~d},{ }^{4} \mathrm{~J}_{\mathrm{C}-\mathrm{F}}=3.6 \mathrm{~Hz}, \operatorname{ArC}\right), 122.10$ $\left(q,{ }^{1} \mathrm{~J}_{\mathrm{C}-\mathrm{F}}=272.5 \mathrm{~Hz}, \mathrm{CF}_{3}\right), 121.85(\mathrm{ArCH}), 117.31\left(\mathrm{q},{ }^{3} \mathrm{~J}_{\mathrm{C}-\mathrm{F}}=4.6 \mathrm{~Hz}, \operatorname{ArCH}\right), 116.32\left(\mathrm{~d},{ }^{2} \mathrm{~J}_{\mathrm{C}-\mathrm{F}}=21.8 \mathrm{~Hz}, \operatorname{ArCH}\right)$, 
$115.63(\mathrm{CN}), 104.08(\mathrm{ArC}), 42.62(\mathrm{CH}), 38.57\left(\mathrm{CH}_{2}\right), 17.66\left(\mathrm{CH}_{3}\right)$. HRMS calcd for $\mathrm{C}_{18} \mathrm{H}_{14} \mathrm{~F}_{4} \mathrm{~N}_{2} \mathrm{OS}[\mathrm{M}+\mathrm{H}]$, 383.0836; found, 383.0836 .

\section{N-(4-cyano-3-(trifluoromethyl)phenyl)-2-methyl-3-((3-(trifluoromethoxy)phenyl)thio) propanamide} (17). Yield; $47 \%$

${ }^{1} \mathrm{H}-\mathrm{NMR}:\left(\mathrm{CDCl}_{3}\right) \delta 8.54(\mathrm{~s}, 1 \mathrm{H}, \mathrm{NH}), 8.08(\mathrm{~d}, \mathrm{~J}=1.5 \mathrm{~Hz}, 1 \mathrm{H}, \mathrm{ArH}), 7.94(\mathrm{dd}, \mathrm{J}=2,8.5 \mathrm{~Hz}, 1 \mathrm{H}, \operatorname{ArH}), 7.74$ $(\mathrm{d}, \mathrm{J}=8.5 \mathrm{~Hz}, 1 \mathrm{H}, \operatorname{Ar} H), 7.27(\mathrm{~m}, 2 \mathrm{H}, \operatorname{Ar} H), 7.16(\mathrm{~s}, 1 \mathrm{H}, \operatorname{ArH}), 6.99(\mathrm{~d}, \mathrm{~J}=7.5 \mathrm{~Hz}, 1 \mathrm{H}, \operatorname{ArH}), 3.35(\mathrm{dd}, \mathrm{J}=9$, $\left.13.5 \mathrm{~Hz}, 1 \mathrm{H}, \mathrm{CH}_{2}\right), 3.09\left(\mathrm{dd}, \mathrm{J}=5.5,13.5 \mathrm{~Hz}, 1 \mathrm{H}, \mathrm{CH}_{2}\right), 2.83-2.74(\mathrm{~m}, 1 \mathrm{H}, \mathrm{CH}), 1.40\left(\mathrm{~d}, \mathrm{~J}=7 \mathrm{~Hz}, 3 \mathrm{H}, \mathrm{CH}_{3}\right)$. ${ }^{19} \mathrm{~F}-\mathrm{NMR}:\left(\mathrm{CDCl}_{3}\right) \delta-57.86,-62.34,{ }^{13} \mathrm{C}-\mathrm{NMR}:\left(\mathrm{CDCl}_{3}\right) \delta 173.93(\mathrm{C}=0), 149.50(\operatorname{ArC}), 142.58(\operatorname{ArC})$, $138.06(\operatorname{ArC}), 135.73(\operatorname{ArCH}), 133.91\left(q^{2}{ }^{2} \mathrm{C}_{\mathrm{C}-\mathrm{F}}=32.4 \mathrm{~Hz}, \operatorname{ArC}\right), 130.21(\operatorname{ArCH}), 127.10(\operatorname{ArCH}), 122.12(\mathrm{q}$, $\left.{ }^{1} \mathrm{~J}_{\mathrm{C}-\mathrm{F}}=272.5 \mathrm{~Hz}, \mathrm{OCF}_{3}\right), 121.93(\mathrm{ArCH}), 121.11(\mathrm{ArCH}), 120.33\left(\mathrm{q},{ }^{1} \mathrm{~J}_{\mathrm{C}-\mathrm{F}}=253.5 \mathrm{~Hz}, \mathrm{CF}_{3}\right), 118.53(\operatorname{ArCH})$, $117.42\left(\mathrm{q},{ }^{3} \mathrm{~J}_{\mathrm{C}-\mathrm{F}}=4.8 \mathrm{~Hz}, \mathrm{ArCH}\right), 115.89(\mathrm{CN}), 103.41(\mathrm{ArC}), 42.49(\mathrm{CH}), 36.72\left(\mathrm{CH}_{2}\right), 17.76\left(\mathrm{CH}_{3}\right) . \mathrm{HRMS}$ calcd for $\mathrm{C}_{19} \mathrm{H}_{14} \mathrm{~F}_{6} \mathrm{~N}_{2} \mathrm{O}_{2} \mathrm{~S}, 449.0753$; found, $449.0752[\mathrm{M}+\mathrm{H}]$, $466.1015\left[\mathrm{M}+\mathrm{NH}_{4}^{+}\right]$.

3-((4-Fluorophenyl)thio)-2-methyl-N-(4-nitro-3-(trifluoromethyl)phenyl)propanamide (18). Yield; 45 $\%$

${ }^{1} \mathrm{H}$ NMR $\left(\mathrm{CDCl}_{3}\right) \delta 8.36(\mathrm{~s}, 1 \mathrm{H}, \mathrm{NH}), 8.02(\mathrm{~d}, J=1.5 \mathrm{~Hz}, 1 \mathrm{H}, \operatorname{ArH})$, 7.98-7.95 (m, 2H, ArH), 7.38-7.33 (m, $2 \mathrm{H}, \operatorname{ArH}), 6.99-6.94(\mathrm{~m}, 2 \mathrm{H}, \mathrm{ArH}), 3.27$ (dd, $\left.J=8.5,13.5 \mathrm{~Hz}, 1 \mathrm{H}, \mathrm{CH}_{2}\right), 3.03\left(\mathrm{dd}, J=5,13.5 \mathrm{~Hz}, 1 \mathrm{H}, \mathrm{CH}_{2}\right.$ ), 2.72-2.64 (m, $1 \mathrm{H}, \mathrm{CH}), 1.36\left(\mathrm{~d}, J=6.5 \mathrm{~Hz}, 3 \mathrm{H}, \mathrm{CH}_{3}\right) ;{ }^{19} \mathrm{~F} \mathrm{NMR}\left(\mathrm{CDCl}_{3}\right) \delta-60.14,-114.70 ;{ }^{13} \mathrm{C} \mathrm{NMR}\left(\mathrm{CDCl}_{3}\right)$ $\delta 173.99(\mathrm{C}=0), 161.95\left(\mathrm{~d},{ }^{1} \mathrm{~J}_{\mathrm{C}-\mathrm{F}}=245.8 \mathrm{~Hz}, \operatorname{ArC}\right), 142.68(\operatorname{ArC}), 142.36(\operatorname{ArC}), 132.52\left(\mathrm{~d},{ }^{3} \mathrm{~J}_{\mathrm{C}-\mathrm{F}}=7.8 \mathrm{~Hz}\right.$, $\operatorname{ArCH}), 130.12\left(\mathrm{~d},{ }^{4} \mathrm{~J}_{\mathrm{C}-\mathrm{F}}=2.9 \mathrm{~Hz}, \operatorname{ArC}\right), 127.12(\operatorname{ArCH}), 125.15\left(\mathrm{q},{ }^{2} \mathrm{~J}_{\mathrm{C}-\mathrm{F}}=34.3 \mathrm{~Hz}, \operatorname{ArC}\right), 122.23(\operatorname{ArCH})$, $121.74\left(q,{ }^{1} J_{C-F}=271.9 \mathrm{~Hz}, C F_{3}\right), 118.16\left(q,{ }^{3} J_{C-F}=6.1 \mathrm{~Hz}, \operatorname{ArCH}\right), 116.23\left(d,{ }^{2} J_{C-F}=21.9 \mathrm{~Hz}, \operatorname{ArCH}\right), 42.56$ $(\mathrm{CH}), 38.42\left(\mathrm{CH}_{2}\right), 17.72\left(\mathrm{CH}_{3}\right)$. MS [ESI, m/z]: HRMS calcd for $\mathrm{C}_{17} \mathrm{H}_{14} \mathrm{~F}_{4} \mathrm{~N}_{2} \mathrm{O}_{3} \mathrm{~S}[\mathrm{M}+\mathrm{H}]$, 403.0739; found, 403.0746.

\section{2-Methyl-N-(4-nitro-3-(trifluoromethyl)phenyl)-3-((4-(trifluoromethyl)phenyl)thio)propanamide}

(19). Yield; $52 \%$

${ }^{1} \mathrm{H} \mathrm{NMR}\left(\mathrm{CDCl}_{3}\right) \delta 8.00-7.92(\mathrm{~m}, 3 \mathrm{H}, \mathrm{ArH}), 7.74(\mathrm{~s}, 1 \mathrm{H}, \mathrm{NH}), 7.53(\mathrm{~d}, J=8 \mathrm{~Hz}, 2 \mathrm{H}, \operatorname{ArH}), 7.41(\mathrm{~d}, J=8 \mathrm{~Hz}$, $2 \mathrm{H}, \mathrm{ArH}), 3.27\left(\mathrm{dd}, J=9,13.5 \mathrm{~Hz}, 1 \mathrm{H}, \mathrm{CH}_{2}\right), 3.16\left(\mathrm{dd}, J=5,14 \mathrm{~Hz}, 1 \mathrm{H}, \mathrm{CH}_{2}\right), 2.75-2.67(\mathrm{~m}, 1 \mathrm{H}, \mathrm{CH}), 1.44$ $\left(\mathrm{d}, J=7 \mathrm{~Hz}, 3 \mathrm{H}, \mathrm{CH}_{3}\right) ;{ }^{19} \mathrm{~F} \mathrm{NMR}\left(\mathrm{CDCl}_{3}\right) \delta-60.13,-62.56 ;{ }^{13} \mathrm{C} \mathrm{NMR}\left(\mathrm{CDCl}_{3}\right) \delta 173.16(\mathrm{C}=0), 143.13(\operatorname{ArC})$, $141.71(\operatorname{ArC}), 140.58(\operatorname{ArC}), 128.25\left(\mathrm{q},{ }^{2} \mathrm{~J}_{\mathrm{C}-\mathrm{F}}=32.6 \mathrm{~Hz}, \operatorname{ArC}\right), 127.94(\operatorname{ArCH}), 127.10(\operatorname{ArCH}), 125.95\left(\mathrm{q},{ }^{3} \mathrm{~J}_{\mathrm{C}-}\right.$ $\mathrm{F}=3.8 \mathrm{~Hz}, \operatorname{ArCH}), 125.30\left(\mathrm{q},{ }^{2} \mathrm{~J}_{\mathrm{C}-\mathrm{F}}=33.9 \mathrm{~Hz}, \operatorname{ArC}\right), 122.13(\mathrm{ArCH}), 123.90\left(\mathrm{q},{ }^{1} \mathrm{~J}_{\mathrm{C}-\mathrm{F}}=270.3 \mathrm{~Hz}, \mathrm{CF}_{3}\right), 121.66$ $\left(q,{ }^{1} \mathrm{~J}_{\mathrm{C}-\mathrm{F}}=272.4 \mathrm{~Hz}, \mathrm{CF}_{3}\right), 118.22\left(\mathrm{q},{ }^{3} \mathrm{~J}_{\mathrm{C}-\mathrm{F}}=6 \mathrm{~Hz}, \mathrm{ArCH}\right), 42.73(\mathrm{CH}), 35.92\left(\mathrm{CH}_{2}\right), 17.90\left(\mathrm{CH}_{3}\right) . \mathrm{MS}[\mathrm{ESI}$, $\mathrm{m} / \mathrm{z}$ ]: HRMS calcd for $\mathrm{C}_{18} \mathrm{H}_{14} \mathrm{~F}_{6} \mathrm{~N}_{2} \mathrm{O}_{3} \mathrm{~S}$ [M+H], 453.0702; found, 453.0699. 
3-((3,5-Bis(trifluoromethyl)phenyl)thio)-N-(4-cyano-2-(trifluoromethyl)phenyl)-2-methyl propanamide (23). Yield; $41 \%$

${ }^{1} \mathrm{H} \mathrm{NMR}\left(\mathrm{CDCl}_{3}\right) \delta 8.54(\mathrm{~d}, J=9 \mathrm{~Hz}, 1 \mathrm{H}, \mathrm{ArH}), 7.92(\mathrm{~d}, J=1.5 \mathrm{~Hz}, 1 \mathrm{H}, \operatorname{ArH}), 7.84(\mathrm{dd}, J=2,9 \mathrm{~Hz}, 1 \mathrm{H}, \operatorname{ArH})$, $7.75(\mathrm{~s}, 1 \mathrm{H}, \mathrm{ArH}), 7.70(\mathrm{~s}, 1 \mathrm{H}, \mathrm{NH}), 7.67(\mathrm{~s}, 1 \mathrm{H}, \mathrm{ArH}), 3.47$ (dd, J= 8.5, $13.5 \mathrm{~Hz}, 1 \mathrm{H}, \mathrm{CH}_{2}$ ), 3.19 (dd, J= 5.5, $\left.13.5 \mathrm{~Hz}, 1 \mathrm{H}, \mathrm{CH}_{2}\right), 2.77-2.69(\mathrm{~m}, 1 \mathrm{H}, \mathrm{CH}), 1.45\left(\mathrm{~d}, \mathrm{~J}=7 \mathrm{~Hz}, 3 \mathrm{H}, \mathrm{CH}_{3}\right) ;{ }^{19} \mathrm{~F} \mathrm{NMR}\left(\mathrm{CDCl}_{3}\right) \delta-61.15,-63.10$;

${ }^{13} \mathrm{C} \mathrm{NMR}\left(\mathrm{CDCl}_{3}\right) \delta 172.43(\mathrm{C}=\mathrm{O}), 139.27(\operatorname{ArC}), 138.79(\operatorname{ArC}), 136.69(\mathrm{ArCH}), 132.34\left(\mathrm{q},{ }^{2} \mathrm{~J}_{\mathrm{C}-\mathrm{F}}=33.3 \mathrm{~Hz}\right.$, $\operatorname{ArC}), 130.25\left(q,{ }^{3} \mathrm{~J}_{C-F}=5.4 \mathrm{~Hz}, \operatorname{ArCH}\right), 128.38\left(q,{ }^{3} \mathrm{~J}_{\mathrm{C}-\mathrm{F}}=3.3 \mathrm{~Hz}, \operatorname{ArCH}\right), 123.64(\mathrm{ArCH}), 122.89\left(q,{ }^{1} \mathrm{~J}_{C-F}=\right.$ $\left.271.9 \mathrm{~Hz}, C_{3}\right), 122.24(\operatorname{ArC}), 118.64\left(\mathrm{q},{ }^{1} \mathrm{~J}_{\mathrm{C}-\mathrm{F}}=304 \mathrm{~Hz}, \mathrm{CF}_{3}\right), 120.01$ (sept, $\left.{ }^{3} \mathrm{~J}_{\mathrm{C}-\mathrm{F}}=3.8 \mathrm{~Hz}, \operatorname{ArCH}\right), 117.43$ $(\mathrm{CN}), 108.08(\mathrm{ArC}), 43.06(\mathrm{CH}), 36.62\left(\mathrm{CH}_{2}\right), 17.63\left(\mathrm{CH}_{3}\right) . \mathrm{C}_{20} \mathrm{H}_{13} \mathrm{~F}_{9} \mathrm{~N}_{2} \mathrm{OS}, \mathrm{MS}(\mathrm{ES}+) \mathrm{m} / \mathrm{z}$ : 523.0491 $\left[\mathrm{M}+\mathrm{Na}^{+}\right], 518.0943\left[\mathrm{M}+\mathrm{NH}_{4}^{+}\right]$.

3-((4-Fluorophenyl)thio)-2-methyl-N-(4-nitro-2-(trifluoromethyl)phenyl)propanamide (24). Yield; 49 $\%$

${ }^{1} \mathrm{H} \mathrm{NMR}\left(\mathrm{CDCl}_{3}\right) \delta 8.65(\mathrm{~d}, J=9 \mathrm{~Hz}, 1 \mathrm{H}, \operatorname{Ar} H), 8.52(\mathrm{~d}, J=2 \mathrm{~Hz}, 1 \mathrm{H}, \operatorname{Ar} H), 8.42(\mathrm{dd}, J=2,9 \mathrm{~Hz}, 1 \mathrm{H}, \operatorname{ArH})$, $7.84(\mathrm{~s}, 1 \mathrm{H}, \mathrm{NH}), 7.40$ (dd, J = 5.5, 8.5 Hz, 2H, ArH), 7.01 (t, $J=8.5 \mathrm{~Hz}, 2 \mathrm{H}, \operatorname{ArH}), 3.28$ (dd, J = 8.5, $14 \mathrm{~Hz}$, $1 \mathrm{H}, \mathrm{CH}_{2}$ ), $3.28\left(\mathrm{dd}, J=5,13.5 \mathrm{~Hz}, 1 \mathrm{H}, \mathrm{CH}_{2}\right), 2.65$ (sext, $\left.J=7 \mathrm{~Hz}, 1 \mathrm{H}, \mathrm{CH}\right), 1.38\left(\mathrm{~d}, J=7 \mathrm{~Hz}, 3 \mathrm{H}, \mathrm{CH}_{3}\right) ;{ }^{19} \mathrm{~F}$ $\operatorname{NMR}\left(\mathrm{CDCl}_{3}\right) \delta-61.03,-114.95 ;{ }^{13} \mathrm{C} \mathrm{NMR}\left(\mathrm{CDCl}_{3}\right) \delta 173.15$ (C=O), $162.14\left(\mathrm{~d},{ }^{1} \mathrm{~J}_{\mathrm{C}-\mathrm{F}}=245.8 \mathrm{~Hz}, \operatorname{ArC}\right), 142.89$ $(\operatorname{ArC}), 140.76(\operatorname{ArC}), 133.03\left(\mathrm{~d},{ }^{3} \mathrm{~J}_{\mathrm{C}-\mathrm{F}}=8 \mathrm{~Hz}, \operatorname{ArCH}\right), 129.83\left(\mathrm{~d},{ }^{4} \mathrm{~J}_{\mathrm{C}-\mathrm{F}}=3.4 \mathrm{~Hz}, \operatorname{ArC}\right), 128.26(\operatorname{ArCH}), 123.36$ $(\operatorname{ArCH}), 122.89\left(\mathrm{q},{ }^{1} \mathrm{~J}_{\mathrm{C}-\mathrm{F}}=272.1 \mathrm{~Hz}, \mathrm{CF}_{3}\right), 122.32\left(\mathrm{q},{ }^{3} \mathrm{~J}_{\mathrm{C}-\mathrm{F}}=6 \mathrm{~Hz}, \operatorname{ArCH}\right), 119.14\left(\mathrm{q},{ }^{2} \mathrm{~J}_{\mathrm{C}-\mathrm{F}}=31 \mathrm{~Hz}, \operatorname{ArC}\right)$, $116.36\left(\mathrm{~d},{ }^{2} \mathrm{~J}_{\mathrm{C}-\mathrm{F}}=22 \mathrm{~Hz}, \operatorname{ArCH}\right), 43.05(\mathrm{CH}), 38.76\left(\mathrm{CH}_{2}\right), 17.41\left(\mathrm{CH}_{3}\right) . \mathrm{MS}$ [ESI, m/z]: HRMS calcd for $\mathrm{C}_{17} \mathrm{H}_{14} \mathrm{~F}_{4} \mathrm{~N}_{2} \mathrm{O}_{3} \mathrm{~S}[\mathrm{M}+\mathrm{H}]$, 403.0734; found, 403.0733.

\section{2-Methyl-N-(4-nitro-2-(trifluoromethyl)phenyl)-3-((4-(trifluoromethyl)phenyl)thio)propanamide}

(25). Yield; $56 \%$

${ }^{1} \mathrm{H} \mathrm{NMR}\left(\mathrm{CDCl}_{3}\right) \delta 8.62(\mathrm{~d}, J=9 \mathrm{~Hz}, 1 \mathrm{H}, \operatorname{ArH}), 8.52(\mathrm{~d}, J=2.5 \mathrm{~Hz}, 1 \mathrm{H}, \operatorname{ArH}), 8.47(\mathrm{dd}, J=2.5,9 \mathrm{~Hz}, 1 \mathrm{H}, \operatorname{ArH})$, $7.81(\mathrm{~s}, 1 \mathrm{H}, \mathrm{NH}), 7.54(\mathrm{~d}, J=8 \mathrm{~Hz}, 2 \mathrm{H}, \operatorname{ArH}), 7.43(\mathrm{~d}, J=8 \mathrm{~Hz}, 2 \mathrm{H}, \operatorname{ArH}), 3.42(\mathrm{dd}, J=8.5,13.5 \mathrm{~Hz}, 1 \mathrm{H}$, $\mathrm{CH}_{2}$ ), $3.16\left(\mathrm{dd}, J=5.5,14 \mathrm{~Hz}, 1 \mathrm{H}, \mathrm{CH}_{2}\right.$ ), 2.74 (sextet of triplet, $J=7,1.5 \mathrm{~Hz}, 1 \mathrm{H}, \mathrm{CH}$ ), $1.44(\mathrm{~d}, J=7 \mathrm{~Hz}, 3 \mathrm{H}$, $\left.\mathrm{CH}_{3}\right) ;{ }^{19} \mathrm{~F} \mathrm{NMR}\left(\mathrm{CDCl}_{3}\right) \delta-61.05,-62.58 ;{ }^{13} \mathrm{C} \mathrm{NMR}\left(\mathrm{CDCl}_{3}\right) \delta 172.84(\mathrm{C}=0), 140.58(\operatorname{ArC}), 140.49(\operatorname{ArC})$, $128.36(\mathrm{ArCH}), 128.29\left(\mathrm{q},{ }^{2} \mathrm{~J}_{\mathrm{C}-\mathrm{F}}=32.5 \mathrm{~Hz}, \mathrm{ArC}\right), 128.25(\mathrm{ArCH}), 125.91$ (q, $\left.{ }^{3} \mathrm{~J}_{\mathrm{C}-\mathrm{F}}=3.6 \mathrm{~Hz}, \operatorname{ArCH}\right), 123.94(\mathrm{q}$, $\left.{ }^{1} \mathrm{~J}_{\mathrm{C}-\mathrm{F}}=270 \mathrm{~Hz}, \mathrm{CF}_{3}\right), 122.85\left(\mathrm{q},{ }^{1} \mathrm{~J}_{\mathrm{C}-\mathrm{F}}=271.8 \mathrm{~Hz}, \mathrm{CF}_{3}\right), 122.31\left(\mathrm{q},{ }^{3} \mathrm{~J}_{\mathrm{C}-\mathrm{F}}=5.6 \mathrm{~Hz}, \operatorname{ArCH}\right), 119.25\left(\mathrm{q},{ }^{2} \mathrm{~J}_{\mathrm{C}-\mathrm{F}}=31.5\right.$ $\mathrm{Hz}, \operatorname{ArC}), 43.03(\mathrm{CH}), 36.18\left(\mathrm{CH}_{2}\right), 17.51\left(\mathrm{CH}_{3}\right) . \mathrm{MS}$ [ESI, m/z]: HRMS calcd for $\mathrm{C}_{18} \mathrm{H}_{14} \mathrm{~F}_{6} \mathrm{~N}_{2} \mathrm{O}_{3} \mathrm{~S}[\mathrm{M}+\mathrm{H}]$, 453.0708; found, 453.0711. 
3-((3,5-Bis(trifluoromethyl)phenyl)thio)-2-methyl-N-(4-nitro-2-(trifluoromethyl)phenyl) propanamide (26). Yield; $24 \%$

${ }^{1} \mathrm{H} \mathrm{NMR}\left(\mathrm{CDCl}_{3}\right) \delta 8.64(\mathrm{~d}, J=9.5 \mathrm{~Hz}, 1 \mathrm{H}, \mathrm{ArH}), 8.54(\mathrm{~d}, J=3 \mathrm{~Hz}, 1 \mathrm{H}, \operatorname{ArH}), 8.43(\mathrm{dd}, J=2.5,9.5 \mathrm{~Hz}, 1 \mathrm{H}$, $\operatorname{ArH}), 7.79(\mathrm{~s}, 1 \mathrm{H}, \mathrm{NH}), 7.76(\mathrm{~s}, 2 \mathrm{H}, \mathrm{ArH}), 7.01(\mathrm{~s}, 1 \mathrm{H}, \mathrm{ArH}), 3.48\left(\mathrm{dd}, J=8,13.5 \mathrm{~Hz}, 1 \mathrm{H}, \mathrm{CH}_{2}\right), 3.21(\mathrm{dd}, J$ $=5.5,13.5 \mathrm{~Hz}, 1 \mathrm{H}, \mathrm{CH}_{2}$ ), 2.76 (sextet of triplet, $\left.J=7,1.5 \mathrm{~Hz}, 1 \mathrm{H}, \mathrm{CH}\right), 1.47\left(\mathrm{~d}, J=7 \mathrm{~Hz}, 3 \mathrm{H}, \mathrm{CH}_{3}\right.$ ); ${ }^{19} \mathrm{~F} \mathrm{NMR}$ $\left(\mathrm{CDCl}_{3}\right) \delta-61.10,-63.11 ;{ }^{13} \mathrm{C} \mathrm{NMR}\left(\mathrm{CDCl}_{3}\right) \delta 172.47(\mathrm{C}=0), 143.09(\operatorname{ArC}), 140.41(\operatorname{ArC}), 139.21(\operatorname{ArC})$, $132.38\left(q,{ }^{2} J_{C-F}=33.3 \mathrm{~Hz}, \operatorname{ArC}\right), 128.40\left(\mathrm{~d},{ }^{4} \mathrm{~J}_{\mathrm{C}-\mathrm{F}}=3.3 \mathrm{~Hz}, \operatorname{ArCH}\right), 128.31(\operatorname{ArCH}), 123.30(\operatorname{ArCH}), 122.87(q$, $\left.{ }^{1} J_{C-F}=271.1 \mathrm{~Hz}, C F_{3}\right), 122.85\left(q,{ }^{1} J_{C-F}=271.9 \mathrm{~Hz}, C F_{3}\right), 122.34\left(q,{ }^{3} J_{C-F}=5.9 \mathrm{~Hz}, A r C H\right), 119.30\left(q,{ }^{2} J_{C-F}=\right.$ $31.1 \mathrm{~Hz}, \operatorname{ArC}), 120.06\left(\mathrm{sept},{ }^{3} \mathrm{~J}_{\mathrm{C}-\mathrm{F}}=3.6 \mathrm{~Hz}, \mathrm{ArCH}\right), 43.13(\mathrm{CH}), 36.62\left(\mathrm{CH}_{2}\right), 17.63\left(\mathrm{CH}_{3}\right) . \mathrm{MS}[\mathrm{ESI}, \mathrm{m} / \mathrm{z}]$ : HRMS calcd for $\mathrm{C}_{19} \mathrm{H}_{13} \mathrm{~F}_{9} \mathrm{~N}_{2} \mathrm{O}_{3} \mathrm{~S}[\mathrm{M}+\mathrm{H}]$, 521.0573; found, 521.0576.

\section{$\mathrm{N}$-(4-cyano-3-(trifluoromethyl)phenyl)-2-methyl-2,3-bis((4-(trifluoromethyl)phenyl)thio)} propanamide (27). Yield; $42 \%$

${ }^{1} \mathrm{H}-\mathrm{NMR}:\left(\mathrm{CDCl}_{3}\right) \delta 9.06(\mathrm{~s}, 1 \mathrm{H}, \mathrm{NH}), 7.97(\mathrm{~d}, \mathrm{~J}=2 \mathrm{~Hz}, 1 \mathrm{H} \mathrm{ArH}), 7.85(\mathrm{dd}, \mathrm{J}=2,8.5 \mathrm{~Hz}, 1 \mathrm{H}, \mathrm{Ar}-\mathrm{H}), 7.79(\mathrm{~d}, \mathrm{~J}$ $=8.5 \mathrm{~Hz}, 1 \mathrm{H}, \operatorname{ArH}), 7.59(\mathrm{~d}, \mathrm{~J}=8.5 \mathrm{~Hz}, 2 \mathrm{H}, \operatorname{ArH}), 7.51(\mathrm{~d}, \mathrm{~J}=8 \mathrm{~Hz}, 2 \mathrm{H}, \operatorname{ArH}), 7.44(\mathrm{dd}, \mathrm{J}=8.5,13.5 \mathrm{~Hz}, 4 \mathrm{H}$, $\mathrm{ArH}), 3.60\left(\mathrm{~d}, \mathrm{~J}=13.5 \mathrm{~Hz}, 1 \mathrm{H}, \mathrm{CH}_{2}\right), 3.52\left(\mathrm{~d}, \mathrm{~J}=13.5 \mathrm{~Hz}, 1 \mathrm{H}, \mathrm{CH}_{2}\right), 1.73\left(\mathrm{~s}, 3 \mathrm{H}, \mathrm{CH}_{3}\right) .{ }^{19} \mathrm{~F}-\mathrm{NMR}:\left(\mathrm{CDCl}_{3}\right) \delta-$ 62.23, -62.65, -63.00. ${ }^{13} \mathrm{C}-\mathrm{NMR}:\left(\mathrm{CDCl}_{3}\right) \delta 170.74(\mathrm{C}=\mathrm{O}), 141.22(\operatorname{ArC}), 140.60(\operatorname{ArC}), 135.86(\operatorname{ArCH})$, 134.35 (ArCH), $134.23(\operatorname{ArC}), 134.11\left(q,{ }^{2} \mathrm{~J}_{C-F}=31 \mathrm{~Hz}, \operatorname{ArC}\right), 131.69\left(\mathrm{q},{ }^{2} \mathrm{~J}_{\mathrm{C}-\mathrm{F}}=33.1 \mathrm{~Hz}, \operatorname{ArC}\right), 131.26(\operatorname{ArCH})$, $129.00(\mathrm{ArCH}), 128.64\left(\mathrm{q},{ }^{2} \mathrm{~J}_{\mathrm{C}-\mathrm{F}}=32.6 \mathrm{~Hz}, \operatorname{ArC}\right), 126.35\left(\mathrm{q},{ }^{3} \mathrm{~J}_{\mathrm{C}-\mathrm{F}}=3.6 \mathrm{~Hz}, \mathrm{ArCH}\right), 125.89-125.74(\mathrm{~m}, \operatorname{ArCH})$, $123.77\left(q,{ }^{1} \mathrm{~J}_{\mathrm{C}-\mathrm{F}}=270 \mathrm{~Hz}, C F_{3}\right), 123.51\left(\mathrm{q}, \mathrm{J}_{\mathrm{C}-\mathrm{F}}=270.8 \mathrm{~Hz}, C F_{3}\right), 122.00\left(\mathrm{q},{ }^{1} \mathrm{~J}_{\mathrm{C}-\mathrm{F}}=272.3 \mathrm{~Hz}, \mathrm{CF}_{3}\right), 117.14(\mathrm{q}$, $\left.{ }^{3} \mathrm{~J}_{\mathrm{C}-\mathrm{F}}=5 \mathrm{~Hz}, \mathrm{ArCH}\right), 115.30(\mathrm{CN}), 105.04(\mathrm{ArC}), 59.51\left(-\mathrm{C}_{-} \mathrm{CH}_{3}\right), 42.06\left(\mathrm{CH}_{2}\right), 23.87\left(\mathrm{CH}_{3}\right) . \mathrm{HRMS}$ calcd for $\mathrm{C}_{26} \mathrm{H}_{17} \mathrm{~F}_{9} \mathrm{~N}_{2} \mathrm{OS}_{2}, 609.0711$; found, $609.0708[\mathrm{M}+\mathrm{H}], 626.0965\left[\mathrm{M}+\mathrm{NH}_{4}^{+}\right]$.

\section{2,3-Bis((3,5-bis(trifluoromethyl)phenyl)thio)-2-methyl-N-(4-nitro-2-(trifluoromethyl)phenyl)}

propanamide (28). Yield; $48 \%$

${ }^{1} \mathrm{H} \mathrm{NMR}\left(\mathrm{CDCl}_{3}\right) \delta 9.19(\mathrm{~s}, 1 \mathrm{H}, \mathrm{NH}), 8.59(\mathrm{~d}, J=3 \mathrm{~Hz}, 1 \mathrm{H}, \mathrm{ArH}), 8.54(\mathrm{~d}, J=9.5 \mathrm{~Hz}, 1 \mathrm{H}, \mathrm{ArH}), 8.45(\mathrm{dd}, J=$ 2.5, $9 \mathrm{~Hz}, 1 \mathrm{H}, \operatorname{ArH}), 7.92(\mathrm{~s}, 1 \mathrm{H}, \operatorname{ArH}), 7.89(\mathrm{~s}, 2 \mathrm{H}, \operatorname{ArH}), 7.78(\mathrm{~s}, 2 \mathrm{H}, \operatorname{ArH}), 7.67(\mathrm{~s}, 1 \mathrm{H}, \operatorname{ArH}), 3.63(\mathrm{~d}, J=$ $13.5 \mathrm{~Hz}, 1 \mathrm{H}, \mathrm{CH}_{2}$ ), $3.49\left(\mathrm{~d}, J=13.5 \mathrm{~Hz}, 1 \mathrm{H}, \mathrm{CH}_{2}\right), 1.80\left(\mathrm{~s}, 3 \mathrm{H}, \mathrm{CH}_{3}\right) ;{ }^{19} \mathrm{~F} \mathrm{NMR}\left(\mathrm{CDCl}_{3}\right) \delta-61.05,-63.14$, 63.19; ${ }^{13} \mathrm{C} \mathrm{NMR}\left(\mathrm{CDCl}_{3}\right) \delta 169.75(\mathrm{C}=0), 143.34(\operatorname{ArC}), 139.89(\operatorname{ArC}), 138.78(\operatorname{ArC}), 132.30(\operatorname{ArC}), 132.87$ $\left(q,{ }^{2} \mathrm{~J}_{C-F}=33.9 \mathrm{~Hz}, \operatorname{ArC}\right), 132.42\left(q,{ }^{2} \mathrm{~J}_{C-F}=33.3 \mathrm{~Hz}, \operatorname{ArC}\right), 134.69,134.66(\operatorname{ArCH}), 129.58\left(\mathrm{~d},{ }^{3} \mathrm{~J}_{\mathrm{C}-\mathrm{F}}=3.6 \mathrm{~Hz}\right.$, $\operatorname{ArCH}), 128.53(\mathrm{ArCH}), 122.44\left(\mathrm{q},{ }^{1} \mathrm{~J}_{\mathrm{C}-\mathrm{F}}=271.6 \mathrm{~Hz}, \mathrm{CF}_{3}\right), 123.87$ (septet, $\left.{ }^{3} \mathrm{~J}_{\mathrm{C}-\mathrm{F}}=3.6 \mathrm{~Hz}, \mathrm{ArCH}\right), 122.53(\mathrm{q}$, $\left.{ }^{3} \mathrm{~J}_{\mathrm{C}-\mathrm{F}}=5.5 \mathrm{~Hz}, \mathrm{ArCH}\right), 122.88\left(\mathrm{q},{ }^{1} \mathrm{~J}_{\mathrm{C}-\mathrm{F}}=272.3 \mathrm{~Hz}, \mathrm{CF}_{3}\right), 122.75\left(\mathrm{q},{ }^{1} \mathrm{~J}_{\mathrm{C}-\mathrm{F}}=274.4 \mathrm{~Hz}, \mathrm{CF}_{3}\right), 122.31(\operatorname{ArCH})$, 
120.72 (septet, $\left.{ }^{3} \mathrm{~J}_{\mathrm{C}-\mathrm{F}}=3.9 \mathrm{~Hz}, \operatorname{ArCH}\right), 119.29\left(\mathrm{q},{ }^{2} \mathrm{~J}_{\mathrm{C}-\mathrm{F}}=31.5 \mathrm{~Hz}, \operatorname{ArC}\right), 57.94\left(\mathrm{CH}_{3} \mathrm{C}\right), 42.43\left(\mathrm{CH}_{2}\right), 14.15$ $\left(\mathrm{CH}_{3}\right)$. MS [ESI, m/z]: HRMS for $\mathrm{C}_{27} \mathrm{H}_{15} \mathrm{~F}_{15} \mathrm{~N}_{2} \mathrm{O}_{3} \mathrm{~S}_{2}[\mathrm{M}+\mathrm{H}]$ ], 765.0371 .

\subsubsection{General method for the preparation of sulfones derivatives 29-41}

To a stirring solution of the corresponding sulfide $14-26(0.7 \mathrm{mmol})$ in $5 \mathrm{~mL}$ anhydrous dichloromethane, was added 3-chloroperbenzoic acid (MCPBA) (1.4 mmol). The solution was stirred at room temperature for $24 \mathrm{~h}$. The reaction mixture was neutralized with $1 \mathrm{M}$ sodium hydroxide. $50 \mathrm{~mL}$ distilled water was added to the reaction mixture and was extracted with $2 \times 50 \mathrm{~mL}$ of dichloromethane. The combined organic layers were washed, dried over anhydrous sodium sulfate, and concentrated in vacuo. The crude residue was purified by column chromatography, preparative TLC or crystallization from methanol.

$\mathrm{N}$-(4-cyano-3-(trifluoromethyl)phenyl)-3-((4-fluorophenyl)sulfonyl)-2-methylpropanamide (29). Yield; 69\%

${ }^{1} \mathrm{H}-\mathrm{NMR}:\left(\left(\mathrm{CD}_{3}\right)_{2} \mathrm{SO}\right) \delta 10.82(\mathrm{~s}, 1 \mathrm{H}, \mathrm{NH}), 8.12(\mathrm{~d}, \mathrm{~J}=2 \mathrm{~Hz}, 1 \mathrm{H}, \mathrm{ArH}), 8.09(\mathrm{~d}, \mathrm{~J}=8.5 \mathrm{~Hz}, 1 \mathrm{H}, \operatorname{ArH}), 7.94(\mathrm{dd}$, $\mathrm{J}=5,9 \mathrm{~Hz}, 2 \mathrm{H}, \operatorname{ArH}), 7.82(\mathrm{dd}, \mathrm{J}=2,8 \mathrm{~Hz}, 1 \mathrm{H}, \operatorname{ArH}), 7.38(\mathrm{t}, \mathrm{J}=9 \mathrm{~Hz}, 2 \mathrm{H}, \operatorname{ArH}), 3.81(\mathrm{dd}, \mathrm{J}=9.5,14.5 \mathrm{~Hz}$, $\left.1 \mathrm{H}, \mathrm{CH}_{2}\right), 3.50\left(\mathrm{dd}, \mathrm{J}=4,14.5 \mathrm{~Hz}, 1 \mathrm{H}, \mathrm{CH}_{2}\right), 3.06-2.98(\mathrm{~m}, 1 \mathrm{H}, \mathrm{CH}), 1.23\left(\mathrm{~d}, \mathrm{~J}=7.5 \mathrm{~Hz}, 3 \mathrm{H}, \mathrm{CH}_{3}\right) .{ }^{19} \mathrm{~F}-\mathrm{NMR}$ : $\left(\left(\mathrm{CD}_{3}\right)_{2} \mathrm{SO}\right) \delta-61.34,-104.87,{ }^{13} \mathrm{C} \mathrm{NMR}\left(\left(\mathrm{CD}_{3}\right)_{2} \mathrm{SO}\right) \delta 173.24(\mathrm{C}=\mathrm{O}), 165.56\left(\mathrm{~d},{ }^{1} \mathrm{~J}_{\mathrm{C}-\mathrm{F}}=250 \mathrm{~Hz}, \operatorname{ArC}\right), 143.76$ $(\operatorname{ArC}), 136.92(\operatorname{ArCH}), 135.71(\operatorname{ArC}), 132.13\left(\mathrm{q}^{2}{ }^{2} \mathrm{~J}_{\mathrm{C}-\mathrm{F}}=31.5 \mathrm{~Hz}, \operatorname{ArC}\right), 131.61\left(\mathrm{~d},{ }^{3} \mathrm{~J}_{\mathrm{C}-\mathrm{F}}=9.9 \mathrm{~Hz}, \operatorname{ArCH}\right), 122.86$ (q, $\left.{ }^{1} \mathrm{~J}_{\mathrm{C}-\mathrm{F}}=273.3 \mathrm{~Hz}, \mathrm{CF}_{3}\right), 122.49(\mathrm{ArCH}), 116.93\left(\mathrm{~d},{ }^{2} \mathrm{~J}_{\mathrm{C}-\mathrm{F}}=22.6 \mathrm{~Hz}, \operatorname{ArCH}\right), 116.84(\mathrm{~m}, \operatorname{ArCH}), 116.21(\mathrm{CN})$, 102.26 ( $\mathrm{ArC}), 57.72\left(\mathrm{CH}_{2}\right), 36.81(\mathrm{CH}), 18.76\left(\mathrm{CH}_{3}\right)$. HRMS calcd for $\mathrm{C}_{18} \mathrm{H}_{14} \mathrm{~F}_{4} \mathrm{~N}_{2} \mathrm{O}_{3} \mathrm{~S}[\mathrm{M}+\mathrm{H}], 415.0734$; found, 415.0735, $\left[\mathrm{M}+\mathrm{NH}_{4}^{+}\right], 432.0999$.

\section{$\mathrm{N}$-(4-cyano-3-(trifluoromethyl)phenyl)-2-methyl-3-((4-(trifluoromethyl)phenyl)sulfonyl)}

propanamide (30). Yield; $21 \%$

${ }^{1} \mathrm{H}-\mathrm{NMR}:\left(\mathrm{CDCl}_{3}\right) \delta 8.88(\mathrm{~s}, 1 \mathrm{H}, \mathrm{NH}), 8.12(\mathrm{~d}, \mathrm{~J}=8.5 \mathrm{~Hz}, 2 \mathrm{H} \mathrm{ArH}), 7.96(\mathrm{~d}, \mathrm{~J}=2 \mathrm{~Hz}, 1 \mathrm{H}, \mathrm{ArH}), 7.88-7.83$ $(\mathrm{m}, 3 \mathrm{H}, \mathrm{ArH}), 7.72(\mathrm{~d}, \mathrm{~J}=8.5 \mathrm{~Hz}, 1 \mathrm{H}, \mathrm{ArH}), 3.99\left(\mathrm{dd}, \mathrm{J}=9.5,14 \mathrm{~Hz}, 1 \mathrm{H}, \mathrm{CH}_{2}\right), 3.43-3.35(\mathrm{~m}, 1 \mathrm{H}, \mathrm{CH}), 3.22$ $\left(\mathrm{dd}, \mathrm{J}=3,14 \mathrm{~Hz}, 1 \mathrm{H}, \mathrm{CH}_{2}\right), 1.43\left(\mathrm{~d}, \mathrm{~J}=7.5 \mathrm{~Hz}, 3 \mathrm{H}, \mathrm{CH}_{3}\right) .{ }^{19} \mathrm{~F}-\mathrm{NMR}:\left(\mathrm{CDCl}_{3}\right) \delta-62.31,-63.42 .{ }^{13} \mathrm{C}-\mathrm{NMR}$ : $\left(\mathrm{CDCl}_{3}\right) \delta 172.27(C=\mathrm{O}), 142.37(\operatorname{ArC}), 142.25(\operatorname{ArC}), 136.04\left(\mathrm{q},{ }^{2} \mathrm{~J}_{\mathrm{C}-\mathrm{F}}=33 \mathrm{~Hz}, \operatorname{ArC}\right), 135.75(\operatorname{ArCH}), 133.72$ $\left(q,{ }^{2} \mathrm{~J}_{\mathrm{C}-\mathrm{F}}=32.5 \mathrm{~Hz}, \operatorname{ArC}\right), 128.65(\mathrm{ArCH}), 126.67\left(\mathrm{q},{ }^{3} \mathrm{~J}_{\mathrm{C}-\mathrm{F}}=3.6 \mathrm{~Hz}, \operatorname{ArCH}\right), 122.87\left(\mathrm{q},{ }^{1} \mathrm{~J}_{\mathrm{C}-\mathrm{F}}=271.6 \mathrm{~Hz}, C F_{3}\right)$, $122.07\left(\mathrm{q},{ }^{1} \mathrm{~J}_{\mathrm{C}-\mathrm{F}}=272.5 \mathrm{~Hz}, \mathrm{CF}_{3}\right), 121.81(\mathrm{ArCH}), 117.18\left(\mathrm{q},{ }^{3} \mathrm{~J}_{\mathrm{C}-\mathrm{F}}=4.9 \mathrm{~Hz}, \operatorname{ArCH}\right), 115.52(\mathrm{CN}), 104.40(\operatorname{ArC})$, $58.88\left(-\mathrm{CH}_{2}\right), 36.69(\mathrm{CH}), 18.88\left(\mathrm{CH}_{3}\right)$. HRMS calculated for $\mathrm{C}_{19} \mathrm{H}_{14} \mathrm{~F}_{6} \mathrm{~N}_{2} \mathrm{O}_{3} \mathrm{~S}[\mathrm{M}+\mathrm{H}], 465.0708$; found, 465.0703.

3-((3,5-Bis(trifluoromethyl)phenyl)sulfonyl)-N-(4-cyano-3-(trifluoromethyl)phenyl)-2-methyl propanamide (31). Yield; $19 \%$ 
${ }^{1} \mathrm{H}-\mathrm{NMR}:\left(\mathrm{CDCl}_{3}\right) \delta 8.38(\mathrm{~s}, 1 \mathrm{H}, \mathrm{NH}), 8.30(\mathrm{~s}, 2 \mathrm{H}, \mathrm{ArH}), 8.06(\mathrm{~s}, 1 \mathrm{H}, \operatorname{ArH}), 7.88(\mathrm{~d}, \mathrm{~J}=2 \mathrm{~Hz}, 1 \mathrm{H}, \operatorname{ArH}), 7.74$ $(\mathrm{dd}, \mathrm{J}=2,8.5 \mathrm{~Hz}, 1 \mathrm{H}, \mathrm{ArH}), 7.68(\mathrm{~d}, \mathrm{~J}=8.5 \mathrm{~Hz}, 1 \mathrm{H}, \mathrm{ArH}), 3.91\left(\mathrm{dd}, \mathrm{J}=9.5,14.5 \mathrm{~Hz}, 1 \mathrm{H}, \mathrm{CH}_{2}\right), 3.29-3.21$ $(\mathrm{m}, 1 \mathrm{H}, \mathrm{CH}), 3.17\left(\mathrm{dd}, \mathrm{J}=3.5,14.5 \mathrm{~Hz}, 1 \mathrm{H}, \mathrm{CH}_{2}\right), 1.37\left(\mathrm{~d}, \mathrm{~J}=7 \mathrm{~Hz}, 3 \mathrm{H}, \mathrm{CH}_{3}\right) .{ }^{19} \mathrm{~F}-\mathrm{NMR}:\left(\mathrm{CDCl}_{3}\right) \delta-62.38$, 63.04. ${ }^{13} \mathrm{C}-\mathrm{NMR}:\left(\mathrm{CDCl}_{3}\right) \delta 171.78(\mathrm{C}=\mathrm{O}), 141.89(\mathrm{ArC}), 141.81(\mathrm{ArC}), 135.82(\mathrm{ArCH}), 134.03\left(\mathrm{q},{ }^{2} \mathrm{~J}_{\mathrm{C}-\mathrm{F}}=\right.$ $32.6 \mathrm{~Hz}, \operatorname{ArC}), 133.43\left(q,{ }^{2} \mathrm{~J}_{\mathrm{C}-\mathrm{F}}=34.6 \mathrm{~Hz}, \operatorname{ArC}\right), 128.43\left(\mathrm{q},{ }^{3} \mathrm{~J}_{\mathrm{C}-\mathrm{F}}=3 \mathrm{~Hz}, \operatorname{ArCH}\right), 128.01-127.77(\mathrm{~m}, \operatorname{ArCH})$, $122.14\left(\mathrm{q},{ }^{1} \mathrm{~J}_{\mathrm{C}-\mathrm{F}}=271.8 \mathrm{~Hz}, \mathrm{CF}_{3}\right), 122.00\left(\mathrm{q},{ }^{1} \mathrm{~J}_{\mathrm{C}-\mathrm{F}}=272.4 \mathrm{~Hz}, \mathrm{CF}_{3}\right), 121.79(\mathrm{ArCH}), 117.23\left(\mathrm{q},{ }^{3} \mathrm{~J}_{\mathrm{C}-\mathrm{F}}=4.6 \mathrm{~Hz}\right.$, $\operatorname{ArCH}), 115.52(\mathrm{CN}), 104.40(\mathrm{ArC}), 58.88\left(\mathrm{CH}_{2}\right), 36.69(\mathrm{CH}), 18.88\left(\mathrm{CH}_{3}\right)$. HRMS calculated for $\mathrm{C}_{20} \mathrm{H}_{13} \mathrm{~F}_{9} \mathrm{~N}_{2} \mathrm{O}_{3} \mathrm{~S}[\mathrm{M}+\mathrm{H}]$, 533.0576; found, 533.0572.

\section{N-(4-cyano-3-(trifluoromethyl)phenyl)-2-methyl-3-((3-(trifluoromethoxy)phenyl)sulfonyl)} propanamide (32). Yield; 95\%

${ }^{1} \mathrm{H}-\mathrm{NMR}:\left(\mathrm{CDCl}_{3}\right) \delta 8.67(\mathrm{~s}, 1 \mathrm{H}, \mathrm{NH}), 7.88(\mathrm{~d}, \mathrm{~J}=2 \mathrm{~Hz}, 1 \mathrm{H}, \operatorname{ArH}), 7.82(\mathrm{~d}, \mathrm{~J}=7.5 \mathrm{~Hz}, 1 \mathrm{H}, \operatorname{ArH}), 7.77(\mathrm{dd}, \mathrm{J}=$ 2, 8.5Hz, 1H, ArH), $7.72(\mathrm{~s}, 1 \mathrm{H}, \operatorname{ArH}), 7.63(\mathrm{~d}, \mathrm{~J}=8.5 \mathrm{~Hz}, 1 \mathrm{H}, \operatorname{ArH}), 7.57(\mathrm{t}, \mathrm{J}=8 \mathrm{~Hz}, 1 \mathrm{H}, \operatorname{ArH}), 7.45(\mathrm{~d}, \mathrm{~J}$ $=8.5 \mathrm{~Hz}, 1 \mathrm{H}, \mathrm{ArH}), 3.86\left(\mathrm{dd}, \mathrm{J}=9.5,14 \mathrm{~Hz}, 1 \mathrm{H}, \mathrm{CH}_{2}\right), 3.34-3.25(\mathrm{~m}, 1 \mathrm{H}, \mathrm{CH}), 3.12(\mathrm{dd}, \mathrm{J}=3.5,14.5 \mathrm{~Hz}, 1 \mathrm{H}$, $\left.\mathrm{CH}_{2}\right), 1.34\left(\mathrm{~d}, \mathrm{~J}=7 \mathrm{~Hz}, 3 \mathrm{H}, \mathrm{CH}_{3}\right) .{ }^{19} \mathrm{~F}-\mathrm{NMR}:\left(\mathrm{CDCl}_{3}\right) \delta-58.04,-62.34 .{ }^{13} \mathrm{C}-\mathrm{NMR}:\left(\mathrm{CDCl}_{3}\right) \delta 171.69(\mathrm{C}=\mathrm{O})$, $149.10(\operatorname{ArC}), 141.72(\operatorname{ArC}), 140.37(\operatorname{ArC}), 135.21(\operatorname{ArCH}), 133.28\left(q,{ }^{2} J_{C-F}=32.8 \mathrm{~Hz}, \operatorname{ArC}\right), 130.95(\operatorname{ArCH})$, $126.19(\mathrm{ArCH}), 125.65(\mathrm{ArCH}), 121.55\left(\mathrm{q},{ }^{1} \mathrm{~J}_{\mathrm{C}-\mathrm{F}}=272.3 \mathrm{~Hz}, \mathrm{OCF}_{3}\right), 121.30(\mathrm{ArCH}), 119.92(\mathrm{ArCH}), 119.68$ $\left(q,{ }^{1} J_{C-F}=258.3 \mathrm{~Hz}, C F_{3}\right), 116.76\left(q,{ }^{3} J_{C-F}=4.8 \mathrm{~Hz}, \mathrm{ArCH}\right), 115.05(\mathrm{CN}), 103.58(\operatorname{ArC}), 58.43\left(\mathrm{CH}_{2}\right), 35.82(-$ $\mathrm{CH}), 18.46\left(\mathrm{CH}_{3}\right)$. HRMS calculated for $\mathrm{C}_{19} \mathrm{H}_{14} \mathrm{~F}_{6} \mathrm{~N}_{2} \mathrm{O}_{4} \mathrm{~S}[\mathrm{M}+\mathrm{H}]$, 481.0657; found, 481.0654 .

\section{3-((4-Fluorophenyl)sulfonyl)-2-methyl-N-(4-nitro-3-(trifluoromethyl)phenyl)propanamide (33).}

Yield; $41 \%$

${ }^{1} \mathrm{H}$ NMR $\left(\mathrm{CD}_{3} \mathrm{OD}\right) \delta 8.14(\mathrm{~d}, J=2 \mathrm{~Hz}, 1 \mathrm{H}, \operatorname{ArH}), 8.14(\mathrm{~d}, J=2 \mathrm{~Hz}, 1 \mathrm{H}, \operatorname{ArH}), 8.01-7.97(\mathrm{~m}, 2 \mathrm{H}, \operatorname{ArH}), 7.88$ (dd, $J=2,9 \mathrm{~Hz}, 1 \mathrm{H}, \operatorname{ArH}), 7.32-7.26(\mathrm{~m}, 2 \mathrm{H}, \mathrm{ArH}), 3.91$ (dd, $\left.J=9.5,14.5 \mathrm{~Hz}, 1 \mathrm{H}, \mathrm{CH}_{2}\right), 3.34(\mathrm{dd}, J=3,14.5$ $\left.\mathrm{Hz}, 1 \mathrm{H}, \mathrm{CH}_{2}\right), 3.17-3.08(\mathrm{~m}, 1 \mathrm{H}, \mathrm{CH}), 1.34\left(\mathrm{~d}, \mathrm{~J}=7.5 \mathrm{~Hz}, 3 \mathrm{H}, \mathrm{CH}_{3}\right) ;{ }^{19} \mathrm{~F} \mathrm{NMR}\left(\mathrm{CD}_{3} \mathrm{OD}\right) \delta-61.67,-105.84 ;{ }^{13} \mathrm{C}$ $\operatorname{NMR}\left(\mathrm{CD}_{3} \mathrm{OD}\right) \delta 175.65(\mathrm{C}=0), 168.31\left(\mathrm{~d},{ }^{1} \mathrm{~J}_{\mathrm{C}-\mathrm{F}}=253.5 \mathrm{~Hz}, \mathrm{ArC}\right), 145.40(\operatorname{ArC}), 145.01(\operatorname{ArC}), 137.66(\mathrm{~d}$, $\left.{ }^{4} J_{C-F}=3.3 \mathrm{~Hz}, \operatorname{ArC}\right), 133.52\left(\mathrm{~d},{ }^{3} \mathrm{~J}_{\mathrm{C}-\mathrm{F}}=9.9 \mathrm{~Hz}, \mathrm{ArCH}\right), 129.05(\mathrm{ArCH}), 126.38\left(\mathrm{q},{ }^{2} \mathrm{~J}_{\mathrm{C}-\mathrm{F}}=33.5 \mathrm{~Hz}, \operatorname{ArC}\right), 124.53$ $(\mathrm{ArCH}), 124.46\left(\mathrm{q},{ }^{1} \mathrm{~J}_{\mathrm{C}-\mathrm{F}}=270.9 \mathrm{~Hz}, \mathrm{CF}_{3}\right), 119.95\left(\mathrm{q},{ }^{3} \mathrm{~J}_{\mathrm{C}-\mathrm{F}}=5.8 \mathrm{~Hz}, \operatorname{ArCH}\right), 118.53\left(\mathrm{~d},{ }^{2} \mathrm{~J}_{\mathrm{C}-\mathrm{F}}=23.3 \mathrm{~Hz}, \operatorname{ArCH}\right)$, $60.25\left(\mathrm{CH}_{2}\right), 39.09(\mathrm{CH}), 20.14\left(\mathrm{CH}_{3}\right)$. MS [ESI, m/z]: HRMS calcd for $\mathrm{C}_{17} \mathrm{H}_{14} \mathrm{~F}_{4} \mathrm{~N}_{2} \mathrm{O}_{5} \mathrm{~S}[\mathrm{M}+\mathrm{H}], 435.0638$; found, 435.0643 .

\section{2-Methyl-N-(4-nitro-3-(trifluoromethyl)phenyl)-3-((4-(trifluoromethyl)phenyl)sulfonyl)} propanamide (34). Yield; $78 \%$

${ }^{1} \mathrm{H} \mathrm{NMR}\left(\mathrm{CDCl}_{3}\right) \delta 8.77(\mathrm{~s}, 1 \mathrm{H}, \mathrm{NH}), 8.15-8.11(\mathrm{~m}, 3 \mathrm{H}, \mathrm{ArH}), 7.96(\mathrm{dd}, J=9,2.5 \mathrm{~Hz}, 1 \mathrm{H}, \mathrm{ArH}), 7.94-7.91$ (m, $1 \mathrm{H}, \operatorname{ArH}), 7.90-7.87(\mathrm{~m}, 2 \mathrm{H}, \mathrm{ArH}), 3.97\left(\mathrm{dd}, \mathrm{J}=9.5,14 \mathrm{~Hz}, 1 \mathrm{H}, \mathrm{CH}_{2}\right), 3.45-3.35(\mathrm{~m}, 1 \mathrm{H}, \mathrm{CH}), 3.22$ (dd, 
$\left.J=3,14 \mathrm{~Hz}, 1 \mathrm{H}, \mathrm{CH}_{2}\right), 1.45\left(\mathrm{~d}, J=7 \mathrm{~Hz}, 3 \mathrm{H}, \mathrm{CH}_{3}\right) ;{ }^{19} \mathrm{~F} \mathrm{NMR}\left(\mathrm{CDCl}_{3}\right) \delta-60.18,-63.35 ;{ }^{13} \mathrm{C} \mathrm{NMR}\left(\mathrm{CDCl}_{3}\right) \delta$ $172.02(C=0), 143.06(\operatorname{ArC}), 142.22(\operatorname{ArC}), 141.96(\operatorname{ArC}), 136.20\left(q,{ }^{2} \mathrm{~J}_{C-F}=33.3 \mathrm{~Hz}, \operatorname{ArC}\right), 128.58(\operatorname{ArCH})$, $127.02(\operatorname{ArCH}), 126.79\left(\mathrm{q},{ }^{3} \mathrm{~J}_{\mathrm{C}-\mathrm{F}}=3.6 \mathrm{~Hz}, \operatorname{ArCH}\right), 125.15\left(\mathrm{q},{ }^{2} \mathrm{~J}_{\mathrm{C}-\mathrm{F}}=33.8 \mathrm{~Hz}, \operatorname{ArC}\right), 122.87\left(\mathrm{q},{ }^{1} \mathrm{~J}_{\mathrm{C}-\mathrm{F}}=271.4\right.$ $\left.\mathrm{Hz}, \mathrm{CF}_{3}\right), 122.12(\mathrm{ArCH}), 121.65\left(\mathrm{q},{ }^{1} \mathrm{~J}_{\mathrm{C}-\mathrm{F}}=271.9 \mathrm{~Hz}, \mathrm{CF}_{3}\right), 118.22\left(\mathrm{q},{ }^{3} \mathrm{~J}_{\mathrm{C}-\mathrm{F}}=5.6 \mathrm{~Hz}, \operatorname{ArCH}\right), 58.98\left(\mathrm{CH}_{2}\right)$, $36.22(\mathrm{CH}), 18.94\left(\mathrm{CH}_{3}\right)$. MS [ESI, m/z]: HRMS calcd for $\mathrm{C}_{18} \mathrm{H}_{14} \mathrm{~F}_{6} \mathrm{~N}_{2} \mathrm{O}_{5} \mathrm{~S}$ [M+NH $\left.\mathrm{NH}_{4}\right], 502.0866$; found, 502.0857 .

\section{3-((3,5-Bis(trifluoromethyl)phenyl)sulfonyl)-2-methyl-N-(4-nitro-3-(trifluoromethyl) phenyl)}

propanamide (35). Yield; 69\%

${ }^{1} \mathrm{H} \mathrm{NMR}\left(\mathrm{CD}_{3} \mathrm{OD}\right) \delta 8.48(\mathrm{~s}, 2 \mathrm{H}, \mathrm{ArH}), 8.25(\mathrm{~s}, 1 \mathrm{H}, \mathrm{ArH}), 8.04(\mathrm{~d}, J=1.5 \mathrm{~Hz}, \mathrm{ArH}), 8.01(\mathrm{~d}, J=9 \mathrm{~Hz}, 1 \mathrm{H}$, $\operatorname{ArH}), 7.78(\mathrm{dd}, J=1.5,9 \mathrm{~Hz}, 1 \mathrm{H}, \mathrm{ArH}), 4.13\left(\mathrm{dd}, J=10.5,15 \mathrm{~Hz}, 1 \mathrm{H}, \mathrm{CH}_{2}\right), 3.51\left(\mathrm{dd}, J=3,15 \mathrm{~Hz}, 1 \mathrm{H}, \mathrm{CH}_{2}\right.$ ), 3.23-3.15 (m, $1 \mathrm{H}, \mathrm{CH}), 1.36\left(\mathrm{~d}, J=7 \mathrm{~Hz}, 3 \mathrm{H}, \mathrm{CH}_{3}\right) ;{ }^{19} \mathrm{~F}$ NMR $\left(\mathrm{CD}_{3} \mathrm{OD}\right) \delta-61.79,-64.50 ;{ }^{13} \mathrm{C} \mathrm{NMR}\left(\mathrm{CD}_{3} \mathrm{OD}\right)$ $\delta 172.90(\mathrm{C}=\mathrm{O}), 142.79(\operatorname{ArC}), 142.71(\operatorname{ArC}), 142.01(\operatorname{ArC}), 132.65\left(\mathrm{q},{ }^{2} \mathrm{~J}_{\mathrm{C}-\mathrm{F}}=38.8 \mathrm{~Hz}, \operatorname{ArC}\right), 128.44\left(\mathrm{q},{ }^{3} \mathrm{JC}_{\mathrm{C}}\right.$ $\mathrm{F}=3 \mathrm{~Hz}, \operatorname{ArCH}), 127.44\left(\mathrm{q},{ }^{3} \mathrm{~J}_{\mathrm{C}-\mathrm{F}}=3 \mathrm{~Hz} \operatorname{ArCH}\right), 126.67(\operatorname{ArCH}), 125.58(\mathrm{~m}, \operatorname{ArC}), 124.31(\mathrm{~m}, \operatorname{ArC}), 123.33(\mathrm{q}$, $\left.{ }^{1} \mathrm{~J}_{\mathrm{C}-\mathrm{F}}=270.3 \mathrm{~Hz}, \mathrm{CF}_{3}\right), 122.01(\mathrm{ArCH}), 121.9\left(\mathrm{q},{ }^{1} \mathrm{~J}_{\mathrm{C}-\mathrm{F}}=270.9 \mathrm{~Hz}, \mathrm{CF}_{3}\right), 117.68(\mathrm{~m}, \mathrm{ArCH}), 57.70\left(\mathrm{CH}_{2}\right), 36.74$ (CH), $18.23\left(\mathrm{CH}_{3}\right)$. MS [ESI, m/z]: HRMS calcd for $\mathrm{C}_{19} \mathrm{H}_{13} \mathrm{~F}_{9} \mathrm{~N}_{2} \mathrm{O}_{5} \mathrm{~S}\left[\mathrm{M}+\mathrm{NH}_{4}\right], 570.0740$; found, 570.0733. N-(4-cyano-2-(trifluoromethyl)phenyl)-3-((4-fluorophenyl)sulfonyl)-2-methylpropanamide (36). Yield; $68 \%$ ${ }^{1} \mathrm{H} \mathrm{NMR}\left(\mathrm{CDCl}_{3}\right) \delta 8.41(\mathrm{~d}, J=8.5 \mathrm{~Hz}, 1 \mathrm{H}, \mathrm{ArH}), 8.00-7.95(\mathrm{~m}, 3 \mathrm{H}, \mathrm{ArH}), 7.86(\mathrm{dd}, J=1.5,8.5 \mathrm{~Hz}, 1 \mathrm{H}, \operatorname{ArH})$, $7.83(\mathrm{~s}, 1 \mathrm{H}, \mathrm{NH}), 7.28-7.24(\mathrm{~m}, 2 \mathrm{H}, \mathrm{ArH}), 3.85-3.79\left(\mathrm{~m}, 1 \mathrm{H}, \mathrm{CH}_{2}\right), 3.21-3.14\left(\mathrm{~m}, 2 \mathrm{H}, \mathrm{CH}, \mathrm{CH}_{2}\right), 1.45(\mathrm{~d}, J=$ $\left.7 \mathrm{~Hz}, 3 \mathrm{H}, \mathrm{CH}_{3}\right) ;{ }^{19} \mathrm{~F} \mathrm{NMR}\left(\mathrm{CDCl}_{3}\right) \delta-61.04,-102.36 ;{ }^{13} \mathrm{C} \mathrm{NMR}\left(\mathrm{CDCl}_{3}\right) \delta 171.66(\mathrm{C}=0), 166.08\left(\mathrm{~d},{ }^{1} \mathrm{~J}_{\mathrm{C}-\mathrm{F}}=\right.$ 256.3 Hz, $\operatorname{ArC}), 138.82(\operatorname{ArC}), 136.59(\operatorname{ArCH}), 135.19(\operatorname{ArC}), 135.16(\operatorname{ArC}), 130.89\left(\mathrm{~d},{ }^{3} \mathrm{~J}_{C-\mathrm{F}}=9.4 \mathrm{~Hz}, \operatorname{ArCH}\right)$, $130.28\left(q,{ }^{3} \mathrm{~J}_{\mathrm{C}-\mathrm{F}}=5.5 \mathrm{~Hz}, \operatorname{ArCH}\right), 124.51(\mathrm{ArCH}), 122.84\left(\mathrm{q},{ }^{1} \mathrm{~J}_{\mathrm{C}-\mathrm{F}}=271.6 \mathrm{~Hz}, \mathrm{CF}_{3}\right), 117.25(\mathrm{CN}), 116.88(\mathrm{~d}$, $\left.{ }^{2} \mathrm{~J}_{\mathrm{C}-\mathrm{F}}=22.6 \mathrm{~Hz}, \operatorname{ArCH}\right), 108.42(\operatorname{ArC}), 58.99\left(\mathrm{CH}_{2}\right), 37.06(\mathrm{CH}), 18.50\left(\mathrm{CH}_{3}\right) . \mathrm{MS}$ [ESI, m/z]: HRMS calcd for $\mathrm{C}_{18} \mathrm{H}_{14} \mathrm{~F}_{4} \mathrm{~N}_{2} \mathrm{O}_{3} \mathrm{~S}[\mathrm{M}+\mathrm{H}], 415.0734$; found, 415.0733.

N-(4-cyano-2-(trifluoromethyl)phenyl)-2-methyl-3-((4-(trifluoromethyl)phenyl)sulfonyl) propanamide (37). Yield; $71 \%$

${ }^{1} \mathrm{H} \mathrm{NMR}\left(\mathrm{CD}_{3} \mathrm{OD}\right) \delta 8.20(\mathrm{~d}, J=8 \mathrm{~Hz}, 2 \mathrm{H}, \operatorname{ArH}), 8.16(\mathrm{~d}, J=2 \mathrm{~Hz}, 1 \mathrm{H}, \operatorname{ArH}), 8.02-7.99(\mathrm{~m}, 3 \mathrm{H}, \operatorname{ArH}), 7.76$ (d, J=8.5 Hz, 1H, ArH), 3.92 (dd, J = 9.5, $14 \mathrm{~Hz}, 1 \mathrm{H}, \mathrm{CH}_{2}$ ), 3.43 (dd, J=3.5, $14.5 \mathrm{~Hz}, 1 \mathrm{H}, \mathrm{CH}_{2}$ ), 3.32-3.25 $(\mathrm{m}, 1 \mathrm{H}, \mathrm{CH}), 1.34\left(\mathrm{~d}, \mathrm{~J}=7 \mathrm{~Hz}, 3 \mathrm{H}, \mathrm{CH}_{3}\right) ;{ }^{19} \mathrm{~F} \mathrm{NMR}\left(\mathrm{CD}_{3} \mathrm{OD}\right) \delta-62.52,-64.66 ;{ }^{13} \mathrm{C} \mathrm{NMR}_{\left(\mathrm{CD}_{3} \mathrm{OD}\right)} \delta 173.92$ $(\mathrm{C}=\mathrm{O}), 143.13(\operatorname{ArC}), 139.04\left(\mathrm{q},{ }^{3} \mathrm{~J}_{\mathrm{C}-\mathrm{F}}=1.5 \mathrm{~Hz} \operatorname{ArC}\right), 136.03(\mathrm{ArCH}), 134.96\left(\mathrm{q},{ }^{2} \mathrm{~J}_{\mathrm{C}-\mathrm{F}}=32.9 \mathrm{~Hz}, \operatorname{ArC}\right), 130.44$ $\left(q,{ }^{3} J_{C-F}=5.4 \mathrm{~Hz}, \operatorname{ArCH}\right), 129.84(\mathrm{ArCH}), 128.85(\mathrm{ArCH}), 126.31\left(\mathrm{q},{ }^{3} \mathrm{~J}_{\mathrm{C}-\mathrm{F}}=3.8 \mathrm{~Hz}, \mathrm{ArCH}\right), 125.35\left(\mathrm{q},{ }^{2} \mathrm{~J}_{\mathrm{C}-\mathrm{F}}=\right.$ 
$30.8 \mathrm{~Hz}, \operatorname{ArC}$ ), 123.39 (q, $\left.{ }^{1} \mathrm{~J}_{\mathrm{C}-\mathrm{F}}=270.9 \mathrm{~Hz}, \mathrm{CF}_{3}\right), 122.61$ (q, $\left.{ }^{1} \mathrm{~J}_{\mathrm{C}-\mathrm{F}}=271.6 \mathrm{~Hz}, \mathrm{CF}_{3}\right), 116.82(\mathrm{CN}), 110.13(\operatorname{ArC})$, $57.47\left(\mathrm{CH}_{2}\right), 35.43(\mathrm{CH}), 17.56\left(\mathrm{CH}_{3}\right)$. MS [ESI, m/z]: HRMS calcd for $\mathrm{C}_{19} \mathrm{H}_{14} \mathrm{~F}_{6} \mathrm{~N}_{2} \mathrm{O}_{3} \mathrm{~S}[\mathrm{M}+\mathrm{H}], 465.0702$; found, 465.0699 .

\section{3-((3,5-Bis(trifluoromethyl)phenyl)sulfonyl)-N-(4-cyano-2-(trifluoromethyl)phenyl)-2-methyl} propanamide (38). Yield; $59 \%$

${ }^{1} \mathrm{H} \mathrm{NMR}\left(\mathrm{CDCl}_{3}\right) \delta 8.40(\mathrm{~s}, 1 \mathrm{H}, \mathrm{ArH}), 8.38(\mathrm{~d}, \mathrm{~J}=9 \mathrm{~Hz}, 1 \mathrm{H}, \operatorname{ArH}), 8.18(\mathrm{~s}, 1 \mathrm{H}, \mathrm{ArH}), 7.96(\mathrm{~s}, 1 \mathrm{H}, \operatorname{ArH}), 7.86$ (d, J= $9 \mathrm{~Hz}, 1 \mathrm{H}, \mathrm{ArH}), 7.81(\mathrm{~s}, 1 \mathrm{H}, \mathrm{NH}), 3.47$ (dd, J=10, $\left.15 \mathrm{~Hz}, 1 \mathrm{H}, \mathrm{CH}_{2}\right), 3.31-3.23\left(\mathrm{~m}, 2 \mathrm{H}, \mathrm{CH}_{2}, \mathrm{CH}\right), 1.50$ $\left(\mathrm{d}, J=7 \mathrm{~Hz}, 3 \mathrm{H}, \mathrm{CH}_{3}\right) ;{ }^{19} \mathrm{~F} \mathrm{NMR}\left(\mathrm{CDCl}_{3}\right) \delta-61.04,-62.95 ;{ }^{13} \mathrm{C} \mathrm{NMR}\left(\mathrm{CDCl}_{3}\right){ }^{13} \mathrm{C} \mathrm{NMR}\left(\mathrm{CDCl}_{3}-d_{1}\right) \delta 171.21$ (C=O), $142.14(\operatorname{ArC}), 138.55(\operatorname{ArC}), 136.65(\operatorname{ArCH}), 133.40$ (q, $\left.{ }^{2} \mathrm{~J}_{\mathrm{C}-\mathrm{F}}=35 \mathrm{~Hz}, \operatorname{ArC}\right), 132.32\left(\mathrm{q},{ }^{3} \mathrm{~J}_{\mathrm{C}-\mathrm{F}}=5.5 \mathrm{~Hz}\right.$, $\operatorname{ArCH}), 128.44\left(q,{ }^{3} \mathrm{~J}_{C-F}=3.4 \mathrm{~Hz}, \operatorname{ArCH}\right), 127.81$ (sept, $\left.{ }^{3} \mathrm{~J}_{\mathrm{C}-\mathrm{F}}=3.8 \mathrm{~Hz}, \operatorname{ArCH}\right), 124.27(\operatorname{ArCH}), 122.84\left(\mathrm{q},{ }^{1} \mathrm{~J}_{\mathrm{C}-\mathrm{F}}\right.$ $\left.=271.8 \mathrm{~Hz}, \mathrm{CF}_{3}\right), 122.66(\mathrm{ArC}), 117.56\left(\mathrm{q},{ }^{1} \mathrm{~J}_{\mathrm{C}-\mathrm{F}}=281.5 \mathrm{~Hz}, \mathrm{CF}_{3}\right),, 117.16(\mathrm{CN}), 108.64(\operatorname{ArC}), 58.77\left(\mathrm{CH}_{2}\right)$, $37.12(\mathrm{CH}), 18.56\left(\mathrm{CH}_{3}\right) . \mathrm{MS}(\mathrm{ES}+) \mathrm{m} / \mathrm{z}: \mathrm{C}_{20} \mathrm{H}_{13} \mathrm{~F}_{9} \mathrm{~N}_{2} \mathrm{O}_{3} \mathrm{~S}, 550.084\left[\mathrm{M}+\mathrm{NH}_{4}^{+}\right], 555.0395\left[\mathrm{M}+\mathrm{Na}^{+}\right]$.

\section{3-((4-Fluorophenyl)sulfonyl)-2-methyl-N-(4-nitro-2-(trifluoromethyl)phenyl)propanamide (39).}

Yield; $72 \%$

${ }^{1} \mathrm{H} \mathrm{NMR}\left(\mathrm{CDCl}_{3}\right) \delta 8.53(\mathrm{~d}, J=2 \mathrm{~Hz}, 1 \mathrm{H}, \operatorname{ArH}), 8.44-8.39(\mathrm{~m}, 2 \mathrm{H}, \operatorname{ArH}), 8.04(\mathrm{~s}, 1 \mathrm{H}, \mathrm{NH}), 7.97(\mathrm{dd}, J=5,9$ $\mathrm{Hz}, 2 \mathrm{H}, \mathrm{ArH}), 7.25(\mathrm{t}, J=8.5 \mathrm{~Hz}, 2 \mathrm{H}, \mathrm{ArH}), 3.84\left(\mathrm{dd}, J=8.5,14 \mathrm{~Hz}, 1 \mathrm{H}, \mathrm{CH}_{2}\right), 3.30-3.22(\mathrm{~m}, 1 \mathrm{H}, \mathrm{CH}), 3.17$ (dd, $\left.J=4,14 \mathrm{~Hz}, 1 \mathrm{H}, \mathrm{CH}_{2}\right), 1.44\left(\mathrm{~d}, J=7.5 \mathrm{~Hz}, 3 \mathrm{H}, \mathrm{CH}_{3}\right) ;{ }^{19} \mathrm{~F} \mathrm{NMR}\left(\mathrm{CDCl}_{3}\right) \delta-60.99,-102.41 ;{ }^{13} \mathrm{C} \mathrm{NMR}$ $\left(\mathrm{CDCl}_{3}\right) \delta 170.91(\mathrm{C}=\mathrm{O}), 165.02\left(\mathrm{~d},{ }^{1} \mathrm{~J}_{\mathrm{C}-\mathrm{F}}=255 \mathrm{~Hz}, \operatorname{ArC}\right), 143.40(\operatorname{ArC}), 140.49(\operatorname{ArC}), 135.13\left(\mathrm{~d},{ }^{4} \mathrm{~J}_{\mathrm{C}-\mathrm{F}}=3 \mathrm{~Hz}\right.$, $\operatorname{ArC}), 130.89\left(\mathrm{~d},{ }^{3} \mathrm{~J}_{\mathrm{C}-\mathrm{F}}=9.9 \mathrm{~Hz}, \operatorname{ArCH}\right), 128.05(\mathrm{ArCH}), 124.67(\mathrm{ArCH}), 122.73\left(\mathrm{q},{ }^{1} \mathrm{~J}_{\mathrm{C}-\mathrm{F}}=271.9 \mathrm{~Hz}, \mathrm{CF}_{3}\right)$, $122.33\left(\mathrm{q},{ }^{3} \mathrm{~J}_{\mathrm{C}-\mathrm{F}}=5.8 \mathrm{~Hz}, \operatorname{ArCH}\right), 120.50\left(\mathrm{q},{ }^{2} \mathrm{~J}_{\mathrm{C}-\mathrm{F}}=31.1 \mathrm{~Hz}, \operatorname{ArC}\right), 116.86\left(\mathrm{~d},{ }^{2} \mathrm{~J}_{\mathrm{C}-\mathrm{F}}=22.6 \mathrm{~Hz}, \operatorname{ArCH}\right), 58.21$ $\left(\mathrm{CH}_{2}\right), 36.88(\mathrm{CH}), 18.53\left(\mathrm{CH}_{3}\right)$. HRMS calcd for $\mathrm{C}_{17} \mathrm{H}_{14} \mathrm{~F}_{4} \mathrm{~N}_{2} \mathrm{O}_{5} \mathrm{~S}[\mathrm{M}+\mathrm{H}], 435.0632$; found, 435.0631 .

\section{2-Methyl-N-(4-nitro-2-(trifluoromethyl)phenyl)-3-((4-(trifluoromethyl)phenyl)sulfonyl)} propanamide (40). Yield; $74 \%$

${ }^{1} \mathrm{H} \mathrm{NMR}\left(\mathrm{CDCl}_{3}\right) \delta 8.56(\mathrm{~d}, J=2 \mathrm{~Hz}, 1 \mathrm{H}, \operatorname{ArH}), 8.48-8.40(\mathrm{~m}, 2 \mathrm{H}, \operatorname{ArH}), 8.10(\mathrm{~d}, J=8.5 \mathrm{~Hz}, 2 \mathrm{H}, \operatorname{ArH}), 7.91-$ $7.84(\mathrm{~m}, 2 \mathrm{H}, \mathrm{ArH}, 1 \mathrm{H}, \mathrm{NH}), 3.89$ (dd, J = 9.5, $\left.15 \mathrm{~Hz}, 1 \mathrm{H}, \mathrm{CH}_{2}\right), 3.26-3.16\left(\mathrm{~m}, 1 \mathrm{H}, \mathrm{CH}_{2}, 1 \mathrm{H}, \mathrm{CH}\right), 1.48(\mathrm{~d}, J=$ $\left.7 \mathrm{~Hz}, 3 \mathrm{H}, \mathrm{CH}_{3}\right) ;{ }^{19} \mathrm{~F} \mathrm{NMR}\left(\mathrm{CDCl}_{3}\right) \delta-60.93,60.97,-63.28 ;{ }^{13} \mathrm{C} \mathrm{NMR}\left(\mathrm{CDCl}_{3}\right) \delta 171.51(\mathrm{C}=0), 143.41(\operatorname{ArC})$, $142.58(\operatorname{ArC}), 140.32(\operatorname{ArC}), 135.88\left(q,{ }^{2} \mathrm{~J}_{C-F}=32.9 \mathrm{~Hz}, \operatorname{ArC}\right), 128.70(\mathrm{ArCH}), 128.19(\operatorname{ArCH}), 126.64\left(q,{ }^{3} \mathrm{~J}_{C}\right.$ $\mathrm{F}=3.6 \mathrm{~Hz}, \mathrm{ArCH}), 124.15(\mathrm{ArCH}), 122.95\left(\mathrm{q},{ }^{1} \mathrm{~J}_{\mathrm{C}-\mathrm{F}}=271.8 \mathrm{~Hz}, \mathrm{CF}_{3}\right), 122.79\left(\mathrm{q},{ }^{1} \mathrm{~J}_{\mathrm{C}-\mathrm{F}}=271.9 \mathrm{~Hz}, \mathrm{CF}_{3}\right), 122.36$ $\left(q,{ }^{3} J_{C-F}=5.5 \mathrm{~Hz}, \operatorname{ArCH}\right), 120.12\left(q,{ }^{2} \mathrm{~J}_{\mathrm{C}-\mathrm{F}}=30.9 \mathrm{~Hz}, \operatorname{ArC}\right), 58.67(\mathrm{CH}), 37.08\left(\mathrm{CH}_{2}\right), 18.57\left(\mathrm{CH}_{3}\right) . \mathrm{MS}[\mathrm{ESI}$, $\mathrm{m} / \mathrm{z}$ ]: HRMS calcd for $\mathrm{C}_{18} \mathrm{H}_{14} \mathrm{~F}_{6} \mathrm{~N}_{2} \mathrm{O}_{5} \mathrm{~S}[\mathrm{M}+\mathrm{H}], 485.0600$; found, 485.0595 . 


\section{3-((3,5-Bis(trifluoromethyl)phenyl)sulfonyl)-2-methyl-N-(4-nitro-2-(trifluoromethyl)phenyl)}

propanamide (41). Yield; $58 \%$.

${ }^{1} \mathrm{H} \mathrm{NMR}\left(\left(\mathrm{CD}_{3}\right)_{2} \mathrm{SO}\right) \delta 10.10(\mathrm{~s}, 1 \mathrm{H}, \mathrm{NH}), 8.65(\mathrm{~s}, 1 \mathrm{H}, \operatorname{ArH}), 8.55(\mathrm{~s}, 2 \mathrm{H}, \operatorname{ArH}), 8.52(\mathrm{~d}, J=8.5 \mathrm{~Hz}, 1 \mathrm{H}, \operatorname{Ar} H)$, $8.46(\mathrm{~d}, J=2 \mathrm{~Hz}, 1 \mathrm{H}, \mathrm{ArH}), 7.72(\mathrm{~d}, J=8.5 \mathrm{~Hz}, 1 \mathrm{H}, \mathrm{ArH}), 4.01$ (dd, J = 9, $14.5 \mathrm{~Hz}, 1 \mathrm{H}, \mathrm{CH}_{2}$ ), 3.84 (dd, J = 3, $\left.14 \mathrm{~Hz}, 1 \mathrm{H}, \mathrm{CH}_{2}\right), 3.34(\mathrm{~m}, 1 \mathrm{H}, \mathrm{CH}), 1.26\left(\mathrm{~d}, \mathrm{~J}=7 \mathrm{~Hz}, 3 \mathrm{H}, \mathrm{CH}_{3}\right) ;{ }^{19} \mathrm{~F} \mathrm{NMR}\left(\left(\mathrm{CD}_{3}\right)_{2} \mathrm{SO}\right) \delta-59.84,-61.32 ;{ }^{13} \mathrm{C}$ $\operatorname{NMR}\left(\left(\mathrm{CD}_{3}\right)_{2} \mathrm{SO}\right) \delta 173.28(\mathrm{C}=\mathrm{O}), 144.86(\operatorname{ArC}), 142.40(\operatorname{ArC}), 141.27(\operatorname{ArC}), 131.92\left(\mathrm{q},{ }^{2} \mathrm{~J}_{\mathrm{C}-\mathrm{F}}=34 \mathrm{~Hz}, \operatorname{ArC}\right)$, 130.21 (ArCH), 129.29 (d, $\left.{ }^{4} \mathrm{~J}_{\mathrm{C}-\mathrm{F}}=3.4 \mathrm{~Hz}, \operatorname{ArCH}\right), 128.65(\mathrm{~m}, \mathrm{ArCH}), 128.33(\mathrm{ArCH}), 124.06\left(\mathrm{q},{ }^{2} \mathrm{~J}_{\mathrm{C}-\mathrm{F}}=31.4\right.$ $\mathrm{Hz}, \operatorname{ArC}), 122.79\left(\mathrm{q},{ }^{1} \mathrm{~J}_{\mathrm{C}-\mathrm{F}}=275.3 \mathrm{~Hz}, \mathrm{CF}_{3}\right), 123.01\left(\mathrm{q},{ }^{1} \mathrm{~J}_{\mathrm{C}-\mathrm{F}}=271.8 \mathrm{~Hz}, \mathrm{CF}_{3}\right), 122.68\left(\mathrm{q},{ }^{3} \mathrm{~J}_{\mathrm{C}-\mathrm{F}}=5.5 \mathrm{~Hz}, \operatorname{ArCH}\right)$, $56.86\left(\mathrm{CH}_{2}\right), 35.22(\mathrm{CH}), 18.70\left(\mathrm{CH}_{3}\right)$. MS [ESI, m/z]: HRMS calcd for $\mathrm{C}_{19} \mathrm{H}_{13} \mathrm{~F}_{9} \mathrm{~N}_{2} \mathrm{O}_{5} \mathrm{~S}\left[\mathrm{M}+\mathrm{NH}_{4}\right], 570.0740$; found, 570.0736 .

\subsection{In vitro cell based assay}

\subsubsection{Cell culture}

All cells were cultured in T75 flasks in a humidified atmosphere of $5 \% \mathrm{CO}_{2}$ at $37^{\circ} \mathrm{C}$. LNCaP cells were cultured in RPMI-1640 medium, PC3 and VCaP cells in DMEM, all supplemented with 10\% FCS and antibiotics (penicillin 100U/ml and streptomycin 100 $\mu \mathrm{g}$ ).

\subsubsection{Anti-androgen treatment in vitro}

Bicalutamide and enzalutamide were used as positive controls (used as the clinical standard) in LNCaP, PC3 and VCaP cells, and DMSO was used as a vehicle control. Nine 1/2 serial dilutions of $10 \mathrm{mM}$ bicalutamide stock were made in $50 \mu \mathrm{L}$ of DMSO to give nine increasing concentrations from $0.1 \mu \mathrm{M}$ to $100 \mu \mathrm{M}$. All novel deshydroxy compounds were tested in LNCaP cells, and compounds $\mathbf{2 7}, \mathbf{2 8}$ and $\mathbf{3 3}$ were subsequently tested in PC3 and VCaP cells because of their low $\mathrm{IC}_{50}$ values.

PC3 and LNCaP cells were plated in a 96- well plate (4000cells/well) and then incubated overnight to adhere. Each drug concentration (0-100uM) was then added in sequence to ten tubes of fresh media to achieve a 1:100 dilution. The old medium was then gently removed and replaced with $200 \mu \mathrm{L}$ of fresh media containing the nine increasing drug concentrations and the DMSO control, in triplicate. Following 96 hours of incubation the samples were tested with the MTT or MTS assay. The IC 50 was then calculated from the mean of these triplicate values and dose-response curves were plotted. VCaP cells were treated as above, with the following exceptions. The novel compounds were diluted 1:50, only $100 \mu \mathrm{L}$ of the old medium was extracted and it was replaced with $100 \mu \mathrm{L}$ of the novel compound in media. This was done to avoid removing the cells from the 96-well plates in view of their poor adherence. 


\subsubsection{MTT and MTS assays}

Colorimetric MTT (LNCaP and PC3) and MTS (VCaP) assays were used to determine cell viability following in vitro anti-androgen treatment. $20 \mu \mathrm{L}(1 / 10$ th well volume) of MTT or MTS were added to the wells as appropriate. MTS absorbance was recorded at $490 \mathrm{~nm}$ by the Elx800TM microplate reader after 1 and 2-hours of incubation. For the MTT assay, following the appearance of purple formazan crystals under the light microscope, the medium was then carefully removed and the formazan crystals dissolved in $200 \mu \mathrm{L}$ of acidified isopropanol and MTT absorbance was recorded at 540nm on the Elx800TM microplate reader. Percentage cell viability was normalised to the DMSO control.

\subsubsection{Statistics}

Cell number-MTT correlations and $\mathrm{IC}_{50}$ values were calculated from the mean of three replicates using Microsoft Excel and GraphPad Prism v6.01 (GraphPad Software, Inc., San Diego, CA). Cell number-MTT correlations were analysed by linear regression, whereas $\mathrm{IC}_{50}$ values were produced through non-linear regression. qPCR results were analysed using the $\triangle \Delta C T$ method in Excel. Mean $\mathrm{IC}_{50}$ values were then analysed for statistical significance $(p=<0.05)$ compared to bicalutamide and enzalutamide using GraphPad Prism v6.01 with consideration to the OECD guidelines.

One-way analysis of variance (ANOVA) followed by Tukey's Honest Significant Difference test analysed the dose-response data for compounds $\mathbf{2 7 ,} \mathbf{2 8}$ and $\mathbf{3 3}$ in LNCaP cells, which satisfied the assumptions of normality and homogeneity of variance according to the D'Agostino- Pearson omnibus, BrownForsythe and Bartlett's tests. The Kruskal-Wallis test followed by the Dunn's test analysed the doseresponse data for compound $\mathbf{2 8}$ in LNCaP cells and compounds $\mathbf{2 7}, \mathbf{2 8}$ and $\mathbf{3 3}$ in PC3 cells.

\subsection{PSA Expression and androgen inhibition qPCR experiments}

LNCaP cells were trypsinised and re-suspended in $13 \mathrm{ml}$ of RPMI. $0.5 \mathrm{ml}$ of this cell suspension was then added to individual wells in 6-well plates with $3 \mathrm{ml}$ of fresh RPMI, and the cells incubated for 24-hours to adhere. Two individual wells in each plate received no treatment and DMSO at a 1:100 dilution as negative controls. The 6-well plates used to analyse PSA expression by qPCR then were treated with 5, 10,50 and $100 \mu \mathrm{M}$ of bicalutamide, compounds 27,28 and 33 , followed by 24 -hours incubation.

\subsubsection{RNA Isolation}

RNA isolation was carried out in the six-well plates using the Sigma procedure. The media was gently removed, $1 \mathrm{ml}$ of TRI-reagent added per sample and the viscous lysate containing DNA, RNA and proteins transferred to $1.5 \mathrm{ml}$ Eppendorf tubes. $200 \mu \mathrm{l}$ of 1-bromo-3-chloropropane was then added, the Eppendorf tubes vortexed, left to stand for 5 minutes and stored at $-80^{\circ} \mathrm{C}$. The samples were then 
warmed to room temperature, vortexed and centrifuged at $12,000 \times \mathrm{g}$ for 15 minutes at $4^{\circ} \mathrm{C}$ to solubilise the RNA in the upper, colourless aqueous phase. The samples were then kept on ice, the aqueous phase transferred to fresh Eppendorf tubes and $0.5 \mathrm{ml}$ of isopropanol added. The tubes were then vortexed, left to stand for 5 minutes and centrifuged at $12,000 \times \mathrm{g}$ for 10 minutes at $4^{\circ} \mathrm{C}$ in order to recover the RNA pellet. After removing the supernatant, the pellet was washed with $1 \mathrm{ml}$ of $75 \%$ ethanol, vortexed and centrifuged at $7500 \times \mathrm{g}$ for 5 minutes at $4^{\circ} \mathrm{C}$. After this, ethanol was carefully removed, the samples briefly air-dried for 5-10 minutes and the RNA pellet dissolved with 20 $\mu$ of RNAse-free PCR water. The RNA concentration was then measured in $\mathrm{ng} / \mu \mathrm{l}$ by recording the absorption of each $1 \mu \mathrm{l}$ sample at $260 \mathrm{~nm}$ on the Implen NanoPhotometer against nuclease-free water as a control. The samples were then stored at $-80^{\circ} \mathrm{C}$ for 24 hours.

\subsubsection{Complementary DNA synthesis (cDNA)}

The RNA samples were uniformly diluted to $50 \mathrm{ng} / \mu \mathrm{l}$ on ice. $10 \mu \mathrm{l}$ of RNA and $10 \mu \mathrm{l}$ of RT mix were then centrally added to a 96-well non-skirted PCR plate on ice, thermosealed and centrifuged up to 1000rpm in the Grant bio LMC-3000. The components of the RT mix are shown below: The samples were then placed in the Simpli-Amp thermal cycler under the following conditions: $25^{\circ} \mathrm{C}$ for 5 minutes $42^{\circ} \mathrm{C}$ for 60 minutes, $70^{\circ} \mathrm{C}$ for 15 minutes, and $4^{\circ} \mathrm{C}$. The samples were then stored at $-20^{\circ} \mathrm{C}$ overnight.

\subsubsection{Quantitative polymerase chain reaction (qPCR)}

qPCR was performed in triplicate to analyse the LNCaP cells for relative PSA gene expression. The PSA primer was run alongside the AR, GAPDH, RPL19 and B-actin as housekeeping genes in order to normalise the data and validate the results. These forward and reverse primer pairs were briefly thawed and vortexed, diluted 1:40 with RNAse-free PCR water in four 1.5ml Eppendorf tubes, and returned to ice. Following this, the cDNA was diluted in $20 \mu \mathrm{l}$ of RNAse-free PCR water. $40 \mathrm{ul}$ of this diluted cDNA was then transferred into $0.5 \mathrm{ml}$ Eppendorf tubes and kept on ice. $2 u$ of this diluted cDNA was added to individual wells of an optical qPCR 96-well plate, followed by $8 \mu$ l of the PCR mix. The qPCR plate was then thermosealed, centrifuged up to 1000rpm in the Grant bio LMC-3000, and loaded into the StepOnePlus real-time PCR system. The PCR reaction volume was $10 \mu \mathrm{l}$, and 50 cycles were performed within the standard 2-hour cycle.

\section{References}

1. C. Chang, S. Lee, S. Yeh, T.M. Chang, Androgen receptor (AR) differential roles in hormonerelated tumors including prostate, bladder, kidney, lung, breast and liver, Oncogene, 33 (2014) 3225-34. 
2. P.E. Lonergan, D. J. Tindall, Androgen receptor signalling in prostate cancer development and progression. J. Carcinogenesis, 10 (2011) 20.

3. A.C. Pippione, D. Boschi, K. Pors, S. Oliaro-Bosso, M.L. Lolli. Androgen-AR axis in primary and metastatic prostate cancer: chasing steroidogenic enzymes for therapeutic intervention. J. Cancer Metastasis Treat. 3 (2017) 328-61.

4. G. Jenster, H.A. van der Korput, C. van Vroonhoven, T.H. van der Kwast, J. Trapman, A.O. Brinkmann, Domains of the human androgen receptor involved in steroid binding, transcriptional activation, and subcellular localization. Mol. Endocrinol. 5 (1991) 1396-1404.

5.G. Jenster, Coactivators and corepressors as mediators of nuclear receptor function: an update. Mol. Cell. Endocrinol. 143 (1998) 1-7.

6. A.O. Brinkmann, J. Trapman, Prostate cancer schemes for androgen escape. Nat Med. 6(6), (2000) 628-9.

7. A.O. Brinkmann, Molecular mechanisms of androgen action - a historical perspective. Methods Mol Biol. 776 (2011) 3-24.

8. C.D. Chen, D. S. Welsbie, C. Tran, S. H. Baek, R. Chen, R. Vessella, M.G. Rosenfeld, C.L. Sawyers, Molecular determinants of resistance to antiandrogen therapy. Nat. Med. 10 (2004) 33-39.

9.A.M. Moilanen, R. Riikonen, R. Oksala, L. Ravanti, E. Aho, G. Wohlfahrt, P.S. Nykänen, O.P. Törmäkangas, J.J. Palvimo, P.J. Kallio, Discovery of ODM-201, a new-generation androgen receptor inhibitor targeting resistance mechanisms to androgen signaling-directed prostate cancer therapies. Sci. Rep. 5 (2015) 12007.

10. P.A. Watson, V. K. Arora, C. L. Sawyers, Emerging Mechanisms of Resistance to Androgen Receptor Inhibitors in Prostate Cancer. Nat. Rev. Cancer, 15 (2015) 701-711.

11. P.L. McGinley, J. T. Koh, Circumventing Anti-Androgen Resistance by Molecular Design. J. Am. Chem. Soc. 129 (2007) 3822- 3823.

12. B. Fuqiang, D. Kush, L. Huifang, L. Eric, S.R. Paul, C. Artem, Best Practices of Computer-Aided Drug Discovery: Lessons Learned from the Development of a Preclinical Candidate for Prostate Cancer with a New Mechanism of Action, J. Chem. Inf. Model., 57 (2017) 1018-1028.

13. S. Kandil, A.D. Westwell, C. McGuigan, 7-Substituted umbelliferone derivatives as androgen receptor antagonists for the potential treatment of prostate and breast cancer. Bioorg Med Chem Lett.26(8), (2016) 2000-4.

14. D.A. Dart, S. Kandil, S. Tommasini-Ghelfi, G.S. de Almeida, C.L. Bevan, W. Jiang and A. D. Westwell, Novel trifluoromethylated enobosarm analogues with potent anti-androgenic activity in vitro and tissue selectivity in vivo, Mol. Cancer. Ther. 17(19) (2018) 1846.

15. S. Ferla, M. Bassetto, F. Pertusati, S. Kandil, A.D. Westwell, A. Brancale, C. McGuigan, Rational design and synthesis of novel anti-prostate cancer agents bearing a 3,5-bistrifluoromethylphenyl moiety. Bioorg Med Chem Lett. 26(15) (2016) 3636-40.

16. Q. Shi, K. Wada, E. Ohkoshi, L. Lin, R. Huang, S.L. Morris-Natschke, M. Goto, K-H. Lee, Antitumor agents 290. Design, synthesis, and biological evaluation of new LNCaP and PC-3 cytotoxic curcumin analogs conjugated with anti-androgens. Bioorg. Med. Chem. 2012, 20, 4020-4031. 
17. M. Bassetto, S. Ferla, F. Pertusati, S. Kandil, A.D. Westwell, A. Brancale, C. McGuigan, Design and synthesis of novel bicalutamide and enzalutamide derivatives as antiproliferative agents for the treatment of prostate cancer. Eur. J. Med. Chem. 118 (2016) 230.

18. B.B. Nandu, G.S. Dhananjay, R. Tarur, D. Raviraj, Synthesis of potential impurities of bicalutamide. Synthetic Communications, 39:9, (2009) 1516-1526.

19. S. Tai, Y. Sun, J.M. Squires, H. Zhang, W.K. Oh, C.Z. Liang, PC3 is a cell line characteristic of prostatic small cell carcinoma. Prostate, 71 (2011) 1668-79.

20. J. Kim, and G. A. Coetzee, Prostate specific antigen gene regulation by androgen receptor. J. Cell. Biochem. 93 (2004) 233-241.

21. C. A. Heinlein, C. Chang, Androgen Receptor in Prostate Cancer, Endocrine Reviews, 25, 2 (2004), 276-308.

22. J. S. Sack, K. F. Kish, C. Wang, R. M. Attar, S. E. Kiefer, Y. An, G.Y. Wu, J. E. Scheffler, M.E. Salvati, Jr.S.R. Krystek, R. Weinmann, H. M. Einspahr, Crystallographic structures of the ligand-binding domains of the androgen receptor and its T877A mutant complexed with the natural agonist dihydrotestosterone. Proc. Natl. Acad. Sci. U.S.A., 98 (2001) 4904.

23. C.E. Bohl, W. Gao, D.D. Miller, C.E. Bell, J.T. Dalton, Structural basis for antagonism and resistance of bicalutamide in prostate cancer. Proc. Natl. Acad. Sci. U.S.A., 102 (2005) 6201.

24. C.A. Marhefka, B.M. Moore, T.C. Bishop, L. Kirkovsky, A. Mukherjee, J.T. Dalton, D.

25. D. Miller, Homology modeling using multiple molecular dynamics simulations and docking studies of the human androgen receptor ligand binding domain bound to testosterone and nonsteroidal ligands, J. Med. Chem., 44 (2001) 1729-1740.

26. K.P. Madauss, E.T. Grygielko, S.J. Deng, A. C. Sulpizio, T.B. Stanley, C. Wu, S.A. Short, S.K. Thompson, E.L. Stewart, N.J. Laping, S.P. Williams, J.D. Bray, A structural and in vitro characterization of asoprisnil: a selective progesterone receptor modulator. Mol. Endocrinol. 21 (2007) 1066.

27. K. Pereira de Jesus-Tran, P.L. Cote, L. Cantin, J. Blanchet, F. Labrie, R. Breton, Comparison of crystal structures of human androgen receptor ligand-binding domain complexed with various agonists reveals molecular determinants responsible for binding affinity. Protein Sci., 15 (2006) 987.

28. M.D. Balbas, M.J. Evans, D.J. Hosfield, J. Wongvipat, V.K. Arora, P.A. Watson, C.L. Sawyers, Overcoming mutation-based resistance to antiandrogens with rational drug design. eLife, 2 (2013) e00499. 


\section{${ }^{1} \mathrm{H}$ NMR spectrum of compound 25}

25
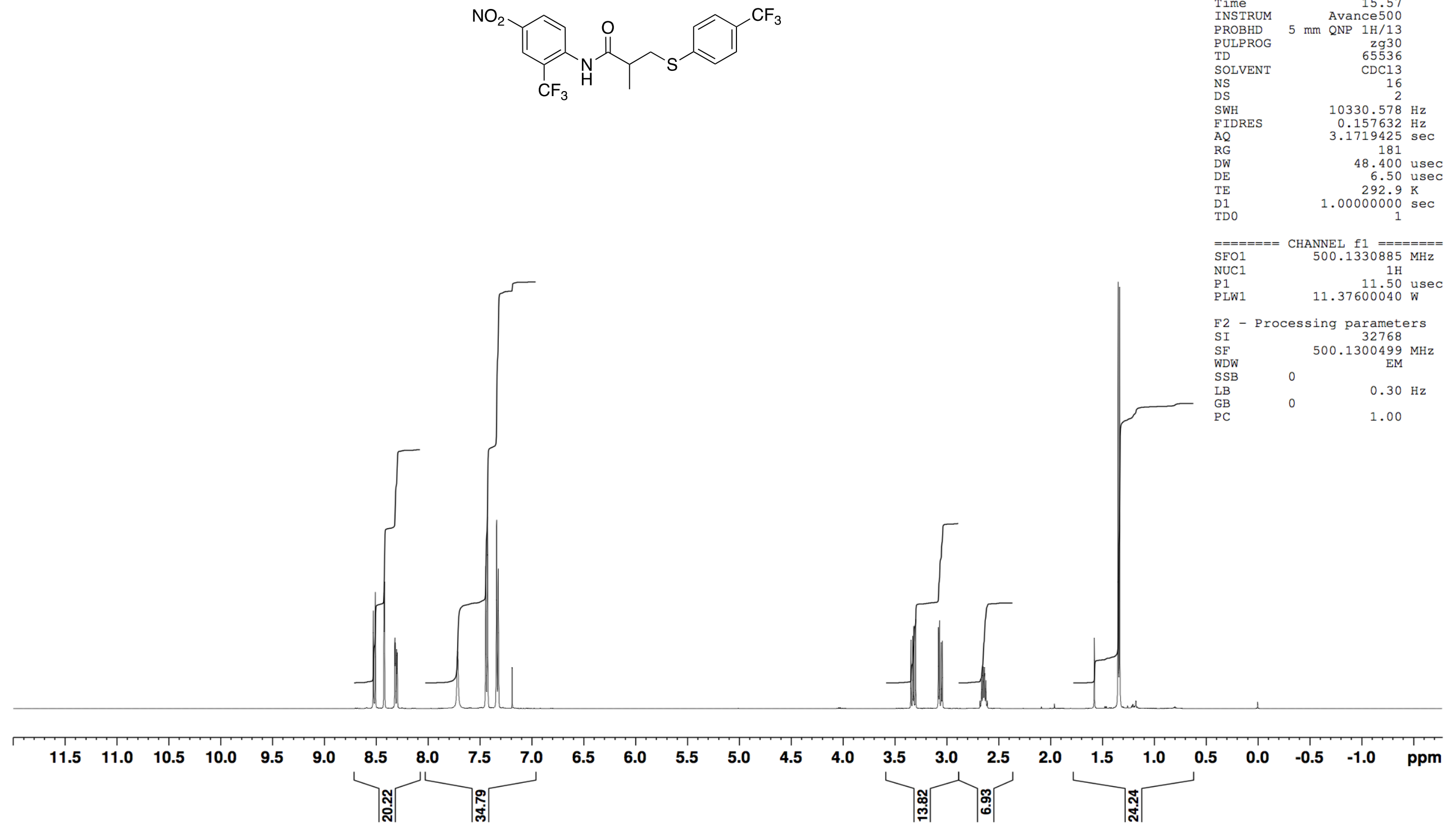


\section{${ }^{19} \mathrm{~F}$ NMR spectrum of compound 25}

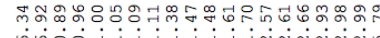

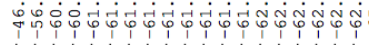

$\begin{array}{lr}\text { NAME } & \text { AW-SK-KL14 } \\ \text { EXPNO } & 2 \\ \text { PROCNO } & 1\end{array}$

$+$

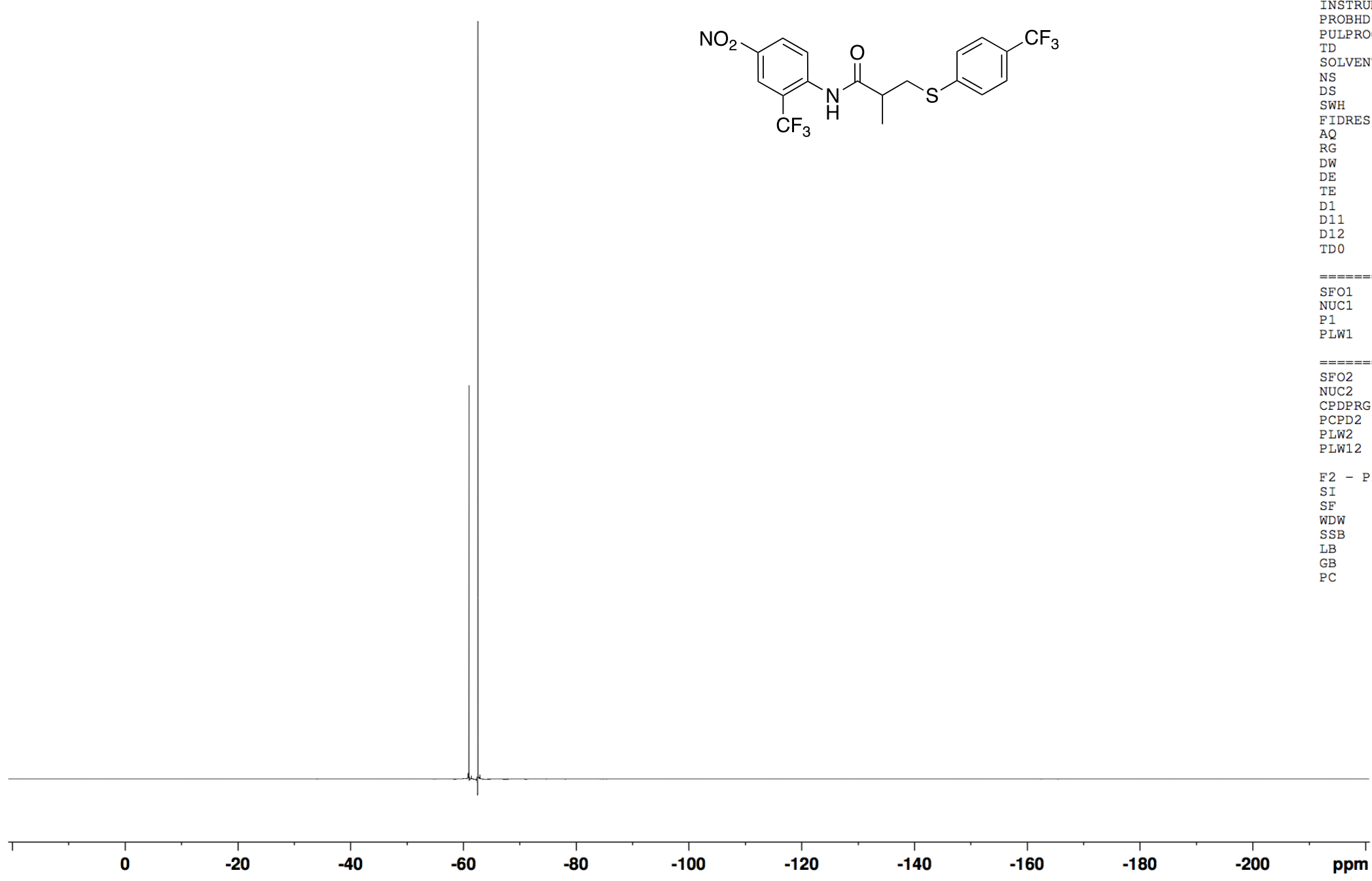

E2 - Acquisition Parameters

$\begin{array}{lr} & 20160915 \\ \text { ime } & 15.59 \\ \text { imerRUM } & \text { ava }\end{array}$

$5 \mathrm{~mm}$ Avance 500

zgfhiggn
131072

SOLVEN

4
$\mathrm{~Hz}$
$0.5669768 \mathrm{~Hz}$

$113636.367 \mathrm{~Hz}$
$0.866977 \mathrm{~Hz}$
$0.5767168 \mathrm{sec}$

575
$4.400 \mathrm{usec}$

$6.50 \mathrm{usec}$
$292.9 \mathrm{~K}$
$1.0000000 \mathrm{sec}$

$1.03000000 \mathrm{sec}$
$0.00002000 \mathrm{sec}$

$=======$ CHANNEL $f 1 \quad=======$
$470.5453182 \mathrm{MHz}$

$19 \mathrm{~F}$
18.60 usec

$======$ CHANNEL $f 2======= \pm$
$500.1320005 \mathrm{MHz}$

CPDPRG [2 waltz16

$80.00 \mathrm{use}$
PLW2
$14.33199978 \mathrm{~W}$

F2 - Processing parameter

SE $\quad 470.5923772 \mathrm{MHz}$

$\begin{array}{lll}\mathrm{SSB} & 0 & 0.30 \mathrm{~Hz}\end{array}$

$\begin{array}{lll}\mathrm{GB} & 0 & 1.40\end{array}$ 


\section{${ }^{13} \mathrm{C}$ NMR spectrum of compound 25}

\section{5}

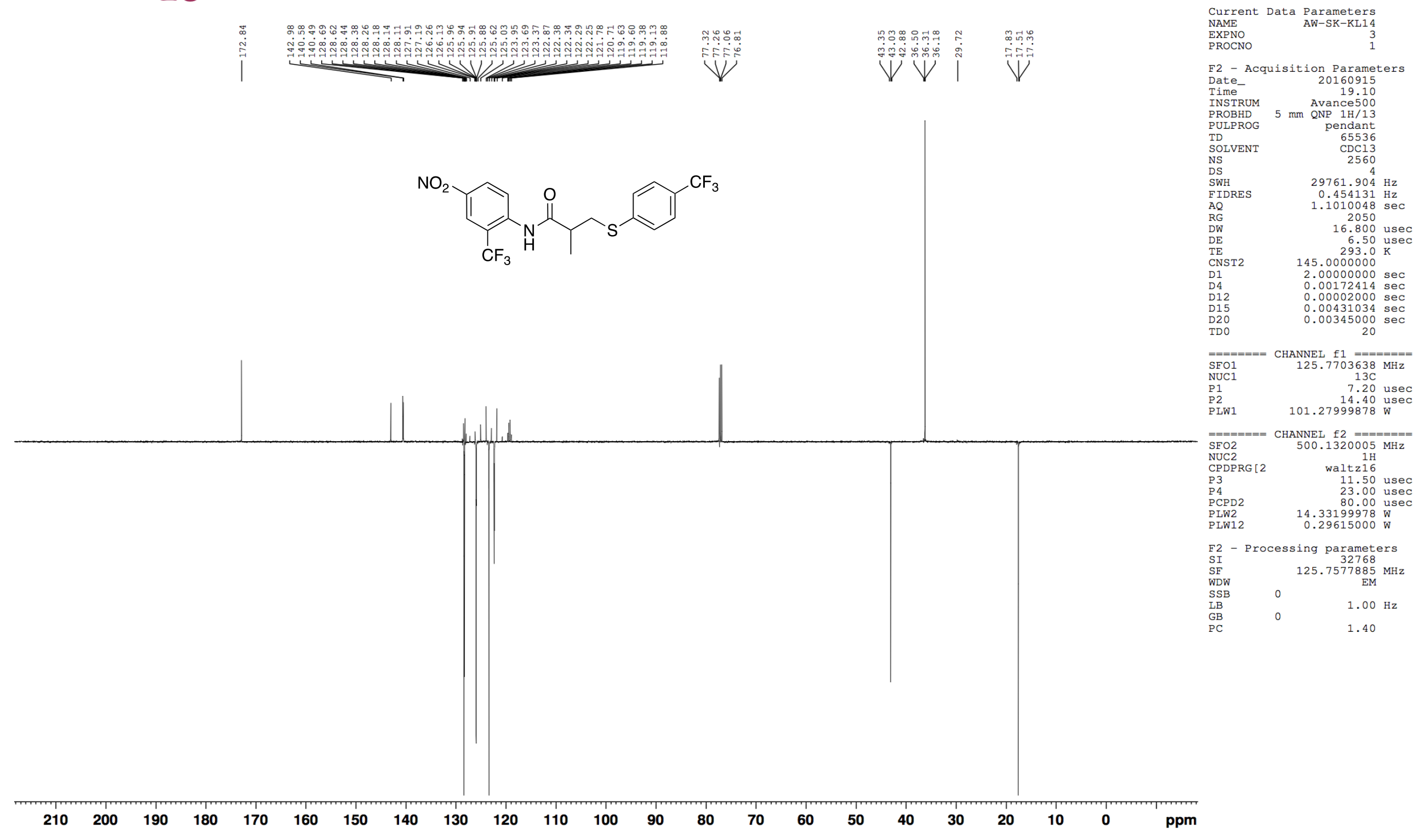


Mass spectrum of compound 25 


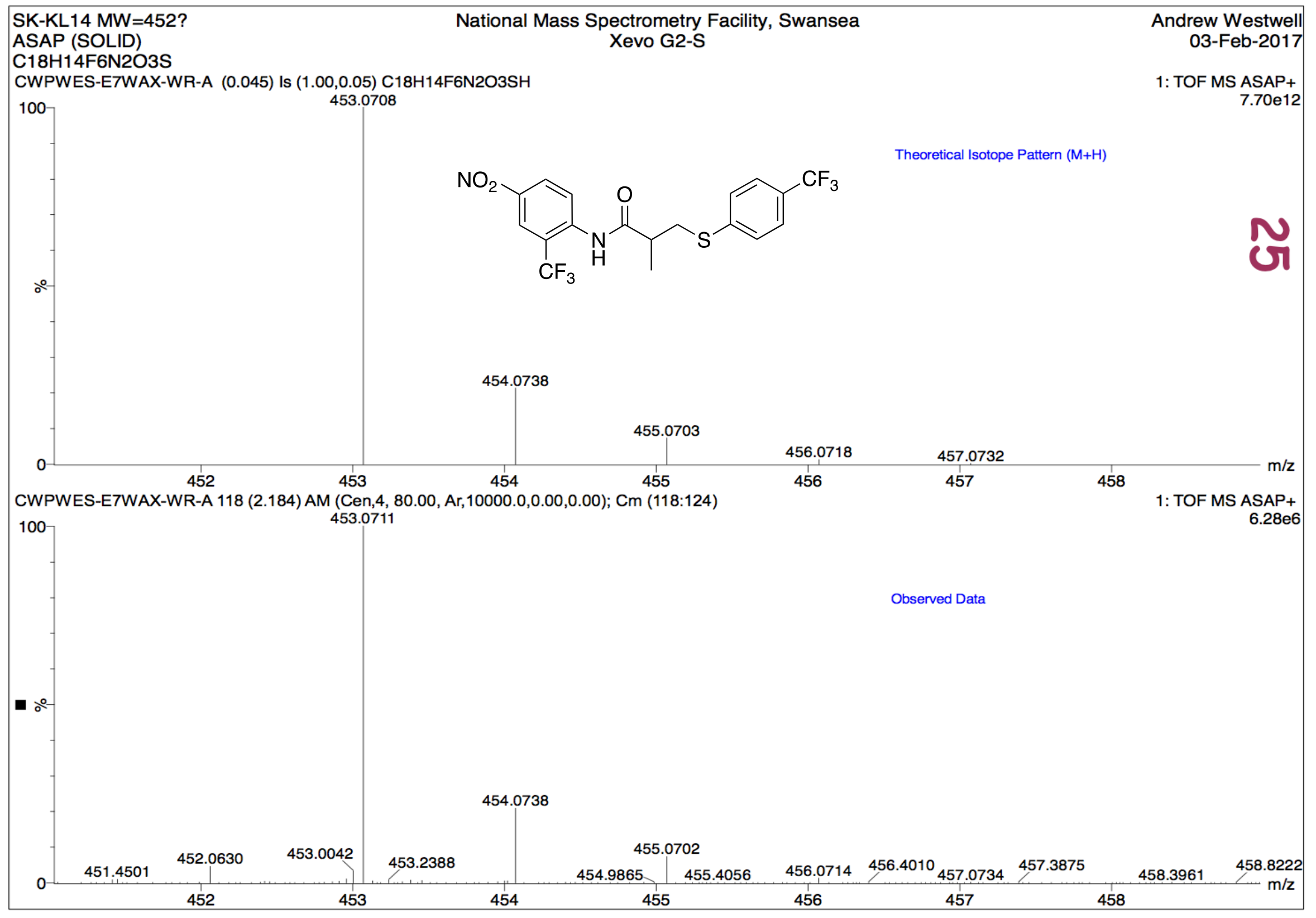


${ }^{1} \mathrm{H}$ NMR spectrum of compound 28

28
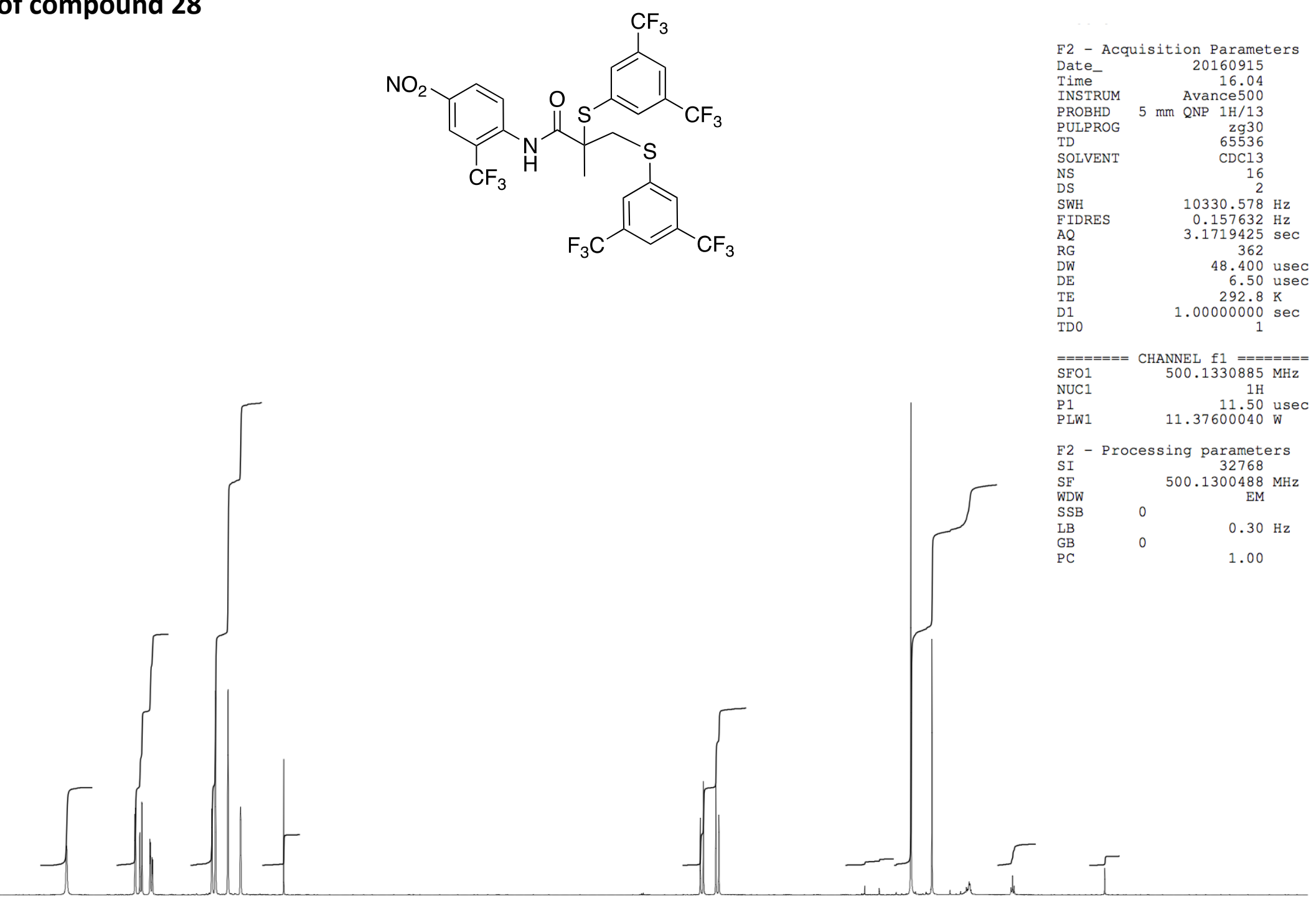

$\begin{array}{llll}11.5 & 11.0 & 10.5 & 10.0\end{array}$
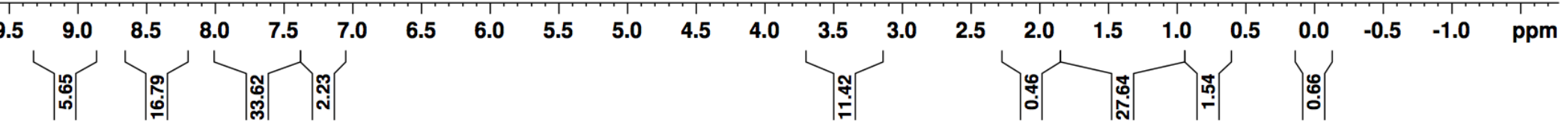
${ }^{19} \mathrm{~F}$ NMR spectrum of compound 28

\section{8}

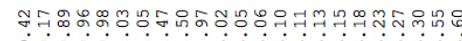

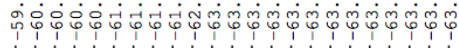

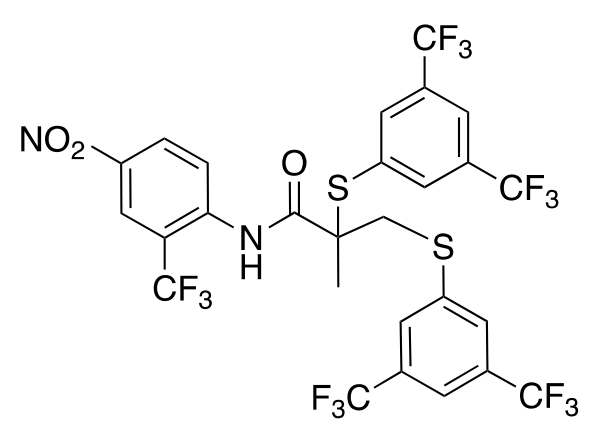

$\begin{array}{lr}\text { Current } & \text { Data Parameters } \\ \text { NAME } & \text { AW-SK-KL13-2 } \\ \text { EXPNO } & 2 \\ \text { PROCNO } & 1\end{array}$

F2 - Acquisition Parameter

Time 16.55

INSTRUM 5 Avances50

PULPROG 5 TIm QNP

NS

$\begin{array}{lr}\text { DS } & 113636.367 \mathrm{~Hz} \\ \text { SWH } & 113697 \mathrm{~Hz} \\ \text { FIDRES } & 0.866976 \mathrm{~Hz}\end{array}$

$0.5767168 \mathrm{sec}$

$\begin{array}{lr}1030 \\ \text { DW } & 4.400 \text { usec } \\ D E & 6.50 \text { usec } \\ \text { TE } & 292.9 \text { K }\end{array}$

$\begin{array}{ll}\text { TE } & 1.00000000 \mathrm{sec} \\ \text { D1 } & 0.00000000 \mathrm{sec} \\ \text { D11 } & 0.00002000 \mathrm{sec}\end{array}$

D12

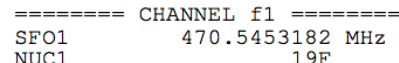

$\begin{array}{lr}\text { NUC1 } & 18.60 \text { usec } \\ \text { P1 } & 11.14099979 \mathrm{~W}\end{array}$

$====$
$\mathrm{SFO} 2$

CHANNEL $f 2========$
$500.1320005 \mathrm{MHz}$

NUC2 1 waltz16

80.00 usec
14.33199978 W

PLW2
PLW12

80.000 usec
$14.33199978 \mathrm{~W}$
$0.29615000 \mathrm{~W}$

F2 - Processing parameters

$\begin{array}{ll}\text { SF } & 65536 \\ \text { WDW } & 470.5923772 \mathrm{MHz}\end{array}$

WDW

${ }_{P C}$

$0.30 \mathrm{~Hz}$

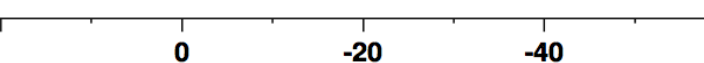




\section{${ }^{13} \mathrm{C}$ NMR spectrum of compound 28}

\section{8}

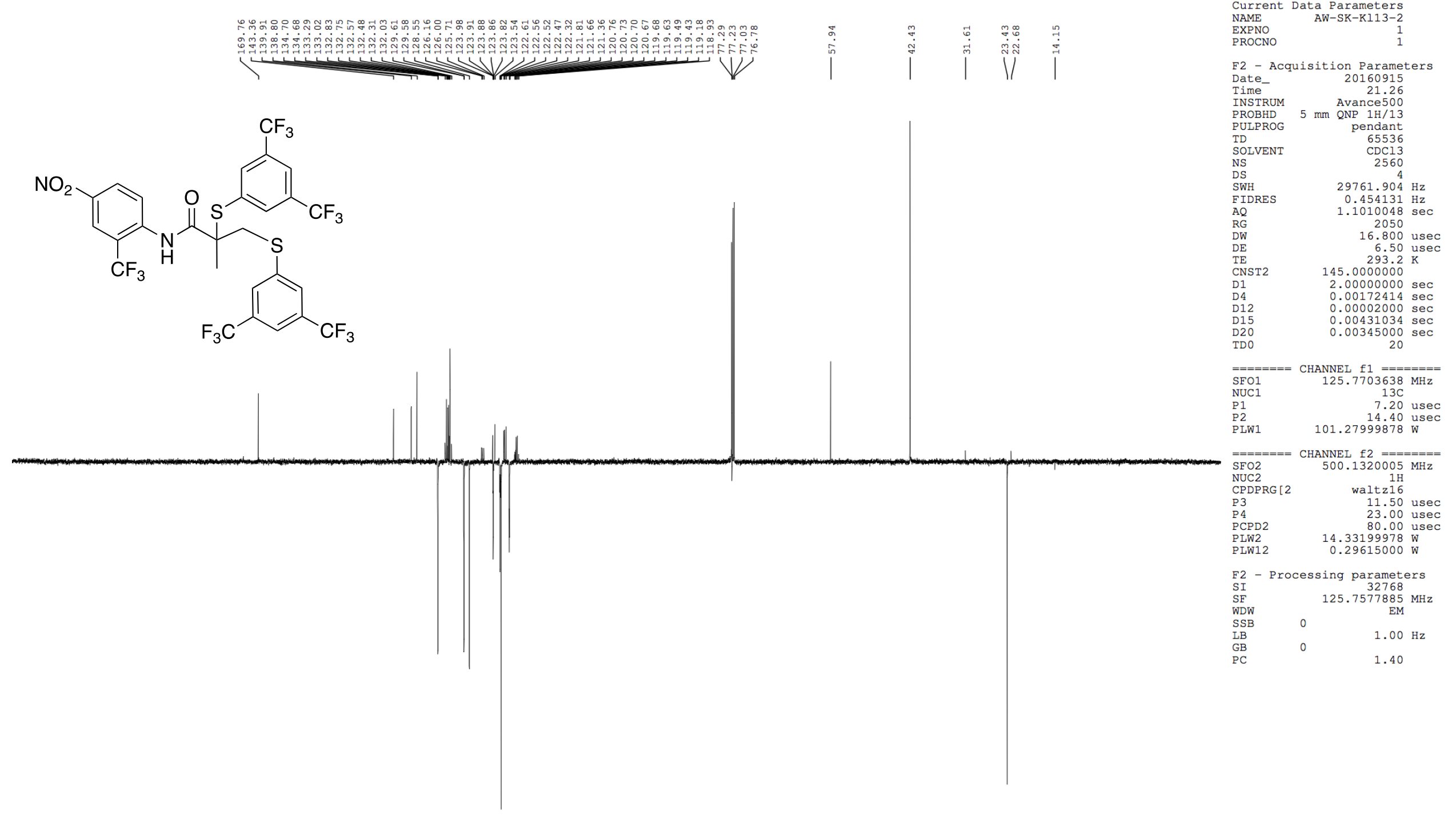




\section{Mass spectrum of compound 28}






\section{${ }^{1} \mathrm{H}$ NMR spectrum of compound 35}

35

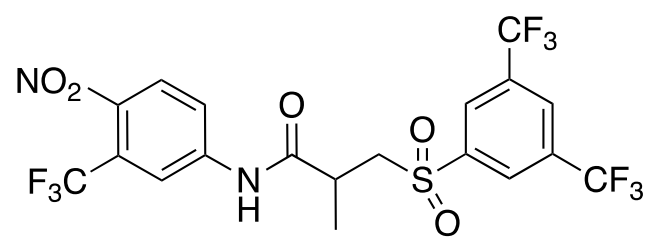

\section{PROCNO}

F2 - Acquisition Parameters$$
\text { Date }
$$$$
\begin{array}{lr}
\text { Time } & 13.35 \\
\text { INSTRUM Avance } 500
\end{array}
$$$$
\text { PROBHD } 5 \mathrm{~mm} \text { QNP } 1 \mathrm{H} / 13
$$$$
\text { PULPROG } 2 \mathrm{~g} 30
$$

TDiving

SOLVEN
DS

$\begin{array}{lr}16 \\ \text { DS } & 2 \\ \text { SWH } & 10330.578 \mathrm{~Hz}\end{array}$

$\begin{array}{ll}\text { FIDRES } & 0.157632 \mathrm{~Hz} \\ \text { AQ } & 3.1719425 \mathrm{sec}\end{array}$

$\mathrm{A} Q$
$\mathrm{RG}$

$\mathrm{DW}$
$\mathrm{DE}$
$\mathrm{TE}$
$\mathrm{DI}$

D1
TD0

48.400 usec

48.400 usec
6.50 usec $295.0 \mathrm{~K}$
$1.00000000 \mathrm{sec}$

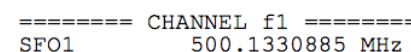

$\begin{array}{lr}\text { SFO1 } & 500.1330885 \mathrm{MHz} \\ \text { NUC1 } & 1 \mathrm{H}\end{array}$

$\begin{array}{lr}\text { NUC1 } & 11.50 \text { usec } \\ \text { P1 } & 11.37600040 \mathrm{~W}\end{array}$

F2 - Processing parameters

SI 32768

SF $\quad 500.1300000 \mathrm{MHz}$

$\begin{array}{ll}\mathrm{SSB} & 0 \\ \mathrm{LB} & 0\end{array}$

$0.30 \mathrm{~Hz}$ 
${ }^{19} \mathrm{~F}$ NMR spectrum of compound 35

35

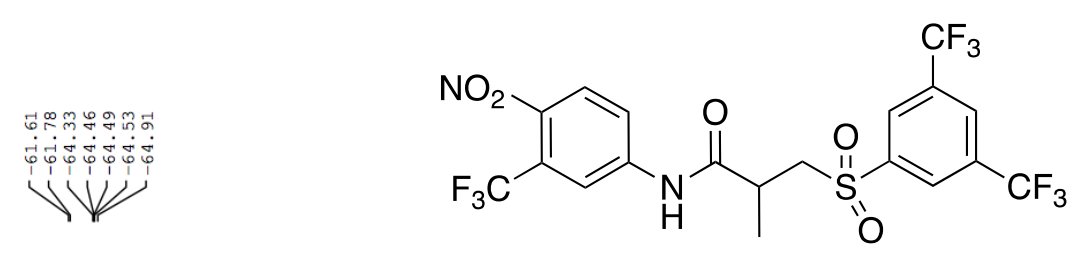

NAME

PROCNO

Date_ 20160708

$\begin{array}{lr}\text { Time } & 13.38 \\ \text { INSTRUM } & \text { Avance5000 }\end{array}$

PROBHD $5 \mathrm{~mm}$ QNP $1 \mathrm{H} / 13$

SOLVEN

DS $\begin{array}{lc}\text { FIDRES } & 0.866977 \mathrm{~Hz} \\ \text { AQ } & 0.5767168 \mathrm{sec} \\ \text { RG } & 2050\end{array}$

4.400 usec
6.50 usec

$295.0 \mathrm{~K}$

TE

D1 11

$1.00000000 \mathrm{sec}$

$0.00002000 \mathrm{sec}$

TDO

$=======$ CHANNEL $f 1 \quad========$
SFO1
NUC1

18.60 use

$11.14099979 \mathrm{~W}$

$\mathrm{SFO} 2$

HANNEL $f 2=======$
$500.1320005 \mathrm{MHz}$

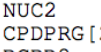

waltz16

80.00 use

$\begin{array}{lr}\text { PLW2 } & 14.33199978 \mathrm{~W} \\ \text { PLW12 } & 0.29615000 \mathrm{~W}\end{array}$

F2 - Processing parameters

$\begin{array}{lr}\text { F2 } & \text { - Processing parameters } \\ \mathrm{SI} & 65536 \\ \mathrm{SF} & 470.5923772 \mathrm{MHz}\end{array}$

WD

EM

$0.30 \mathrm{~Hz}$

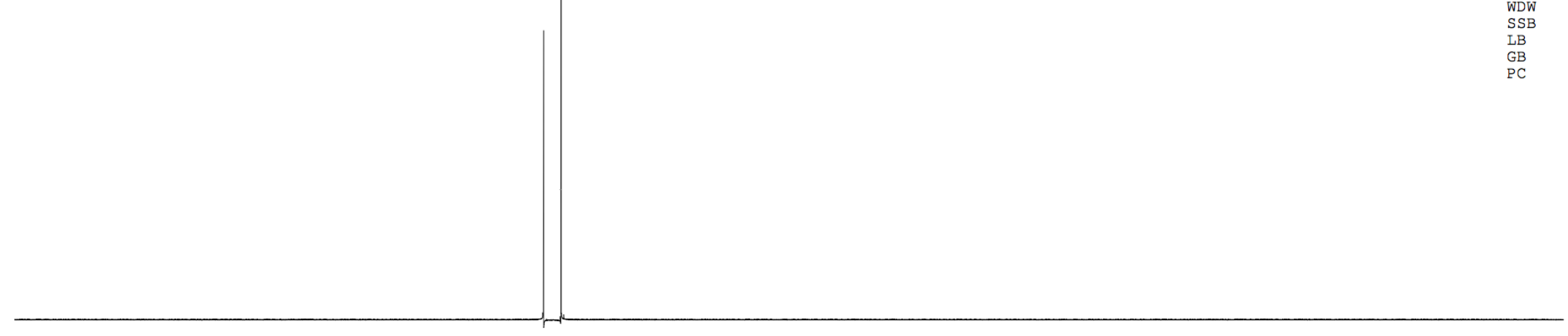

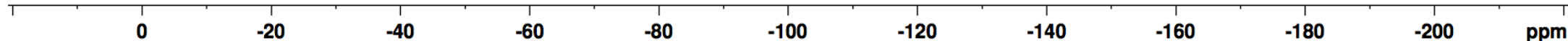




\section{${ }^{13} \mathrm{C}$ NMR spectrum of compound 35}

35<smiles>CC(CS(=O)(=O)c1cc(C(F)(F)F)cc(C(F)(F)F)c1)C(=O)Nc1ccc(O)c(C(F)(F)F)c1</smiles>
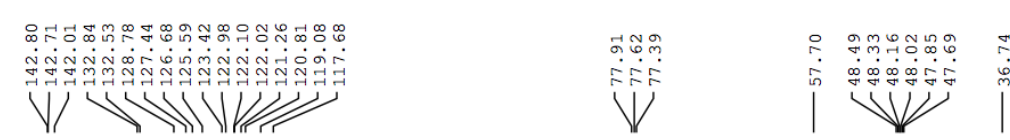

Current Data Parameters
NAME

EXPNO
PROCNO

F2 - Acquisition Parameters

$\begin{array}{lr}\text { Date } & 20160720 \\ \text { Time } & 23.32\end{array}$

$\begin{array}{lr}\text { Time } & 23.32 \\ \text { INSTRUM } & \text { Avance500 } \\ \text { PROBHD } & 5 \mathrm{~mm} \text { QNP } 1 \mathrm{H} / 13\end{array}$

$\begin{array}{lr}\text { PROBHD } & 5 \mathrm{~mm} \text { QNP } 1 \mathrm{H} / 13 \\ \text { PULPROG } & \text { pendant } \\ \text { TD } & 65536\end{array}$

SOLVENT

DS

$29761.904 \mathrm{~Hz}$

AQ $\quad 0.454131 \mathrm{~Hz}$

$\begin{array}{lr}\text { RG } & 2050 \\ \text { DW } & 16.800 \text { usec }\end{array}$

$\begin{array}{lr}\text { DW } & 16.800 \mathrm{usec} \\ \text { DE } & 6.50 \text { usec } \\ \text { TE } & 295.4 \mathrm{~K} \\ \text { CNST2 } & 145.0000000\end{array}$

D1 1

D 4
D12
D15

D20
TD0

145.00000000
$2.0000000 \mathrm{sec}$

$0.00172414 \mathrm{sec}$
$0.00002000 \mathrm{sec}$

$0.00431034 \mathrm{sec}$
$0.00345000 \mathrm{sec}$

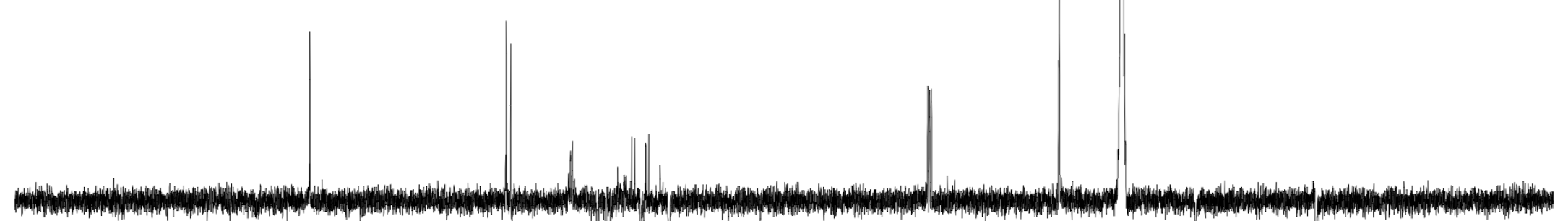

$=======$ CHANNEL $\mathrm{f} 1 \mathrm{=}======$
$\mathrm{125.7703638 \textrm {MHz }}$
$\mathrm{SFO1}$

$\begin{array}{lr}7.20 \mathrm{usec} \\ \text { P2 } & 14.40 \mathrm{usec}\end{array}$

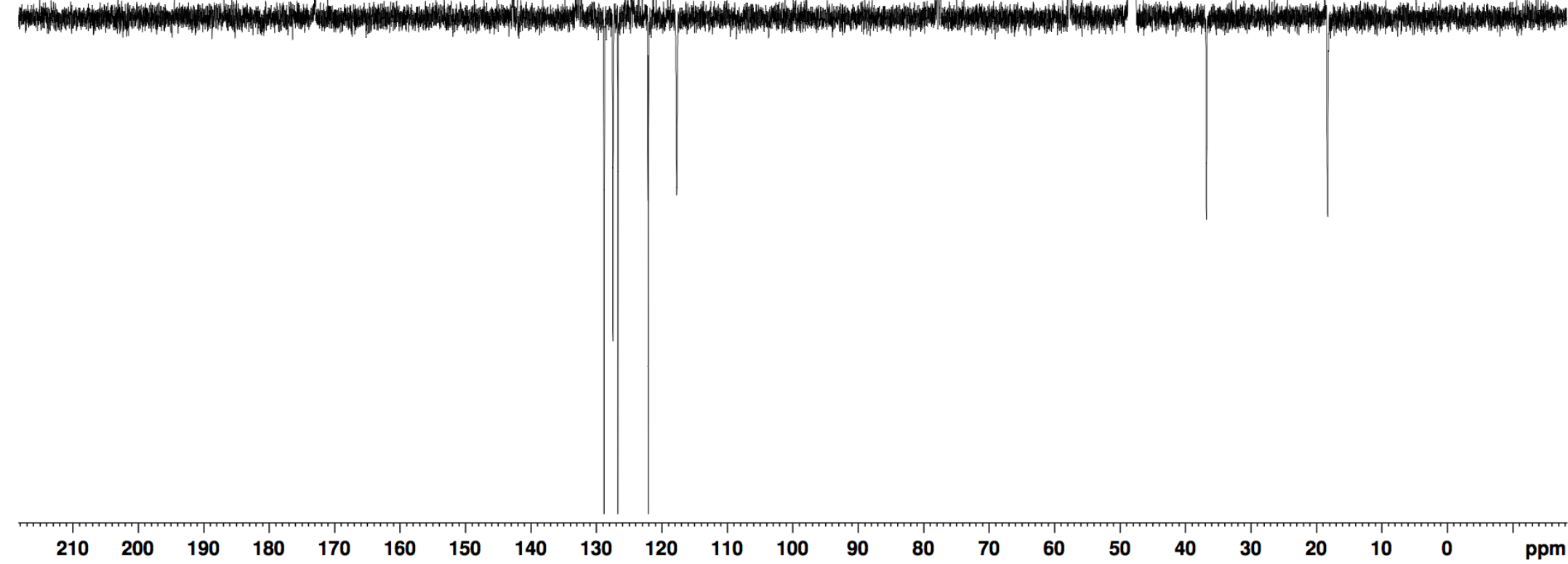




\section{Mass spectrum of compound 35}

\section{SK-KL4}

$(\mathrm{MeOH}) / \mathrm{MeOH}+\mathrm{NH} 4 \mathrm{OAc}$

C19H13F9N2O5S

SM: $7 \mathrm{G}$

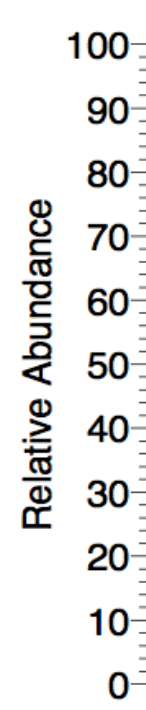

$$
100
$$$$
\begin{array}{r}
100 \\
90
\end{array}
$$$$
\begin{aligned}
& 90 \\
& 80
\end{aligned}
$$$$
\begin{aligned}
& 80 \\
& 70
\end{aligned}
$$$$
\begin{aligned}
& 70 \\
& 60
\end{aligned}
$$

60

40

30

30
20

20
10
EPSRC National Facility Swansea LTQ Orbitrap XL

CWPWES

03/08/2016 07:11:30
$\mathrm{NL}$

\subsection{E6}

CWPWES_IMNS1_58\#32-45

RT: 0.72-1.02 AV: 12 T: FTMS

$+\mathrm{p}$ NSI Full ms

[120.00-1935.00]

\section{Observed Data}

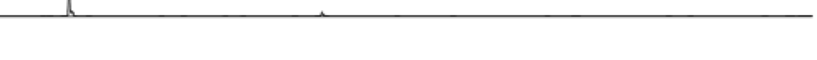

Theoretical Isotope Model: [M + NH4]+
NL:

1.77E4

$\mathrm{C}_{19} \mathrm{H}_{13} \mathrm{~F}_{9} \mathrm{~N}_{2} \mathrm{O}_{5} \mathrm{SNH}_{4}$

$\mathrm{C}_{19} \mathrm{H}_{17} \mathrm{~F}_{9} \mathrm{~N}_{3} \mathrm{O}_{5} \mathrm{~S}_{1}$

p (gss, s /p:40) Chrg 1

R: 100000 Res.Pwr . @FWHM

\begin{tabular}{|c|c|c|c|c|c|c|}
\hline $0^{\prime}$ & & & 572.0699 & 573.0730 & 574.0748 & \\
\hline 569 & 570 & 571 & 572 & 573 & 574 & 575 \\
\hline
\end{tabular}

571.0769 